\title{
Sustainability in Retailing - Environmental Effects of Transport Processes, Shopping Trips and Related Consumer Behaviour
}

\author{
Dissertation
}

zur Erlangung des wirtschaftswissenschaftlichen Doktorgrades der Wirtschaftswissenschaftlichen Fakultät der Universität Göttingen

vorgelegt von

Anne Wiese

aus Hannover

Göttingen, 2013 
Erstgutachter: Prof. Dr. Waldemar Toporowski

Zweitgutachter: Prof. Dr. Stephan Zielke

Tag der mündlichen Prüfung: 16.08.2013 


\section{Foreword}

In recent years, sustainability has taken a solid place in socio-political discussions. In parallel, researchers and practitioners began to focus on the topic of sustainability and in particular on the interdependencies between calls for sustainable behaviour and economic effects. The interdependencies are both complex and difficult to quantify.

The present thesis is concerned with the $\mathrm{CO}_{2}$ effects of shopping processes. A systematic overview of the academic and practice-oriented literature on sustainability is provided at the beginning. In doing so, the author observes that particular attention is devoted to the topics of CSR and $\mathrm{CO}_{2}$ effects in retail. Consequently, she decides to analyse the impact that consumer behaviour and the entrepreneurial actions of retailers have on $\mathrm{CO}_{2}$ emissions in more detail. Considering the development and rapid growth of online retailing, the choice of distribution channels by retailers and the choice of shopping venues by consumers have become the focus of entrepreneurial and academic analyses. The thesis picks up this trend and compares the effects that are caused by shopping online versus offline in a quantitative study. The factors affecting the advantageousness of both channels are analysed extremely carefully. Furthermore, another study centred on shopping trips is conducted to gain a better understanding of consumer shopping behaviour. Using a qualitative approach, this explorative study succeeds in highlighting consumer behaviour realistically and extracting central influence factors of behaviour.

The thesis deserves credit in several respects. The analysis of the relevant literature on sustainability provides a detailed picture of the recent state of the research and the practical interests in this topic. By pointing out the focuses and gaps in the recent discussion, the thesis yields important impulses for future research and practical projects. The empirical analysis of $\mathrm{CO}_{2}$ effects caused by the online versus brickand-mortar retail alternatives and the associated sensitivity analyses contributes significantly to an understanding of the circumstances under which the distributions channels are advantageous. These findings will support companies and policy makers in developing incentive mechanisms that will stimulate sustainable behaviour among consumers. Finally, the value of the thesis also lies in both the qualitative study, in 
which the author asks consumers to report on their shopping behaviour, and the quantitative study based on company data. This shift in perspectives brings additional interesting findings to light that merit consideration when deducing the implications for entrepreneurial and political decisions. At the same time, this analysis yields a series of proposals for further research projects that could confirm the supposed relationships.

Prof. Dr. Waldemar Toporowski 


\section{Acknowledgements}

This doctoral thesis was written during my time as a research assistant at the Chair of Retailing at the Georg-August-Universität Göttingen and would not exist without the help and support of many people, whom I would like to single out here.

I would like to express my particular gratitude to my examiners. I thank my supervisor Professor Waldemar Toporowski for his constant support and faith in my skills, as well as all the feedback and discussions. Furthermore, I thank my second examiner Professor Stephan Zielke for his invaluable support in honing my skills as a researcher. I am also grateful to Professor Gerhard Rübel for agreeing to be my third examiner and for his support on administrative issues.

Special thanks go to my colleague Julian Kellner for being my closest friend in my working life in recent years. Thanks for your support and everything else. Furthermore, I would like to mention my colleagues and friends at the Chair of Retailing: Tim Nierobisch, Nadine Ahrend, Kristine Knipper, Victoria Osburg and Sebastian Ludorf - thank you and all the best for your doctoral projects! I am also grateful to Professor Maik Hammerschmidt, Welf Weiger and Sebastian Klein for being great friends and pillars. Thanks for letting me be your best-practice Anne! Our student assistants should also be mentioned. Thanks particularly to Marten Meschkat, John-Patrick Collins, Raphaela Piechota, Felicitas Karsch and Petra Montag. Moreover, Dr Yvonne Siebert helped me a lot to keep my head during the final stages. Furthermore, thanks to all my other colleagues for making my time here so special. My gratitude also goes to my friends from Finland, Timo Rintamäki and Dr Pekka Puustinen, for being such good conference company as well as valuable supporters and for organizing a great day for me in Tampere - kiitos! Philip Brown should also be mentioned for his help and support with the proofreading. Thank you in particular for your flexibility and the nice evening in Basel. And last but not least, my friends and former colleagues Dr Britta Lietke and Dr Madlen Boslau had a huge impact on my decision to do a doctorate and helped launch my academic career thank you, my Handeletten girls!

Of course, I also received considerable support in my private life. First of all, my husband Jan and our dog Minnie have to be mentioned: thanks for all your support 
and understanding and the distraction you gave me. Now let's go for the board shorts! My heartfelt gratitude also goes to my parents and brother for their love and care throughout my life. I would also like to show my appreciation for my friends, especially Nora Vick (you were the best neighbour ever; miss you here), Björn Kniza and Vanessa Eberle (thanks for taking care of my cultural education), Mirja Göttsche (thanks for being a great study mate and friend), Iris Kühl and Tessa Paetow (thanks for being my oldest and still among my closest friends). Thank you all for your understanding in busy times and the support you gave me. Now my life is back to normal!

Anne Wiese 


\section{Table of Contents}

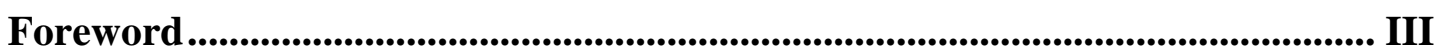

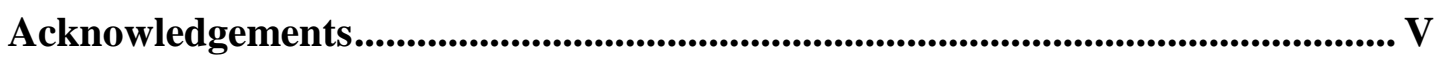

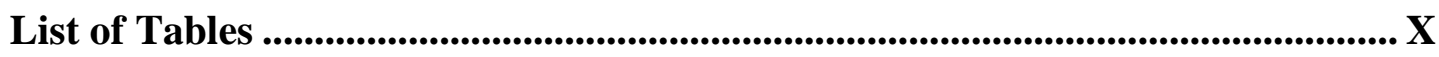

List of Figures ...................................................................................................................................XI

List of Abbreviations .................................................................................................... XII

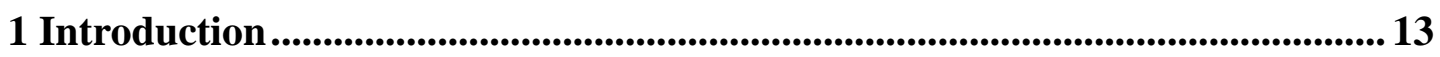

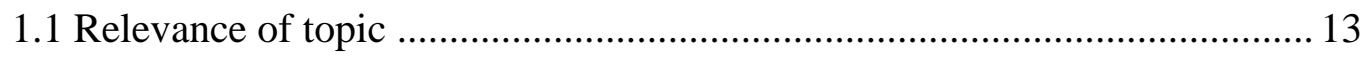

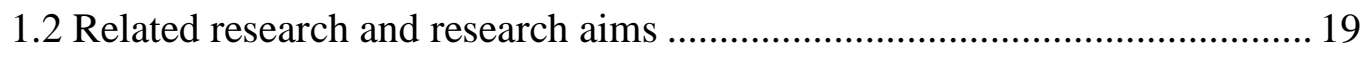

1.3 Classification within related research streams ......................................... 24

2 Summaries of the papers and main results........................................................28

2.1 Summary: Sustainability in retailing - a summative content analysis

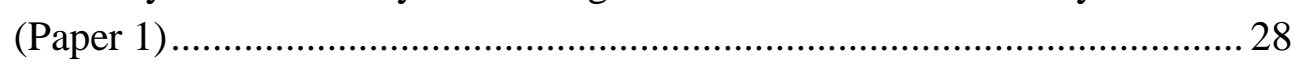

2.2 Summary: Transport-Related $\mathrm{CO}_{2}$ Effects of Online and Brick-and-Mortar Shopping: A Comparison and Sensitivity Analysis of Clothing Retailing (Paper 2)

2.3 Summary: Environmental effects of shopping trips - a qualitative analysis of consumer travel behaviour (Paper 3) ....................................................... 29

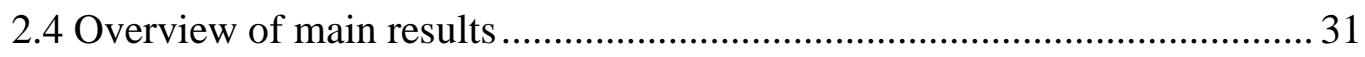

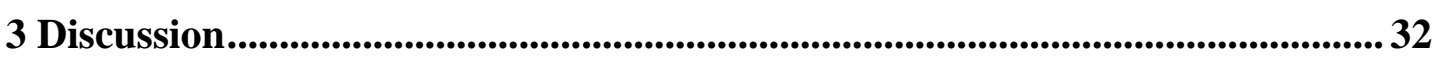

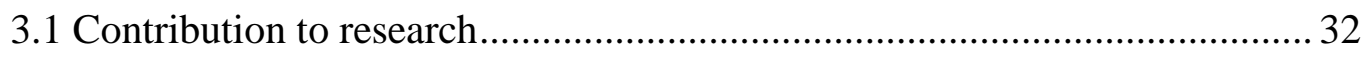

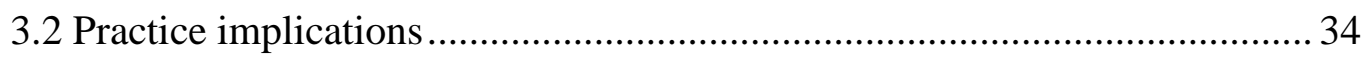

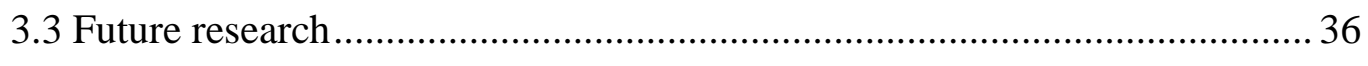

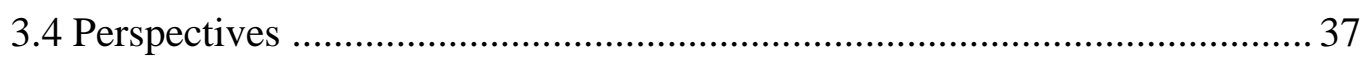


4 Sustainability in retailing - a summative content analysis (Paper 1)............... 38

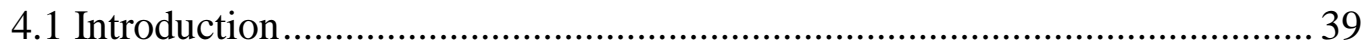

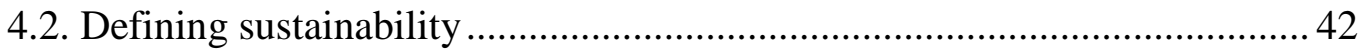

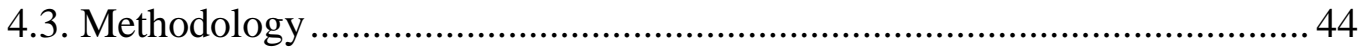

4.3.1 Analysis of scientific research ....................................................... 44

4.3.2 Analysis of practice considerations .............................................. 46

4.4 General research on sustainability .......................................................... 47

4.4.1 Structuring sustainability research according to economic research

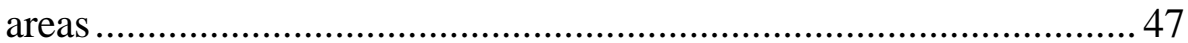

4.4.2 Structuring sustainability research according to industrial sectors ..... 49

4.5 Sustainability considerations in retail research and practice .......................51

4.5.1 Sustainability in retail research ................................................... 51

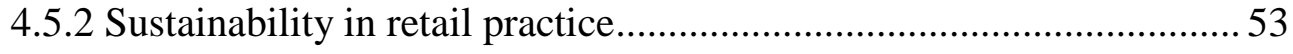

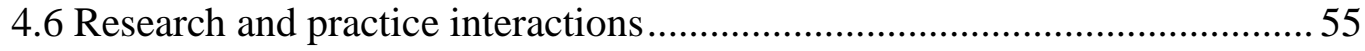

4.7 Implications and directions for future research ........................................5 57

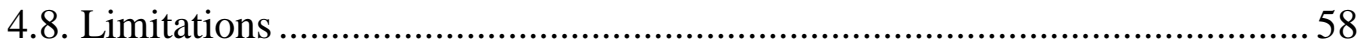

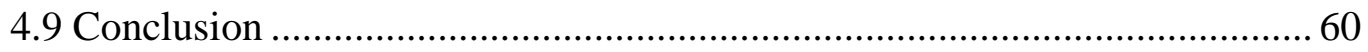

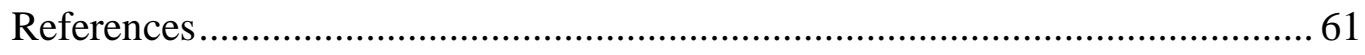

5 Transport-Related $\mathrm{CO}_{2}$ Effects of Online and Brick-and-Mortar Shopping: A Comparison and Sensitivity Analysis of Clothing Retailing (Paper 2)........ 65

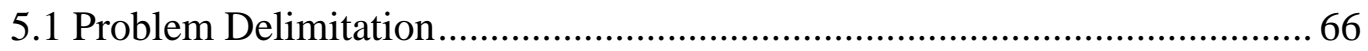

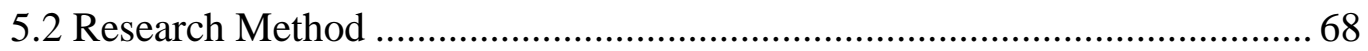

5.2.1 Calculating $\mathrm{CO}_{2}$ emissions for the brick-and-mortar supply chain .... 69

5.2.2 Calculating $\mathrm{CO}_{2}$ emissions for the online supply chain.................... 70

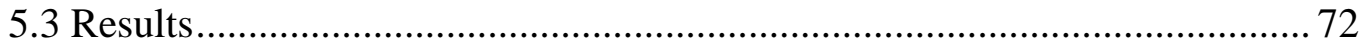

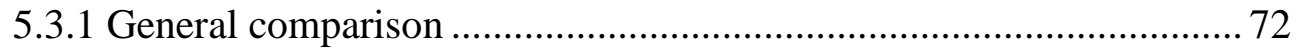

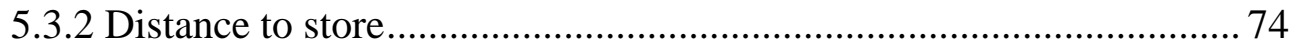




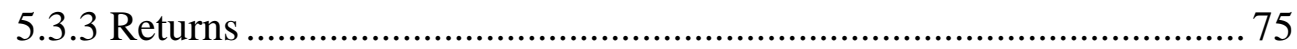

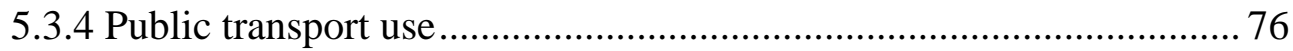

5.3.5 Influence of information behaviour ............................................ 76

5.4 General Discussion and Implications ....................................................... 77

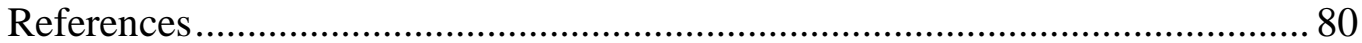

6 Environmental effects of shopping trips - a qualitative analysis of consumer travel behaviour (Paper 3) .........................................................................8 82

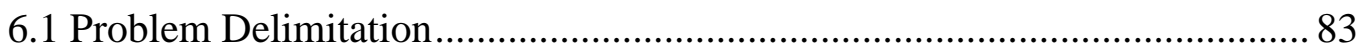

6.2 Theoretical Background and Literature Review ....................................... 85

6.2.1 Relevant influences on travel behaviour........................................... 86

6.2.2 Impact on the environmental effects............................................. 90

6.3 Qualitative Analysis of Consumer Shopping Trip Behaviour .................... 92

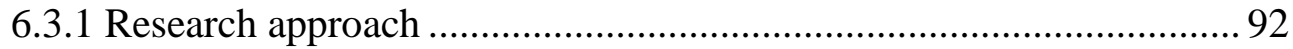

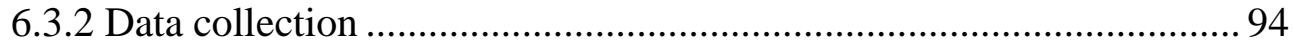

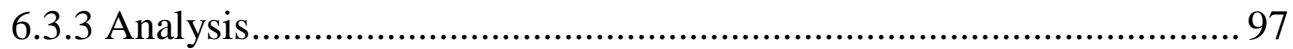

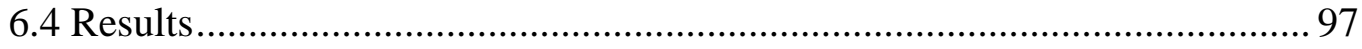

6.4.1 Consumer behaviour and life cycle influence................................. 97

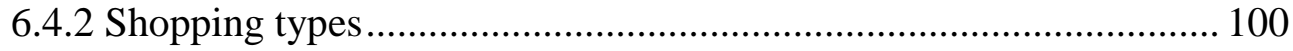

6.4.3 Expectations from retailers and policy makers ............................... 104

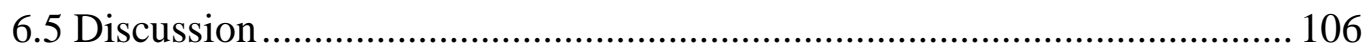

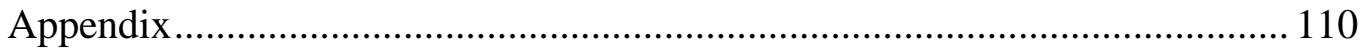

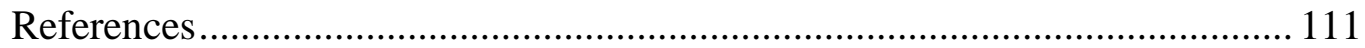

References (complete thesis) .......................................................................................VIII

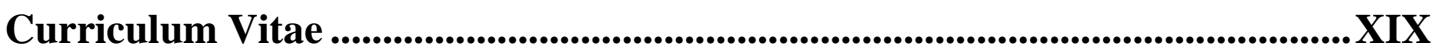




\section{List of Tables}

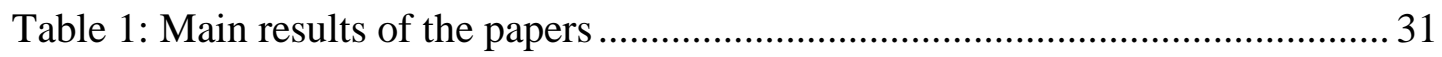

Table 2: Research contributions of the papers …................................................. 34

Table 3: A sample of definitions and interpretations of sustainability and sustainable

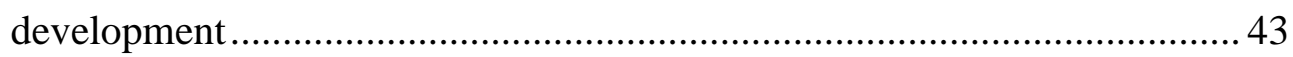

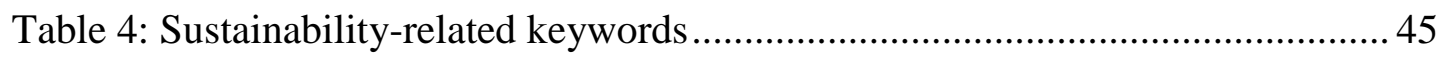

Table 5: $\mathrm{CO}_{2}$ emissions for the brick-and-mortar supply chain (in kilograms) ......... 72

Table 6: $\mathrm{CO}_{2}$ emissions in the online supply chain (in kilograms) .......................... 73

Table 7: $\mathrm{CO}_{2}$ emissions caused by different distances (in kilograms) ..................... 74

Table 8: Influence of returns on $\mathrm{CO}_{2}$ emissions in both channels (in kilograms) ..... 75

Table 9: Research questions for the qualitative analysis ....................................... 93

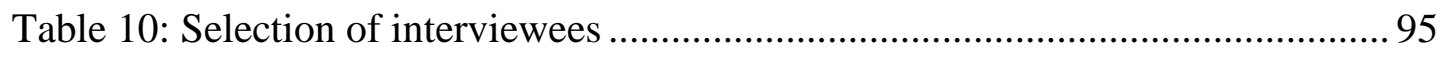

Table 11: Important characteristics for the five life cycles ................................. 100

Table 12: Typology of general shopping behaviour ............................................ 102

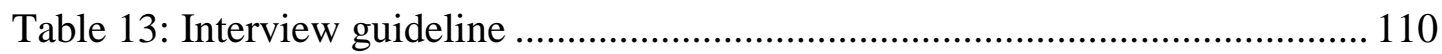




\section{List of Figures}

Figure 1: Stakeholder requests from companies .............................................. 17

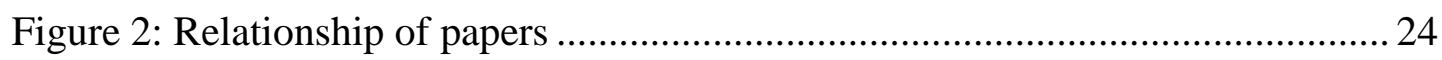

Figure 3: Related research streams (Paper 1) ….................................................. 25

Figure 4: Related research streams (Paper 2) f................................................... 26

Figure 5: Related research streams (Paper 3) …............................................... 27

Figure 6: Development of JEL-based sustainability hits over time ......................... 47

Figure 7: JEL-based sustainability hit distribution ............................................. 48

Figure 8: NAICS-based sustainability hit distribution.......................................... 50

Figure 9: Development of sustainability-related keywords in retail magazines over

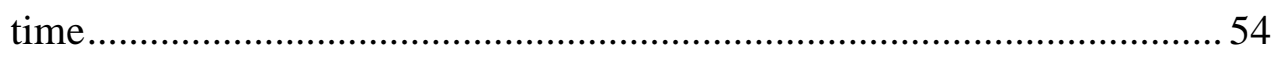

Figure 10: Development of most relevant sustainability-related keywords in retail

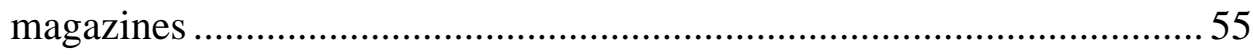

Figure 11: Supply Chain for Brick-and-Mortar Retail............................................ 69

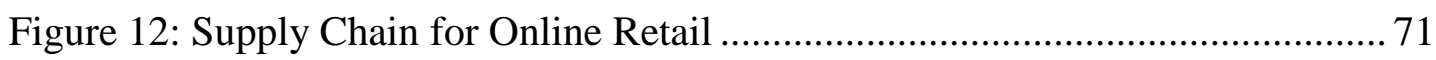

Figure 13: Relevant influences on travel behaviour and its environmental effects ... 91 


\section{List of Abbreviations}

CSR Corporate Social Responsibility

GHG Greenhouse gas

NGO Non-governmental organisation

SCM Supply Chain Management

SSCM Sustainable Supply Chain Management

USSP Unique sustainable selling position 


\section{Introduction}

This thesis is concerned with sustainability in retailing. A focus is set on the environmental pollution caused by shopping processes in the brick-and-mortar and online retail. The analysis integrates the environmental effects of transport processes of retailers and parcel services as well as those of consumers' shopping trips. Furthermore, a particular focus is laid on consumer shopping behaviour and its environmental effects.

This introductory section clarifies the relevance of the thesis topic by highlighting recent developments and the influence they have on companies (section 1.1). Moreover, it analyses the relevant research and deduces the aims of the thesis (section 1.2) and integrates the thesis into related research streams (section 1.3).

\subsection{Relevance of topic}

Regarding recent developments such as climate change and changes in consumer behaviour towards more conscious behaviour, enhancing sustainability has become important for governments and companies alike. Nowadays, companies face diverse challenges in their business operations whereby sustainability and sustainable development have particularly become important.

The concept of sustainability is used broadly and in many circumstances. The most common definition for sustainable development is that of the World Commission on Environment and Development (1987, p. 87) defining it as "development that meets the needs of the present without compromising the ability of future generations to meet their own needs". Sustainable development and sustainability are mostly used synonymously, but it should be mentioned that they differ in their status as sustainable development can be seen as the journey towards achieving the state of sustainability (Lozano, 2008). The definition highlights the broad perspective of the approach and in particular its focus on inter-generation-fairness. To apply sustainability to the situation of companies, the concept has to be specified further.

Sustainability in a business setting is mainly particularised by the Triple Bottom Line model which includes three pillars of sustainability - the social, environmental 
and economic dimension (Elkington, 1998). In congruence with the original concept of sustainable development proposed by the World Commission on Environment and Development (1987), a definition for the business context has been suggested: "sustainable development means adopting business strategies and activities that meet the needs of the enterprise and its stakeholders today while protecting, sustaining and enhancing the human and natural resources that will be needed in the future" (International Institute for Sustainable Development, 1992, p. 11).

Following this definition, various needs and requests of their stakeholders challenge companies in matters of their commitment to sustainability. Stakeholders are all groups that have relationships to a business and are affected by its objectives - either in a positive or a negative sense (Freeman, 1984). Analysing and incorporating the needs of its stakeholders is important because "a company can avoid the risks of damaging publicity and potentially increase its 'social capital' as it gains greater respectability and credibility" (Burchell \& Cook, 2007, p. 35). Depending on the levels of control and influence, distinction can be drawn between primary and secondary stakeholders (Garvare \& Johansson, 2010). In general, consumers, employees, and shareholders are considered primary stakeholders, whilst nongovernmental organisations (NGOs), governments, the community, and the environment are regarded as secondary stakeholders. In the following, a short overview is provided of the main relevant stakeholders and their requests for sustainability issues to clarify the complex market situation for companies.

With respect to primary stakeholders, consumers, employees and shareholders are particularly considered relevant. Over the past years, consumers have become more sensitive to social and environmental issues and request companies to behave in a responsible manner. Products with Fair Trade or organic labels have gained in importance and nowadays receive a high level of consumer interest (Andorfer \& Liebe, 2011; Newholm \& Shaw, 2007; Shaw Hughner, McDonagh, Prothero, Shultz, \& Stanton, 2007). Research also found that consumers are willing to pay more for ethical products and punish companies behaving unethically (Trudel \& Cotte, 2009). Nevertheless it has to be considered that consumers sometimes might "not have (...) the requisite knowledge to make sound ecological decisions" 
(Ellen, 1994, p. 43) and hence might need support on environmentally-friendly behaviour, which should be offered by companies, governments and NGOs.

Employees are also important stakeholders whose needs regarding, for instance, work/life balance, education, or equality and diversity should be considered (Jones, Comfort, \& Hillier, 2005; Clarkson, 1995). In addition to fulfilling its social obligations, these efforts can positively influence the financial performance of a company. Human resources management can lead to a competitive advantage, e.g. improved productivity or higher commitment of the employees (Berman, Wicks, Kotha, \& Jones, 1999; Huselid, 1995).

Besides, shareholders request responsible behaviour of companies to secure their wealth, e.g. return on investment (Piacentini, MacFadyen, \& Eadie, 2000). Shareholders that are not content might remove their investment, thereby endangering the company's existence in the long term. However, through a sustainability commitment companies might be able to gain a competitive advantage, thus creating shareholder value (Hillman \& Keim, 2001).

As secondary stakeholders, NGOs, governments, the community and the environment should be mentioned. NGOs have grown a lot in terms of their influence in the last years (Doh \& Guay, 2006). They consider the behaviour of companies critically and trigger behavioural changes (de Man \& Burns, 2006). Hence, social obligations cannot be met as easily as before by corporate donors, for instance (Barry, 2003). In recent years, popular clothing companies, e.g. Levi`s, Nike or Adidas, have faced scandals in their production processes such as the detection of poor working conditions or environmental pollution and subsequently made improvements (Seuring \& Müller, 2008). Incorporating the NGOs' power, nowadays many companies engage in a stakeholder dialogue with them although this can prove problematic with respect to green washing accusations or diverging aims (Burchell $\&$ Cook, 2007).

In parallel, many governments demand responsible behaviour from companies in their legislation (First \& Khetriwal, 2010). For instance, pollutant contents are fixed for products. Consumers might also react negatively although no official critical 
values are exceeded, so that "legal compliance is not enough" (Barry, 2003, p. 15). Furthermore, government regulations might be too weak, so companies have to get involved in sustainability issues themselves to retain their licence to operate (de Man \& Burns, 2006) or companies beat the targets due to cost-saving possibilities or for being a good example to other companies (Lai, Cheng, \& Tang, 2010).

Also, the community should be considered as a stakeholder affected by company behaviour. Firms have a responsibility towards the community they are operating in, for instance by local hiring or plant closures (Clarkson, 1995). A commitment towards the community might yield advantages like decreased regulatory and an easier attraction of employees (Waddock \& Graves, 1997). Considering the globalisation process, the topic of the community is also viewed from a broader perspective nowadays, renaming the term to communities (Waddock \& Boyle, 1995).

Recent papers also argue that the environment / nature itself should be considered as a stakeholder because it is highly affected by business operations (Gibson, 2012; Driscoll \& Starik, 2004). Incorporating the environment as a stakeholder might yield advantages for a company (Berman et al., 1999; Shrivastava, 1995). For instance, costs might be reduced for complying with future regulations and the company's efficiency might be increased. Also, a competitive advantage might be gained by offering sustainable products and improving the company's image.

Problems in stakeholder management might occur because of conflicting stakeholder interests. For instance, conflicts can arise between company owners and employees regarding the job performance (Eisenhardt, 1989). Also, the interests within a stakeholder group can diverge, e.g. problems might develop between environmental and economic issues (Gibson, 2012; Carney, Gedajlovic, \& Sur, 2011). 
The complexity of companies' stakeholder relationships with regard to sustainability and the main requests of the various stakeholders are depicted in Figure 1.

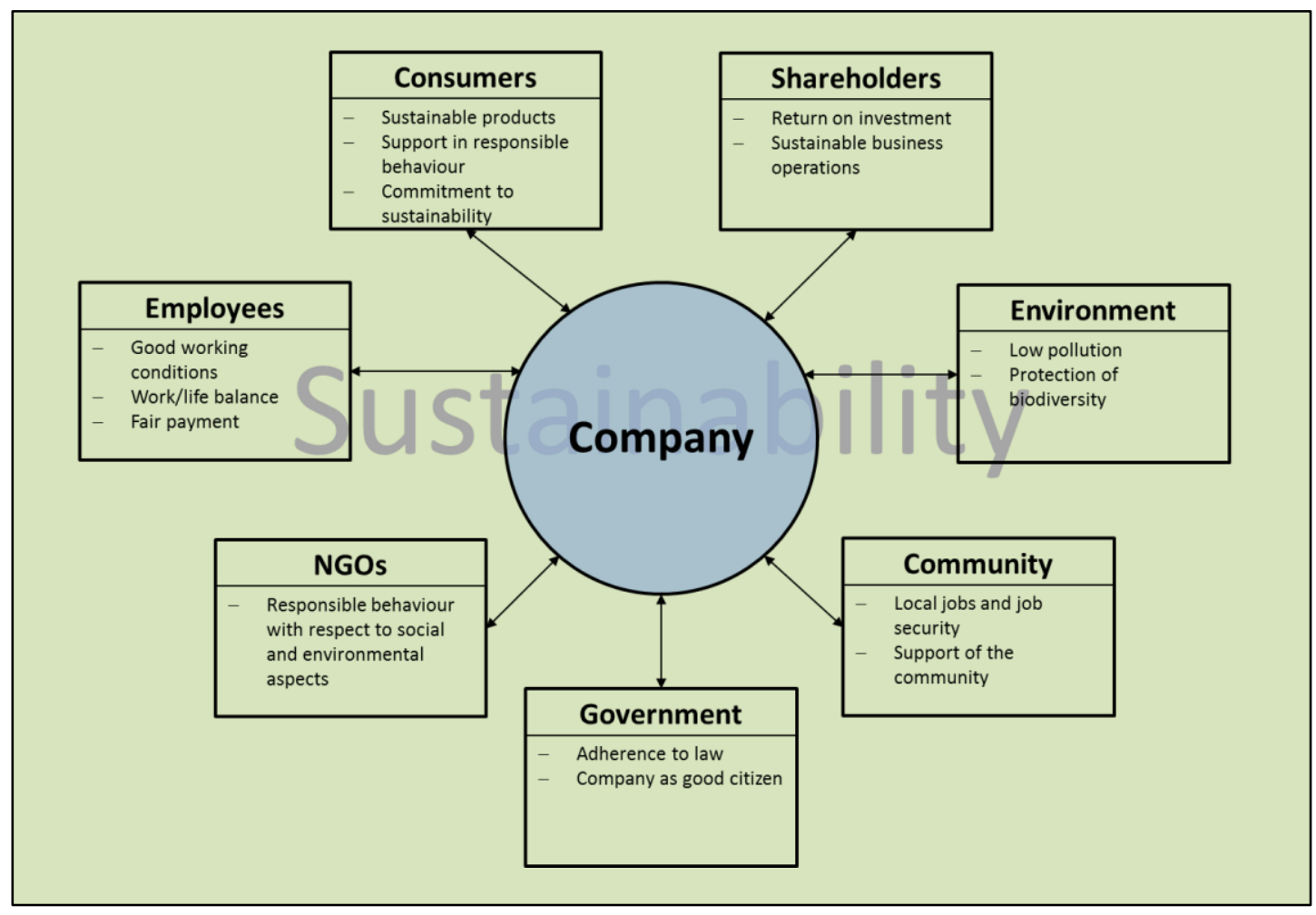

Figure 1: Stakeholder requests from companies

Keeping this complex market situation in mind, it shows that recently retailers have particularly been confronted with sustainability requests. Three factors are considered relevant for this development: a trust deficit due to scandals, an expanded range of environmental and social issues, and NGOs targeting retailers (Barry, 2003).

Along supply chains, retailers assume a special role as gatekeepers between producers and consumers (Ytterhus, Arnestad, \& Lothe, 1999). Adopting this position, retailers can help to incorporate sustainability along their supply chains, causing a multiplier effect (Erol, Cakar, Erel, \& Sari, 2009). As a result, they "can greatly influence changes in production processes and consumption patterns and are well placed to exert pressure on producers in favour of more sustainable consumer choices" (Durieu, 2003, p.7). The power of retailer influences on social and environmental sustainability can be distinguished in two parts. Firstly, retailers can focus on improving their direct impact caused by transport, packaging or assortment selection and secondly they can also address aspects they can influence indirectly, 
such as behaviour along their supply chains and consumer behaviour (Durieu, 2003; United Nations Environment Programme, 2003). In other words, on the one hand retailers should behave responsibly themselves to retain their licence to operate and, on the other hand, also support their customers and business partners in behaving more responsibly.

Nevertheless, due to their position, retailers are also confronted with negative publicity in cases of failures along their supply chains. Consumers and NGOs consider them responsible for the processes taking place in their supply chains (Wiese \& Toporowski, 2013; de Man \& Burns, 2006; Barry, 2003). Hence, neglecting its responsibility might harm a retailer's reputation.

In contrast, sustainability commitment can also be an opportunity to gain a competitive advantage (Connelly, Ketchen, \& Slater, 2010; Lai et al., 2010) when companies exceed legal compliances and reach a unique sustainable selling position (USSP) (Belz, 2006). Also, proactive companies in moral and social issues might achieve first mover advantages (Piacentini et al., 2000). Highlighting the relevance of sustainability for the strategy of a company, there is even talk of a “enviropreneurial marketing strategy" (Menon \& Menon, 1997, p. 51).

The aforementioned developments and its responsible but also vulnerable position in the supply chain pose new challenges for retailers. The need for sustainable behaviour carries opportunities as well as threats. If a company succeeds in fulfilling its stakeholder requests towards sustainability it can strengthen its market position and preserve its licence to operate. Furthermore, even a USSP might be within reach if a company manages to differentiate itself from its competitors and delivers extra value to its stakeholders. In contrast, the business concept might be endangered when sustainability requests are ignored or not fulfilled. Following the approaches of institutional theory and organisational ecology, these companies might risk their legitimisation and if not adapting "their processes to become more sustainable may be selected out of the population" (Connelly et al., 2010, p. 88). 


\subsection{Related research and research aims}

The previous section highlighted the strategic importance of sustainability for companies, in particular for retailers due to their gatekeeper position. Hence, how much attention has been paid to sustainability so far in retail practice and research should be evaluated in a structured manner. This knowledge is important to gain a deeper understanding of the sustainability developments and related trends. Thereby, relevant areas can be identified and a structure can be given to the developments in practice and research. Retailers can learn from this by discovering considerable areas for their business sector. Concordantly, this also helps researchers to identify particularly relevant areas for future research. Until now, only few publications have focussed on a broad analysis of sustainability in retailing (for instance, Erol et al., 2009; Jones et al., 2005).

To discover more about the attention sustainability has received until now, a broad literature review in academic literature and retail practitioner magazines is necessary. In particular, the first part of the thesis (Paper 1) answers the following questions:

- What are the major research areas and industrial branches dealing with sustainability?

- What are the latest important developments in sustainability research, focusing on retailing in particular?

- What sustainability progress can be observed in retail practice? Has the importance of certain sustainability-related aspects changed over time? Do any discrepancies emerge between research and practice?

- Which implications can be drawn for retail research and practice based on the findings presented?

As a main result of the literature review, $\mathrm{CSR}$ and $\mathrm{CO}_{2}$ emissions are identified as central topics in retail practice. Considering the academic perspective, CSR has already gained some interest in retail-related research (for instance, Kolk, Hong, \& Dolen, 2010; Jones et al., 2005; Lee, Chung, \& McNally, 2002; Piacentini et al., 2000). In contrast and despite its practical relevance, the aspect of $\mathrm{CO}_{2}$ emissions has only been analysed scarcely thus far (for instance, Edwards, McKinnon \& Cullinane, 
2011; Weber, Koomey, \& Matthews, 2010; Cullinane, 2009). Aiming to contribute to this research field, the thesis focuses in the following on $\mathrm{CO}_{2}$ emissions as one of the recent retail trends identified.

Supporting the results of the literature review and mirroring the growing relevance of sustainability issues for consumers, distribution processes are increasingly scrutinised for their environmental effects. The manager of a European parcel service reported that his company is regularly confronted with consumers asking for the environmental impact of the parcel delivery process. This confirms the practical relevance of $\mathrm{CO}_{2}$ emissions identified in the review of practitioner magazines. The concerns of consumers over the effects of parcel delivery is also supported by some research, saying that delivery cars in neighbourhoods are perceived as "noisy, dirty and a safety risk to vulnerable road users" (Cairns, 2005, p. 74). The negative perception of delivery services might cause an image loss of online retailers and their delivery processes.

Contrary to this consumer perception, some researchers calculated that shopping online quite often causes fewer $\mathrm{CO}_{2}$ emissions than shopping in traditional brickand-mortar retail (for instance, Edwards et al., 2011; Weber et al,. 2008). Apparently, there seems to be a gap between consumer perception and research results. Therefore, the research conducted so far and appropriate ways to communicate the results to consumers should be examined in more detail.

Regarding the methods applied in the existing studies, the analyses are mainly based on secondary data for transport modes used, articles bought and distance to stores. Including these limitations, the studies mentioned are often limited in reflecting authentic shopping situations and real consumer behaviour in a multi-channel environment. Furthermore, most research is concerned with book retail due to its high suitability for online retail. Hence, there is a need for a closer view on the aspects influencing the advantageousness of the channels with respect to environmental pollution. Also, other goods should be incorporated to gain a deeper understanding of the relationships. 
To account for these limitations, a research project was launched with the aim of analysing the environmental impact caused by either offline or online shopping. This research aim focuses on both aspects that retailers can influence directly (e.g. their transport processes) and aspects they can only affect indirectly (e.g. consumer behaviour). Incorporating the research gaps mentioned above, the study intended to provide a more detailed perspective on the environmental effects of traditional and online retailing with a focus on clothing. Therefore, a cooperation was arranged with a multi-channel retailer and the parcel service mentioned earlier. As a result, real data from two distribution channels could be analysed and compared. For the brick-andmortar channel, a customer survey was conducted in two of the retailer's stores, evaluating information on transport mode, purchase, distances, and the reason for the trip. For the online channel, data was obtained from 40,000 online orders and information on the delivery process from the parcel service. In particular, the following questions are answered in Paper 2:

- Which channel is more environmentally friendly from a general perspective?

- How do factors like returns, public transport use, distance to store, and information behaviour influence the advantageousness?

- Which implications can be deducted for retailers and policy makers?

The results of the analysis presented support the central finding of the other research papers on this topic, i.e. based on $\mathrm{CO}_{2}$ emissions, the online channel is generally more environmentally friendly than the brick-and-mortar channel. Nevertheless, it has also been discovered that traditional retail can be more environmentally friendly in certain situations. For instance, the distance of the customer's home to the store has a huge impact. Also, the use of public transport can decrease the $\mathrm{CO}_{2}$ emissions considerably. Break-even points until which shopping at the brickand-mortar store is more advantageous than an online order were identified. One of the main results of the study is that most emissions are caused by consumer journeys to the stores. Considering these results, the study shows that consumers have an immense impact on the environmental effects of shopping processes through their behaviour. For instance, the choice of transport mode is highly relevant. 
These results yield opportunities for online retailers and delivery services who can position themselves as an environmentally-friendly alternative to traditional retail. This is particularly relevant given the assumed negative perception of the delivery processes. In contrast, the results might cause negative publicity for brick-and-mortar retailers and harm their business models.

The study showed that consumers have a high impact on the environmental effects of the distribution channels. Hence, retailers should try to improve consumer behaviour to make their business formats more environmentally friendly. This follows Barry (2003), who highlights the responsibility of retailers for enhancing behavioural changes that might influence social and environmental aspects. Also, other researchers mention the consumption aspect as part of the retailers' responsibility, although the focus here mainly lies on the product itself and not on the buying process (Kotzab, Munch, Faultrier, \& Teller, 2011).

Hence, it is worthwhile to evaluate in more detail how consumers design their shopping trips and how retailers and policy makers might influence this behaviour to mitigate its environmental effects. Detailed knowledge is important to implement changes in behaviour, as the "first step toward bringing about changes in travel behavior that reduce GHG (i.e. greenhouse gas, AW) emissions is an understanding of the component behaviors and the factors that influence them - what people do and why they do it" (Handy \& Krizek, 2012, p. 43). Hence, when aiming to make shopping processes more environmentally friendly, knowledge of consumer behaviour is needed to detect approaches towards mitigating its environmental effects.

So far, the research has mainly examined travel behaviour quantitatively, chiefly analysing data from household travel surveys. In doing so, the outcomes of consumer behaviour are examined, but the behavioural perspective behind these outcomes is neglected (Ye, Pendyala, \& Gottardi, 2007). As mentioned above, knowledge about the underlying processes is relevant to influence the behaviour. Hence, it is "necessary to go beyond statistical correlation and issues of representativeness and to resort to theoretical thinking about the linkages between (...) characteristics" (Brannen, 1992, p. 8). Consumers' travel choices are complex. For instance, 
decisions on trip chaining and the transport mode have to be made and are influenced by personal characteristics and situative aspects. Therefore, travel behaviour can only be evaluated to a limited extent by quantitative methods, which mainly focus on the analysis of a few selected aspects such as the effects of trip chaining on public transport use (Hensher \& Reyes, 2000). In contrast, qualitative methods allow a more comprehensive analysis of travel behaviour, which is needed to gain a deeper understanding of the motives steering consumer behaviour for these complex decisions.

Considering the aforementioned aspects, qualitative interviews are conducted to gain further knowledge of consumers' shopping trip behaviour and related environmental effects. Sinkovics, Penz, and Ghauri (2005, p. 15) note that researchers turn "to qualitative methods after they experience that quantitative methods cannot provide for answers to selected problems". Hence, aiming to add knowledge of the relevant aspects of travel behaviour and its connection to the environmental friendliness of shopping processes, the last part of the thesis examines consumer travel behaviour. Incorporating the quantitative focus of recent research and the related limitations, a qualitative approach is applied to evaluate the behavioural perspective in more detail. In particular, the following questions are answered:

- Which factors influence consumer travel behaviour and the related environmental effects? Do various consumer groups differ in the way their behaviour is affected by the influences?

- How can brick-and-mortar retailers and policy makers influence shopping trip behaviour? Which implications can be deduced for researchers?

The study reveals the complexity of consumer travel behaviour. In particular, the influences of the lifecycle situation and personal characteristics are highlighted. Four different shopping types are derived from the interviews. Based on the results, detailed implications are deduced for retailers and policy makers on how to mitigate the environmental effects of shopping trips.

To highlight the contribution of the thesis, the following section provides more insights into its structure. In particular, the connections between the papers are 
clarified. Furthermore, the three papers are analysed regarding their relation to other research streams to provide a broader perspective on the topic.

\subsection{Classification within related research streams}

The papers belong together from top-down. Paper 1 provides a broad approach to sustainability in retailing. Paper 2 focuses on the internal and external sustainability of retailers by evaluating the environmental effects of its business processes and the impact consumers have. Paper 3 narrows this down further by addressing the impact of consumers in more detail and deducing implications for retailers on how to improve their external sustainability. An overview of the connections is provided in Figure 2.

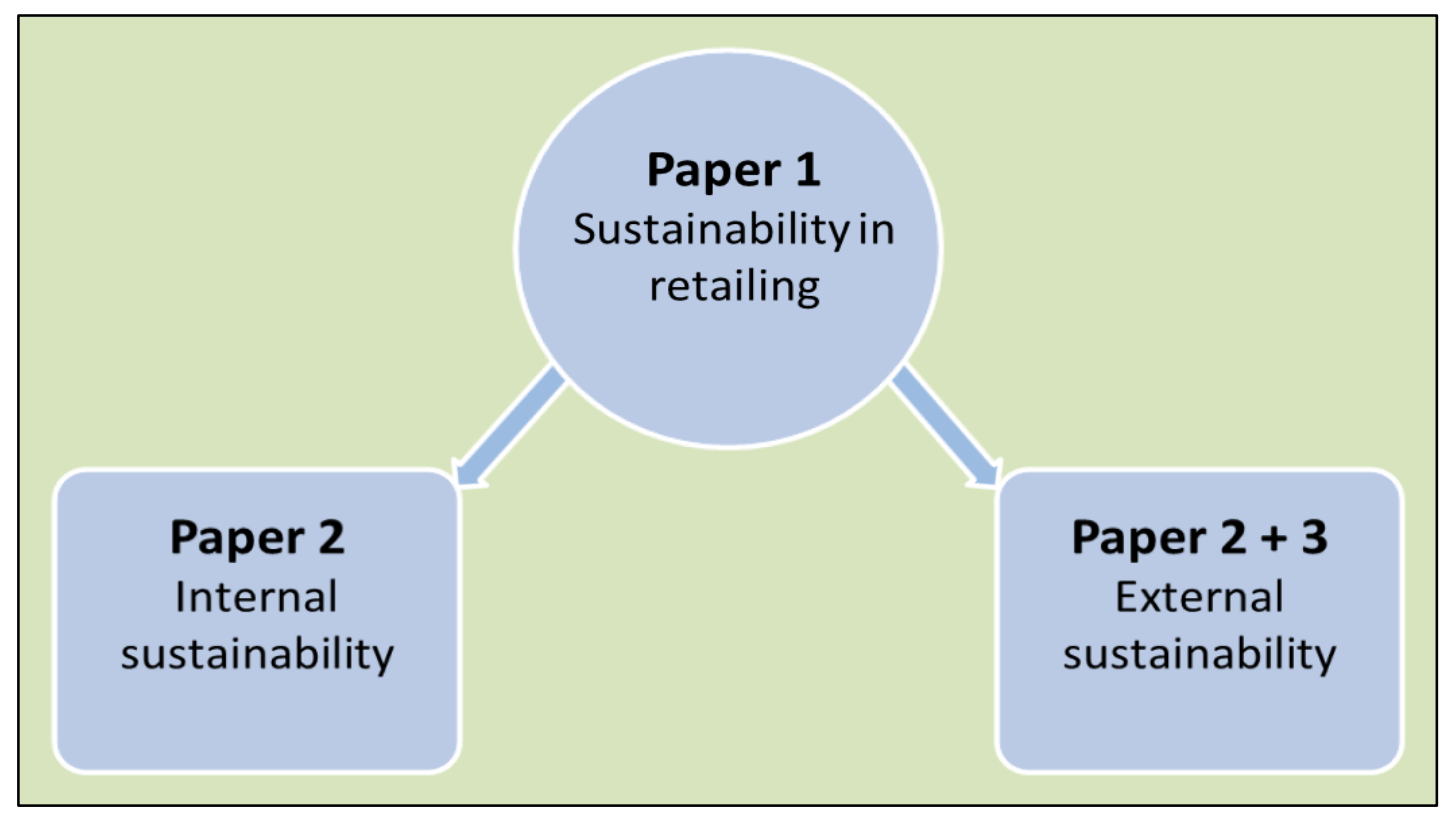

Figure 2: Relationship of papers

The three papers can be integrated into different research streams. A short overview of the papers' contribution and the related literature is given in the following.

Paper 1 contributes to the research on general sustainability developments in retailing. It adds a structured review on developments in retail research and practice to the recent sustainability literature. By approaching the topic from two perspectives - the research and practitioner sides - information about parallel developments in these areas is gained. As a result, research gaps and trends can be detected. The paper is linked to other studies concerned with a broader approach to sustainability in 
retailing (Erol et al., 2009; Lee, Fairhurst, \& Wesley, 2009; Jones, Comfort, \& Hillier, 2008a; Bansal \& Kilbourne, 2001). Furthermore, it also has contact points to studies that analyse sustainability developments in SCM (Carter \& Easton, 2011; Carter \& Rogers, 2008; Seuring \& Müller, 2008). Here, in particular studies focusing on sustainability in retail supply chains are closely related (Kotzab, Munch, de Faultrier, \& Teller, 2011; Ytterhus et al., 1999). Regarding the holistic approach towards sustainability, it is also in line with literature reviews on sustainability in marketing (Chabowski, Mena, \& Gonzalez-Padron, 2011; Connelly et al., 2010). The relationships are clarified in Figure 3.

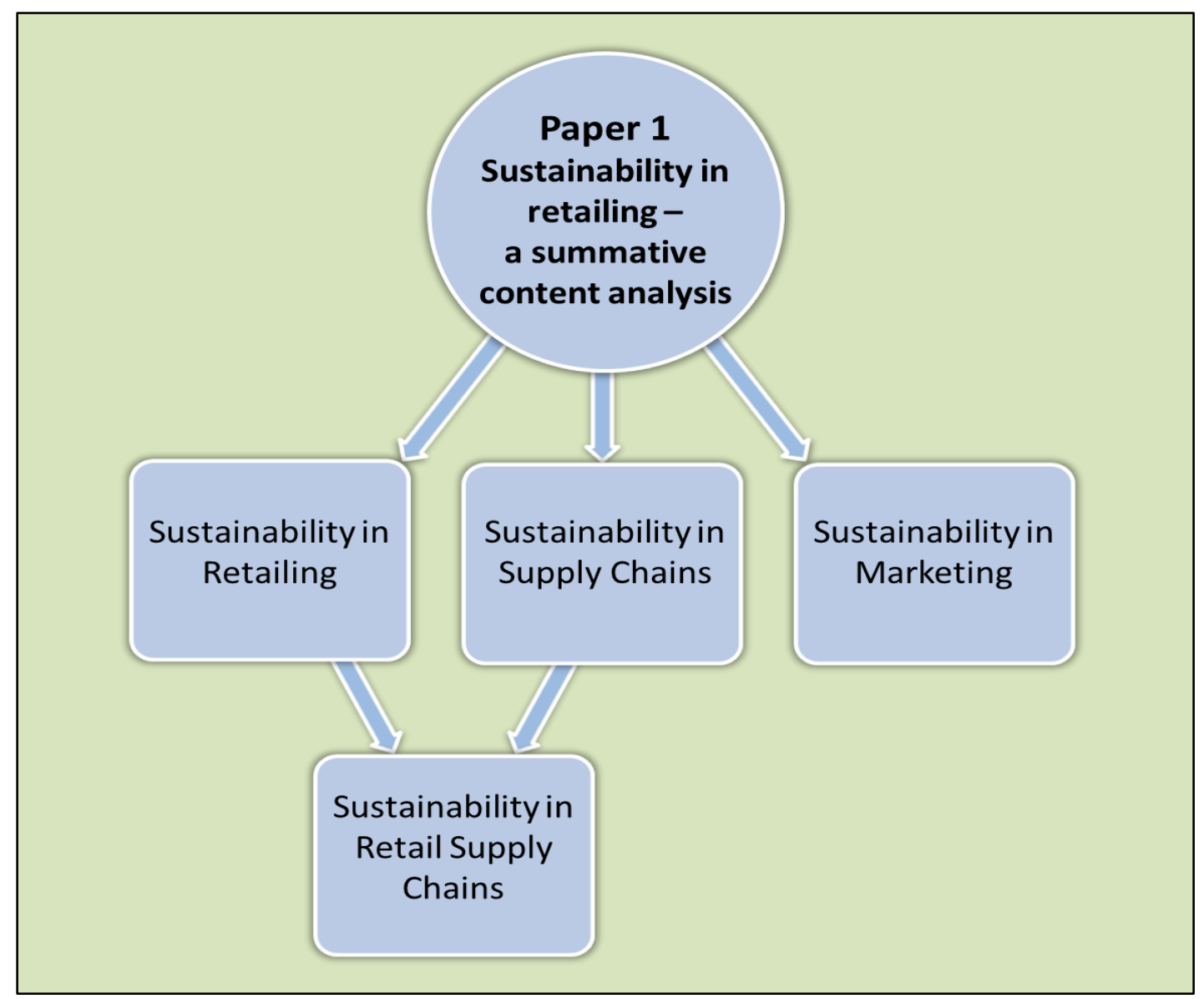

Figure 3: Related research streams (Paper 1)

Paper 2 adds a more detailed perspective on the environmental pollution caused by retailer transport processes and consumer shopping behaviour. By analysing information on shopping trips and online orders derived from customers, a retailer and a parcel service, more detailed analyses can be deduced. In doing so, Paper 2 broadens the research that is concerned with a technical analysis of the effects of the 
shopping and delivery processes (Carling et al., 2013; Edwards et al., 2011; Kim, Xu, Kahhat, Allenby, \& Williams, 2009; Fichter, 2003). In addition, issues of consumer shopping behaviour are addressed. This aspect is highlighted further in the following discussion on Paper 3. Figure 4 shows the relevant research streams for Paper 2.

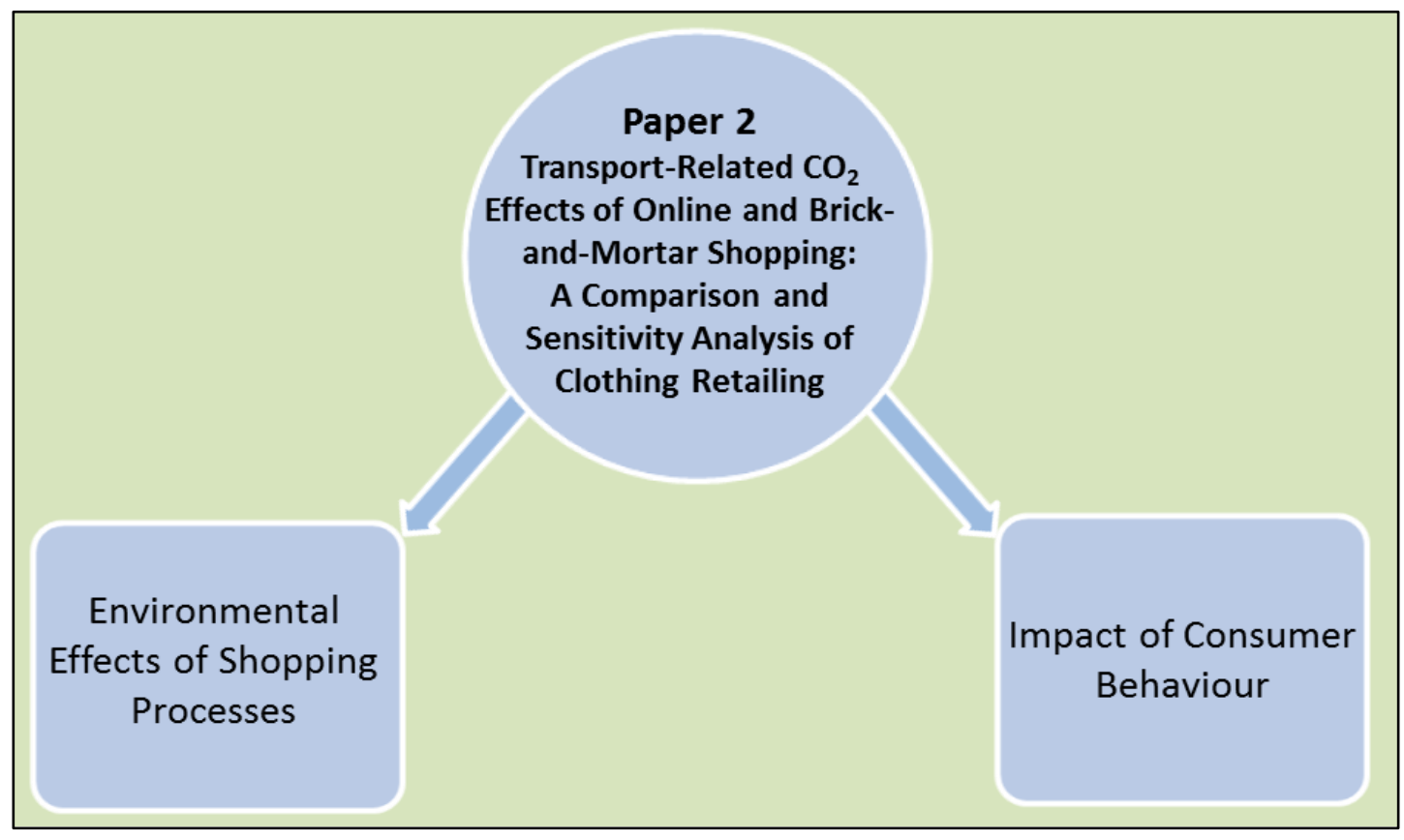

Figure 4: Related research streams (Paper 2)

Paper 3 changes the perspective to an analysis of consumer behaviour with respect to shopping trips. It provides a comprehensive overview of relevant influences affecting consumer behaviour. Furthermore, differences in consumer behaviour are highlighted. Based on this, implications for retailers and policy makers on how to improve the environmental friendliness of consumer behaviour are deduced. In doing so, the paper integrates different research streams. It is related to studies considering consumer behaviour with respect to environmental issues in general (Autio, Heiskanen, \& Heinonen, 2009; Bhate, 2001; Ölander \& Thøgersen, 1995) as well as to studies considering environmental effects of shopping behaviour (Carling et al., 2013; Edwards, McKinnon, \& Cullinane, 2009; Cairns, 2005). Also, it stands next to papers that are concerned with travel behaviour in general (McGuckin \& Murakami, 2005; Götz, 2003; Hanson \& Huff, 1986) and the design of shopping trips in particular (Guy, 2009; Gould \& Golob, 1997; Mulligan, 1987). The study integrates the environmental perspective and analyses how the environmental effects of consumer behaviour can be mitigated. In doing so, Paper 3 can be classified next to 
other studies aimed at mitigating the influence of consumer travel behaviour (Gardner \& Abraham, 2007, 2010; Bamberg, Hunecke, \& Blöbaum, 2007; Nilsson \& Küller, 2000). Furthermore, the paper is geared towards solutions for more sustainable consumption, which relates it to more general approaches towards enhancing sustainable consumption (Thøgersen, 2005; Sanne, 2002; Heiskanen $\&$ Pantzar, 1997). These connections are highlighted in Figure 5.

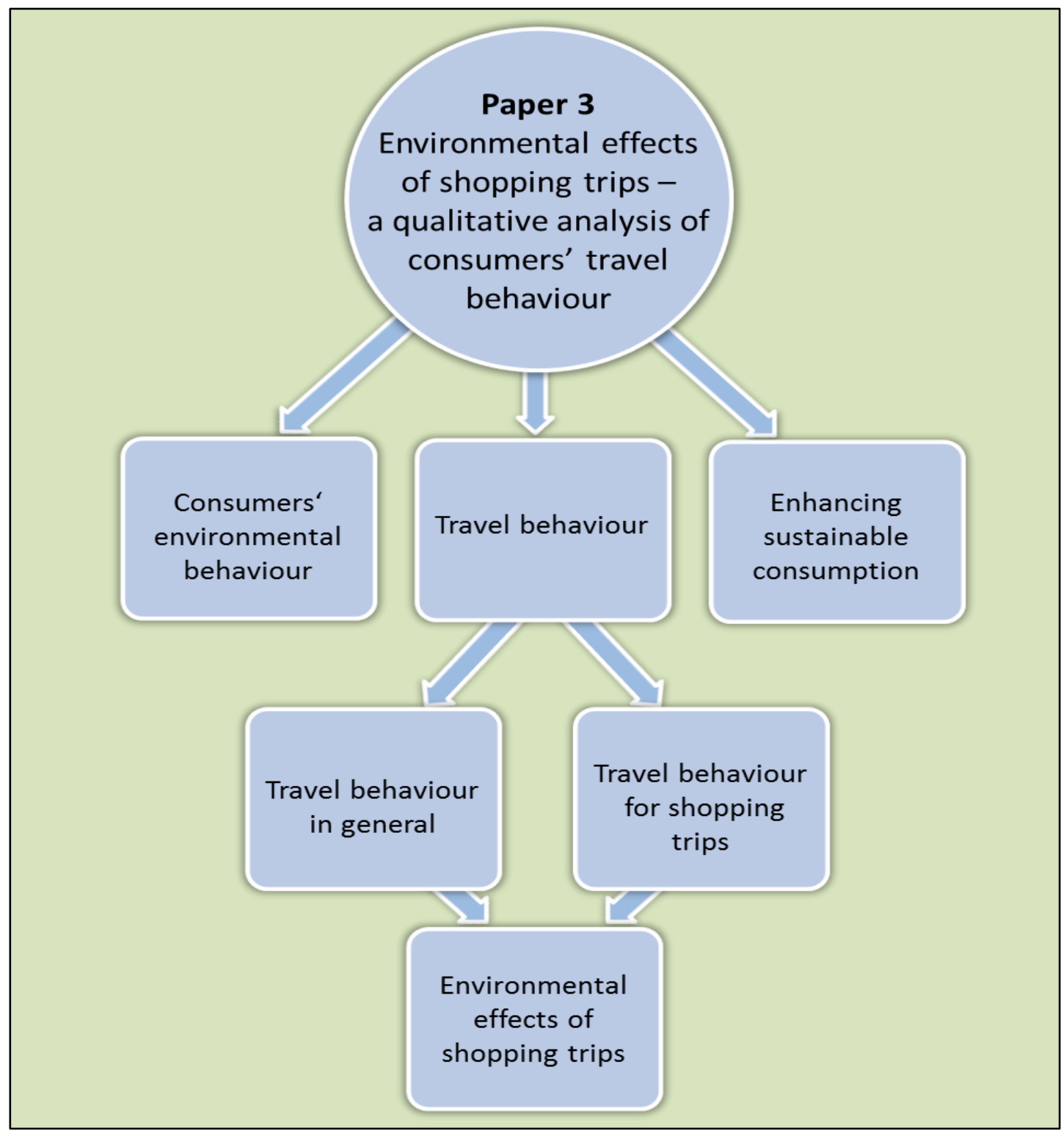

Figure 5: Related research streams (Paper 3) 


\section{Summaries of the papers and main results}

After integrating the papers into the related research areas in the preceding section, this section provides information on the main results of the papers. In particular, a short summary is given for each paper (sections 2.1, 2.2, and 2.3) and their contribution and main results are highlighted (section 2.4).

\subsection{Summary: Sustainability in retailing - a summative content analysis (Paper 1)}

This paper was aimed at analysing past and current sustainability considerations and developments in scientific research and practice with a focus on the role of retailers in supply chains. A summative content analysis was used to identify major research areas and industrial branches in the sustainability literature relevant to retail supply chains, and sustainability considerations in retail practice. It was found that sustainability-related issues have been discussed for many years and the term sustainability has received increased attention in research since the mid-1990s. In retail research, there seems to be a time lag of more than ten years in using the term sustainability compared to other fields in research and industry. However, some of these other research fields and industries have an impact on retail supply chains. For instance, the agricultural industry affects grocery retailers. At the same time, it seems that sustainability has received more attention in retail management compared to research applications. In retail practice, particularly relevant trends are the topics of $\mathrm{CO}_{2}$ emissions and CSR. The results yield valuable insights for researchers and retail practitioners. By highlighting recent developments and trends, concrete implications can be deduced. For instance, future retail research should try to integrate the findings from related research areas and industry sectors, and emerging issues in practice magazines. Also, researchers should set a particular focus on the highly relevant trends of $\mathrm{CO}_{2}$ and $\mathrm{CSR}$. 


\subsection{Summary: Transport-Related $\mathrm{CO}_{2}$ Effects of Online and Brick-and- Mortar Shopping: A Comparison and Sensitivity Analysis of Clothing Retailing (Paper 2)}

Based on the trends identified in Paper 1, this paper compares the transport-related $\mathrm{CO}_{2}$ emissions of online and brick-and-mortar shopping based on supply, delivery, order and travel data concerning one multi-channel clothing retailer. A sensitivity analysis sheds more light on how situational factors, such as the customers' travel distances, returns, the use of public transport modes and information behaviour via different channels, influence the outcome of this comparison. The results show that online retailing causes lower $\mathrm{CO}_{2}$ emissions under many conditions. Nevertheless, the brick-and-mortar channel is more environmentally friendly when travel distances are small. The radius for which brick-and-mortar shopping has an advantage increases when returns, shifts in the use of public transport and information behaviour are also considered. Based on this, implications on how to deal with the results are deduced for brick-and-mortar and online retailers. For instance, online retailers and parcel services can highlight their better environmental performance compared to brick-and-mortar formats. In contrast, brick-and-mortar retailers should try to enhance their environmental friendliness, such as by supporting public transport use. Furthermore, they should address consumers directly and clarify their impact on the environmental effects of shopping processes.

\subsection{Summary: Environmental effects of shopping trips - a qualitative analysis of consumer travel behaviour (Paper 3)}

Incorporating the high influence of consumer behaviour on the environmental effects of brick-and-mortar retailing identified in Paper 2, this paper focuses on the environmental effects of consumer shopping trips. Thus, it evaluates how retailers and policy makers can reduce the pollution caused. After illustrating the complexity of travel decisions and their environmental impact, the relevant influences are analysed more thoroughly. The paper applies qualitative interviews to understand the motives governing consumer travel behaviour, overcoming the weaknesses of quantitative research for analysing behavioural aspects. A broad literature analysis yields four relevant influence areas: sociodemographic and personal characteristics as well as situational and external influences. 
To gain a deeper understanding of consumer behaviour, consumers in five different life cycle stages and with different residential situations were interviewed to analyse their travel behaviour with respect to shopping trips and compare the impact of the relevant influences in different consumer groups. Further insights were gained on the interviewees' expectations of retailers and policy makers and on their environmental consciousness. The results reveal that consumers differ in their shopping behaviour, perceived mobility necessity and environmentally-friendly behaviour. This highlights that consumer groups should be addressed differently when aiming to stimulate environmentally-friendly behaviour. A more detailed look at this is taken by detecting four shopping types from the interviews (the Naïve, the Rational, the Spontaneous and the Optimiser). Based on these results, implications are deduced for retailers and policy makers to enhance more environmentally-friendly shopping trip behaviour. Incentives should be given with a focus on the different life cycles. For instance, consumers with children should particularly be attracted to consider their need for comfort in a transport mode. People without children have greater flexibility and demand this also from a transport mode. The personal characteristics, defined by the four shopping types identified, provide further hints as to how consumers could be approached. For instance, the Naïve might need further information to consider other transport modes as this consumer type does not seem to question its behaviour very much. In contrast, the Optimiser tries to organise his or her shopping trip as well as possible, which often counteracts the use of public transport due to trip chaining or huge shopping baskets. Here, an improvement of public transport is needed to fulfil the requirements with respect to flexibility and comfort. 


\subsection{Overview of main results}

Completing the summaries above, a more detailed overview of the main results for each paper is provided in Table 1 .

\begin{tabular}{|c|c|}
\hline Paper & Main results \\
\hline 1 & $\begin{array}{l}\text { - Low consideration of sustainability issues in retail research so far, higher and } \\
\text { earlier consideration of sustainability in other industries like the agricultural } \\
\text { or transport sector } \\
\text { - Amongst sustainability-related keywords, CSR is most relevant in retail } \\
\text { research } \\
\text { - Increased attention towards sustainability in practitioner magazines } \\
\text { - } \mathrm{CO}_{2} \text { emissions and CSR are the main trends in retail practice } \\
\text { - The increased attention towards sustainability in retail practice is only partly } \\
\text { reflected by research } \\
\text { - Complex nature of sustainability issues in the retail sector is a challenge for } \\
\text { researchers and practitioners }\end{array}$ \\
\hline 2 & $\begin{array}{l}\text { - General advantage of the online channel with respect to } \mathrm{CO}_{2} \text { emissions } \\
\text { - The advantageousness of the channels can change, depending on distance to } \\
\text { store and transport mode used } \\
\text { - Also returns and consumer information behaviour influence the } \\
\mathrm{CO}_{2} \text { emissions in the channels } \\
\text { - Consumer travel behaviour has a high impact on the } \mathrm{CO}_{2} \text { emissions caused in } \\
\text { the brick-and-mortar channel } \\
\text { - Online retailers and parcel services should communicate their better } \\
\text { environmental performance } \\
\text { - Brick-and-mortar retailers should communicate consumers' influence to } \\
\text { enhance behaviour }\end{array}$ \\
\hline 3 & $\begin{array}{l}\text { - Consumer travel behaviour is very complex and mainly affected by four } \\
\text { influences: sociodemographic and personal characteristics, situative variables } \\
\text { and external influences } \\
\text { - Consumer's life cycle situation affects the travel behaviour a lot } \\
\text { - Consumers perceive public transport negatively due to poor connections and } \\
\text { high fares } \\
\text { - Four shopping types can be detected: the Naïve, the Rational, the Spontaneous } \\
\text { and the Optimiser } \\
\text { - Consumers tend to underestimate the impact they can have on environmental } \\
\text { effects } \\
\text { - Policy makers and retailers should incorporate the different needs of } \\
\text { consumers to enhance their offer }\end{array}$ \\
\hline
\end{tabular}

Table 1: Main results of the papers 


\section{Discussion}

After clarifying the main results for each paper, in the following a broader perspective is taken to evaluate the overall contribution of the thesis and its effects on practice, research and policy. Hence, this section provides information on the research contribution (section 3.1) and the practical implications (section 3.2). Moreover, future research possibilities based on the thesis are discussed (section 3.3). The section closes with a short glance at the future perspectives of sustainability in retailing (section 3.4).

\subsection{Contribution to research}

This thesis highlights the complexity of sustainability in retailing and the responsible position of retailers. Due to its particular relevance, the focus was set on environmental issues. By analysing the environmental effects of transport processes, the relevant stakeholders are addressed. In particular, consumers and shareholders are incorporated, but also the environment. Moreover, governmental regulations are partly considered as the parcel services and retailers are faced with requirements regarding the pollution caused by their transport processes. Furthermore, in the case of brick-and-mortar retailers closing down stores, communities might be affected in the long term.

Also, the aforementioned conflicting interests are evident in the situations analysed. For instance, conflicts can occur between fast deliveries and environmental protection as express deliveries are less optimal in terms of pollution. Furthermore, the interests of consumers can be conflictive, e.g. between a joyful and relaxing shopping trip and environmentally-friendly behaviour when public transport connections are insufficient.

The thesis contributes to research in several aspects. By offering a detailed overview of sustainability developments in retailing, Paper 1 provides various streams for future research, whereby the relevance of $\mathrm{CO}_{2}$ emissions and CSR can particularly be highlighted. It points out relevant developments and shows how they have been addressed by retail research and practice so far and where research gaps exist. 
Paper 2 adds a further dimension on the comparison of $\mathrm{CO}_{2}$ emissions in online and brick-and-mortar retailing by including data from real shopping trips and online orders. Information is gained directly from the customers, the retailer and the parcel service. Therefore, more detailed analyses could have been conducted. In that way, a deeper understanding was gained of the relevant influences on the advantageousness of the channels, i.e. distance to stores, transport mode used, returns and information behaviour. Furthermore, knowledge was gathered on situations in which the advantageousness might change due to certain characteristics of the influences, e.g. consumers living close to the store or the use of public transport. Paper 3 is conducive by analysing behavioural aspects of shopping trips which have been widely neglected until now. Applying a qualitative approach via interviews, a vast amount of knowledge is gained on the relevant influences on consumers' shopping trip behaviour and its environmental effects. In detail, four influences were analysed: on the customers' side, the sociodemographic, personal and situational characteristics and the external variables that can be influenced by retailers and policy makers, but are sometimes only partly influenceable (like the weather, which might affect the transport mode choice).

Concluding this section, the main contributions of the papers and the new aspects they add to research are highlighted in Table 2. 


\begin{tabular}{|c|c|c|}
\hline Paper & Contribution & New aspects \\
\hline 1 & $\begin{array}{l}\text { - Overview of recent sustainability } \\
\text { developments in retail research and } \\
\text { practice } \\
\text { - Identification of important trends } \\
\text { - Deduction of implications for } \\
\text { retailers and researchers on the } \\
\text { trends identified }\end{array}$ & $\begin{array}{l}\text { - Structured review on sustainability } \\
\text { in retailing } \\
\text { - Two perspectives on sustainability: } \\
\text { research and practitioner }\end{array}$ \\
\hline 2 & $\begin{array}{l}\text { Focus on } \mathrm{CO}_{2} \text { emissions identified } \\
\text { as one main trend in Paper } 1 \\
\text { - Extension of the research by } \\
\text { analysing shopping related data } \\
\text { from two channels and conducting } \\
\text { detailed sensitivity analyses } \\
\text { - Implications for retailers on how to } \\
\text { deal with the results }\end{array}$ & $\begin{array}{l}\text { Analysis of real shopping data } \\
\text { derived from consumers, a retailer } \\
\text { and a parcel service } \\
\text { - Highlighting break-even points for } \\
\text { changes in the advantageousness }\end{array}$ \\
\hline 3 & $\begin{array}{l}\text { Focus on consumer behaviour that } \\
\text { was identified as a particularly } \\
\text { relevant aspect in Paper } 2 \\
\text { - Extension of the research through a } \\
\text { more in-depth analysis of consumer } \\
\text { shopping behaviour with respect to } \\
\text { its environmental consequences }\end{array}$ & $\begin{array}{l}\text { - Comprehensive overview of } \\
\text { consumer behaviour with respect to } \\
\text { travels for shopping trips } \\
\text { - Knowledge is gained on the } \\
\text { behavioural aspects of consumer } \\
\text { travel behaviour } \\
\text { - The influences of life cycle and } \\
\text { personal characteristics are } \\
\text { highlighted } \\
\text { - Detailed implications for retailers } \\
\text { and policy makers with respect to } \\
\text { differences in consumer behaviour }\end{array}$ \\
\hline
\end{tabular}

Table 2: Research contributions of the papers

\subsection{Practice implications}

In addition to the aforementioned contributions to research, the thesis also yields valuable implications for retailers. The topics analysed mirror the recent situation of retailers on the market. Retailers gain a deeper understanding of relevant developments for their businesses. Therefore, they are supported in developing appropriate approaches to master the challenges they face in daily business, such as consumers and NGOs requesting responsible behaviour and shareholders demanding a high return on investment. Paper 1 illuminates recent developments and their impact on retail practice. The relevance of social and environmental commitment is clarified by the focus on the $\mathrm{CO}_{2}$ emissions and CSR trends. Paper 2 shows how the 
increasing consideration of $\mathrm{CO}_{2}$ emissions can affect retailers in different distribution channels. By detecting the general advantageousness of the online channel, it provides a sound marketing aspect for online retailers and parcel services. In contrast, it also offers implications for brick-and-mortar retailers to strengthen their position on the competitive market with respect to their poor results for the comparison of $\mathrm{CO}_{2}$ emissions. In addition, to support and enhance environmentallyfriendly consumer behaviour through, for instance, good connections to public transport, the consumers should also be informed about their responsibility and the influence they can have. Paper 3 adds further knowledge on implications for brickand-mortar retailers by highlighting how they can support their customers in environmentally-friendly behaviour, thereby strengthening their external sustainability commitment and securing their legitimisation.

The perspective of policy makers was also included to value the general relevance of sustainability and the importance of relevant groups working together to enhance sustainable consumption. Policy makers can learn from all three papers. The overview of developments and trends highlights the relevance of sustainability for retail, a business sector particularly important due to its size and its special gatekeeper position.

Policy makers should support the sustainability commitment of retailers. Paper 1 provides various areas of relevance for political support. The more detailed analysis of the two distribution channels in Paper 2 clarified particular strengths and weaknesses of the business models with respect to the environmental effects. Whilst the online channel proved advantageous for long-distance shopping tours, the brickand-mortar channel performs better for short distances and when public transport is used. Policy makers can try to enhance the environmental friendliness of brick-andmortar shopping by sensitizing consumers to their impact. The closer examination of consumer behaviour in Paper 3 yields various starting points for supporting consumers in environmentally-conscious behaviour. By deriving four consumer shopping types and their requests for comfort and flexibility, more specific incentives can be obtained. In particular, the improvement of public transport modes with respect to the various needs is important. 


\subsection{Future research}

Based on the three papers in this thesis, research implications can be deduced. Paper 1 highlights relevant developments with respect to sustainability in retail. Researchers should focus on $\mathrm{CO}_{2}$ emissions and CSR, which have been identified as highly relevant in retail practice. Hence, a deeper understanding of the processes taking place is needed.

This thesis includes two of the three pillars of the Triple Bottom Line model (Elkington, 1998) by evaluating environmental effects of shopping processes and showing ways for traditional brick-and-mortar retailers to compete with the online channel with respect to environmental effects. To gain a more comprehensive overview of the effects of the two business models, it would be interesting to include the social pillar as well. For instance, this could be done by comparing the effects both channels have on social sustainability indicators, such as the labour situation of employees or consumer health and safety (Erol et al., 2009). Furthermore, by focussing on employees, another important stakeholder group would be included that has not been analysed in this thesis.

Paper 2 sheds further light on the environmental effects of traditional and online retailing. In particular, the sensitivity analyses showed that break-even points exist. Future research should address this topic further to increase the understanding of relevant factors. The data analysed in this thesis stem from one retailer and its related distribution channels. Hence, further evaluation is needed with respect to the generalizability of the results.

Paper 3 highlights the complexity of shopping trip behaviour and provides new insights into influences on consumer behaviour. Future approaches to analysing $\mathrm{CO}_{2}$ emissions in the respective retail channels should incorporate this knowledge. Researchers should try to picture the whole trip chain and include behavioural aspects such as the relevance of comfort and flexibility. An overall evaluation could follow the structure of the interviews applied in Paper 3, i.e. it should start by analysing the planning of the shopping trip. Also, the after-sales phase should be included by evaluating whether the product will be returned and, if so, how this happens. An aspect that has not been included in this thesis is the analysis of the 
connection between online and offline shopping. This should be evaluated in more detail in future research. The approach could be similar to the one mentioned above, i.e. researchers should try to picture the whole shopping trip, including the information behaviour before the purchase is made. Therefore, a more complete view of the advantageousness of online and traditional retail with respect to $\mathrm{CO}_{2}$ emissions could be gained. This would help retailers and policy makers to further mitigate the environmental effects. Moreover, research should try to evaluate the different consumer types (the Naïve, the Rational, the Spontaneous and the Optimiser) and the relevance of comfort and flexibility more deeply.

\subsection{Perspectives}

Despite its high relevance, sustainability research is still at an early stage and it can be expected to increase in the future. $\mathrm{CO}_{2}$ emissions and CSR have been clarified as particularly relevant research streams. Also, the thesis contributes to research by providing deeper insights into the influence of consumer behaviour on the environmental impact of shopping processes. The relevance of involving consumers in enhancing sustainable consumption has been highlighted. Hence, despite the considerable effort required from retailers, consumers should also be involved "to achieve sustainability through the market via a triple-win: improving quality of life for consumers, reducing environmental and social impacts, and increasing the market share of sustainability-minded companies" (Ackerman, 2003, p. 23).

To sum up, companies have to consider the importance of sustainability to retain their licence to operate and survive on highly competitive markets. Their efforts can be supported by researchers. They should provide a deeper understanding of stakeholder requirements such as consumer and NGOs expectations for responsible behaviour. Here, also a more detailed look is needed into the financial effects of company commitment to sustainability. Moreover, the influences companies can have on sustainable consumption and production should be evaluated further. An initial step was taken in this thesis by highlighting ways for companies to enhance sustainable behaviour among their customers. 


\section{Sustainability in retailing - a summative content analysis (Paper 1)}

Paper 1 provides a structured overview of the relevant developments regarding sustainability in retailing. The analysis follows a dual approach, focusing on both retail research and practice. By highlighting trends and research gaps, a structured base for the further analysis of sustainability issues in retailing is provided. The results of the paper are the foundation for the studies following in Paper 2 and Paper 3.

The paper was published in the International Journal of Retail \& Distribution Management (Wiese, Kellner, Lietke, Toporowski, \& Zielke, 2012). The official journal version is available at http://dx.doi.org/10.1108/09590551211211792. This publication was chosen as a Highly Commended Award Winner of the Emerald Literati Network 2013 Awards for Excellence.

An earlier version of the paper was presented at the EIRASS conference 2009 (Niagara Falls, Canada). 
This article is (C) Emerald Group Publishing and permission has been granted for this version to appear here: https://ediss.uni-goettingen.de/handle/11858/17. Emerald does not grant permission for this article to be further copied/distributed or hosted elsewhere without the express permission from Emerald Group Publishing Limited.

\subsection{Introduction}

The relevance of sustainable practices has increased lasting recent years as environmental problems are becoming more severe and consumers have begun to react more sensitively towards the eco-friendliness of product offerings (Trudel \& Cotte, 2009; Laroche, Bergeron, \& Barbaro-Forleo, 2001). Furthermore, ethical aspects attract consumers' interest and are satisfied by initiatives like Fair Trade (Newholm \& Shaw, 2007; Steinrücken \& Jaenichen, 2007).

Therefore, firms look for management approaches which incorporate sustainability considerations; they join ecological initiatives or emphasise their corporate social responsibility. In the recent Top of Mind ranking of The Consumer Goods Forum (2011), corporate responsibility (including sustainability) was ranked first by retailers and manufacturers. The changes in consumer behaviour, the increased interest in social responsibility and the intensified product and supply chain competition have brought greater relevance and research interest to the topic of sustainability for firms along the supply chain. Furthermore, competitive advantages can be gained from incorporating sustainability issues (Reuter, Foerstl, \& Blome, 2010; Flint \& Golicic, 2009; Markley \& Davis, 2007).

Retailers, in particular, play an important role in supply chains as they are intermediaries between consumers and producers (Ytterhus et al., 1999). As large retailers often have a high level of control in supply chains (Hingley, 2005), they are in a position to implement supply chain standards concerning sustainability issues (Brammer, Hoejmose, \& Millington, 2011a). They can engage in environmental supply chain management (Kotzab et al., 2011) and push green products in their supply chains (Jones, Comfort, \& Hillier, 2008b). They can also address food safety and animal welfare by implementing management guidelines, as Tesco did in its meat supply chains (Lindgreen \& Hingley, 2003). Besides, as retailers deal with the consumer directly, they are often affected by product crises related to food safety and 
This article is (C) Emerald Group Publishing and permission has been granted for this version to appear here: https://ediss.uni-goettingen.de/handle/11858/17. Emerald does not grant permission for this article to be further copied/distributed or hosted elsewhere without the express permission from Emerald Group Publishing Limited.

animal welfare issues, for instance (Wiese \& Toporowski, 2013). Therefore, retailers have a high interest in safeguarding sustainable behaviour in their supply chains.

Hence, more light should be shed on the recent developments as retailers play an important intermediary role in implementing sustainability along supply chains. Due to their connections with other supply chain tiers, retailers have to incorporate developments in other industries, such as the agricultural sector, which mainly sells its products via retailers. To analyse the recent developments, on the one hand it is necessary to focus on sustainability in the context of retail and supply chain management (SCM); on the other hand, the developments in other sectors like the agricultural industry should also be included to evaluate the influence of these sectors on retail and SCM.

Although some prior works provide reviews of sustainability literature in retailing and supply chain management, there is still a research gap regarding the role of retailers in implementing sustainability along supply chains. Existing reviews of sustainability issues in retailing have a narrower focus. Erol and co-authors (2009) conducted a "comprehensive analysis of the existing literature" (p. 49), aiding researchers with an additional structured review of sustainability research in grocery retailing. As their review focuses on sustainability indicators and selection criteria, only micro-level (i.e. firm-level) sustainability literature was included. Jones and coauthors (2005) conducted an internet search combining the keywords "sustainability" and "sustainable development" with the names of British retailers to analyse their sustainability engagement.

Also some reviews for SCM and sustainability exist. Carter and Rogers (2008) use conceptual theory building to develop a framework for sustainable SCM (SSCM). Seuring and Müller (2008) also educe a conceptual framework for SSCM, notably focussing on designing two strategies, based on a literature review. Brammer, Hoejmose, and Millington (2011b) particularly address practitioners by analysing how to manage international, sustainable supply chains using a systematic literature review, including articles that do not stem from the classical academic literature. 
This article is (C) Emerald Group Publishing and permission has been granted for this version to appear here: https://ediss.uni-goettingen.de/handle/11858/17. Emerald does not grant permission for this article to be further copied/distributed or hosted elsewhere without the express permission from Emerald Group Publishing Limited.

They discover that retail is the third most analysed industry in the research on international sustainable supply chains. Carter and Easton (2011) provide an overview of the recent academic literature on SSCM since 1991. However, due to their supply chain focus, none of these papers analyses the role of retailers along supply chains in particular.

Hence, our paper aims to close this research gap by focussing on sustainability in retailing research and practice, taking the specific role of retailers along the supply chain into account. In particular, this paper addresses the following research questions:

- What are the major research areas and industrial branches dealing with sustainability? Answering this question is important to understand sustainability considerations in supply chains that are relevant for retailers (e.g. agriculture).

- What are the latest important developments in sustainability research, focussing on retailing in particular?

- What sustainability progress can be observed in retail practice? Has the importance of certain sustainability-related aspects changed over time? Do any discrepancies emerge between research and practice?

- Which implications can be drawn for retail research and practice based on the findings presented?

These research questions are answered using a summative content analysis approach (Hsieh \& Shannon, 2005). The results not only help to analyse how far sustainability research has proceeded in different areas, but also to identify research gaps.

The remainder of this paper is structured as follows. In section 4.2, we briefly discuss definitions of sustainability and suggest a working definition. Section 4.3 presents the methodology. The results of a summative content analysis of general sustainability considerations in research are presented in section 4.4. Section 4.5 adds findings about sustainability considerations and progress in retail research and 
This article is (C) Emerald Group Publishing and permission has been granted for this version to appear here: https://ediss.uni-goettingen.de/handle/11858/17. Emerald does not grant permission for this article to be further copied/distributed or hosted elsewhere without the express permission from Emerald Group Publishing Limited.

practice. These results are discussed in section 4.6, where interactions between sustainability research and the relevance of sustainability in practice are contrasted. Section 4.7 then summarises the implications for retail and supply chain research. The paper concludes with a discussion of limitations in section 4.8 and a summary of the main results in section 4.9 .

\subsection{Defining sustainability}

Before providing an overview of past sustainability research, the term sustainability needs to be defined. A variety of sustainability definitions exists in the relevant literature, often using differing terminology and sometimes overlapping in their meanings. Recent research has mainly agreed on the Triple Bottom Line (TBL) model developed by Elkington (1998), which incorporates the economic, environmental and social dimensions of sustainability and highlights the interdependencies between them. However, different definitions of sustainability still exist, showing the somewhat complex characteristics of this concept. Table 3 presents a selection of these diverse definitions.

\begin{tabular}{|l|l|}
\hline Authors & Sustainability definition \\
\hline $\begin{array}{l}\text { World Commission on } \\
\text { Environment and } \\
\text { Development (1987, p. 8) }\end{array}$ & $\begin{array}{l}\text { "[...] development that meets the needs of the present } \\
\text { without compromising the ability of future generations to } \\
\text { meet their own needs." }\end{array}$ \\
\hline $\begin{array}{l}\text { Costanza and Patten (1995, } \\
\text { p. 193) }\end{array}$ & $\begin{array}{l}\text { "The basic idea of sustainability is quite straightforward: a } \\
\text { sustainable system is one which survives or persists." }\end{array}$ \\
\hline $\begin{array}{l}\text { United Nations Environment } \\
\text { Programme Finance } \\
\text { Initiative (1997, unpaged) }\end{array}$ & $\begin{array}{l}\text { "[...] sustainable development depends upon a positive } \\
\text { interaction between economic and social development, and } \\
\text { environmental protection, to balance the interests of this and } \\
\text { future generations." }\end{array}$ \\
\hline $\begin{array}{l}\text { Parris \& Kates (2003, } \\
\text { p. 581) }\end{array}$ & $\begin{array}{l}\text { "[...] a minimal definition of sustainable development [...] } \\
\text { includes meeting human needs, which reduces hunger and } \\
\text { poverty, while preserving the life support systems of the } \\
\text { planet." }\end{array}$ \\
\hline Ehrenfeld (2005, pp. 24-25) & $\begin{array}{l}\text { "I define sustainability as the possibility that all forms of life } \\
\text { will flourish forever. For human beings, flourishing } \\
\text { comprises not only survival and maintenance of the species } \\
\text { but also a sense of dignity and authenticity. [...] Ultimately, }\end{array}$ \\
\hline
\end{tabular}


This article is (C) Emerald Group Publishing and permission has been granted for this version to appear here: https://ediss.uni-goettingen.de/handle/11858/17. Emerald does not grant permission for this article to be further copied/distributed or hosted elsewhere without the express permission from Emerald Group Publishing Limited.

\begin{tabular}{|l|l|}
\hline & $\begin{array}{l}\text { sustainability requires responsible, ethical choices } \\
\text { everywhere in daily life." } \\
\text { "“...] sustainable development in its economic, social and } \\
\text { environmental aspects constitutes a key element of the } \\
\text { overarching framework of United Nations activities." }\end{array}$ \\
\hline Lozano (2008, p. 8) & $\begin{array}{l}\text { "[...] in order for us to achieve societal sustainability we } \\
\text { must use holistic, continuous and interrelated phenomena } \\
\text { amongst economic, environmental, and social aspects, }[\ldots] \\
\text { and that each of our decisions has implications for all of the } \\
\text { aspects today and in the future." }\end{array}$ \\
\hline
\end{tabular}

Table 3: A sample of definitions and interpretations of sustainability and sustainable development

Although the intention is not to present a comprehensive review of sustainability definitions in this paper (see, e.g., Lozano, 2008; Glavič \& Lukman, 2007; Mebratu, 1998), the different definitions illustrate some of the contrasting understandings of sustainability found in the literature. The definitions range from very broad (Costanza \& Patten, 1995) to quite detailed (Lozano, 2008) approaches. Furthermore, they differ widely with respect to the specificity both in terms of relevant sustainability aspects (needs [World Commission on Environment and Development, 1987]; hunger, poverty [Parris \& Kates, 2003]; dignity, authenticity, ethics [Ehrenfeld, 2005]) and sustainability dimensions (economic, environmental, and social [Lozano, 2008; United Nations Environment Programme Finance Initiative, 1997]) or as a key element of a broader framework and thus an overarching dimensionality of UN activities (United Nations, 2005). Whilst the World Commission on Environment and Development's (1987) definition appears to be most frequently cited, this paper will use the last definition by Lozano (2008) as it is based on the widely accepted Triple Bottom Line model.

Nevertheless, the broad scope of different definitions and the lack of one universal understanding of sustainability and sustainable development may be partially explained by the variety of research questions and the diversity of research areas incorporating sustainability issues. This fact is further illustrated in the following sections. 
This article is (C) Emerald Group Publishing and permission has been granted for this version to appear here: https://ediss.uni-goettingen.de/handle/11858/17. Emerald does not grant permission for this article to be further copied/distributed or hosted elsewhere without the express permission from Emerald Group Publishing Limited.

\subsection{Methodology}

To shed light on both the scientific research areas and the relevant industrial branches sustainability research has focused on so far, a summative content analysis seems appropriate. Furthermore, this approach also seems suitable for analysing the relevance of sustainability in retail research and practice in particular. A study using a summative content analysis approach commonly begins with an identification and quantification of certain words or content in the text or literature. The quantification is usually used to explore usage and focuses on counting the frequency of specific words or content if stopped at this point (Hsieh \& Shannon, 2005; Kondracki, Wellman, \& Amundson, 2002). The results show, for example, in how many documents of a database a word (e.g. sustainability) is used. This frequency can be split into different criteria, such as the year of publication, the respective journal, the research area or the industry classification of a document.

\subsubsection{Analysis of scientific research}

To identify which research areas in business and economics have considered sustainability problems, we firstly conducted an extensive literature search structured according to the Journal of Economic Literature (JEL) Classification System that is used to classify journal articles. JEL distinguishes 20 main categories, all of which include numerous subcategories. The searches were carried out based on the keywords provided by JEL for all main categories in combination with the sustainability search term "sustainab*", which finds both "sustainable" and "sustainability". The American Economic Association (AEA) provides a detailed JEL Classification Codes Guide which supplies relevant keywords for each category and subcategory (American Economic Association, 2009). Both primary category and subcategory keywords were employed in the literature searches. On average, each category (including all subcategories) contained 32 keywords. However, the number of keywords in the different categories varied between 4 and 85 .

Secondly, another literature search was conducted to delineate which industries scientific sustainability research has focused on. The industries were structured based 
This article is (C) Emerald Group Publishing and permission has been granted for this version to appear here: https://ediss.uni-goettingen.de/handle/11858/17. Emerald does not grant permission for this article to be further copied/distributed or hosted elsewhere without the express permission from Emerald Group Publishing Limited.

on the 2007 North American Industry Classification System (NAICS). According to the U.S. Census Bureau (2009), the "North American Industry Classification System (NAICS) is the standard used by Federal statistical agencies in classifying business establishments for the purpose of collecting, analysing and publishing statistical data related to the U.S. business economy". The 2007 NAICS system distinguishes 20 main sectors.

Searches included all major industry sectors according to NAICS and the sustainability search term "sustainab" as described above. As NAICS does not provide keywords for the sectors, NAICS-related search terms were based on the sector descriptions. For example, search terms for Sector 11 (Agriculture, Forestry, Fishing and Hunting) thus include "agricultur*", "forest*", "fish*”, and "hunt*". The NAICS categories include Retail Trade and Wholesale Trade and several other industries related to retail supply chains.

Thirdly, the NAICS category Retail Trade was analysed more thoroughly by discussing the content of the papers identified and searching for additional sustainability-related keywords presented in Table 4. This seems interesting, as research articles may focus solely on specific aspects of sustainability without using the general term.

\begin{tabular}{|ccc|}
\hline sustainability / sustainable & environment / environmental & carbon footprint / $\mathrm{CO}_{2}$ \\
CSR / social responsibility & fair trade & eco-friendly \\
green & eco-marketing & organic \\
\hline
\end{tabular}

Table 4: Sustainability-related keywords

For all analyses, the literature review focused on one major economic online database resource, EBSCO Host / Business Source Premier (BSP). In this database, over 10,000 economic publications are regularly evaluated, approximately 1,800 of which are peer-reviewed titles. Keywords were searched using the field code TI, 
This article is (C) Emerald Group Publishing and permission has been granted for this version to appear here: https://ediss.uni-goettingen.de/handle/11858/17. Emerald does not grant permission for this article to be further copied/distributed or hosted elsewhere without the express permission from Emerald Group Publishing Limited.

which seeks keywords in a record's title, keywords, and abstract. According to Kevork and Vrechopoulos (2009), the authors' keywords can be taken as an authentic indicator about the articles' subject areas. They argue that "the keywords are one of the most revealing characteristics about an article's content" (p. 49). The retrievals were restricted to peer-reviewed academic journals in English.

To secure the quality of the analyses, content checks ensured that any articles were eliminated which do not use "sustainab*" in accordance with at least some aspect(s) of the multidimensional sustainability definition given by Lozano (2008) or use the sustainability term as a general synonym for long-term orientation. One researcher was responsible for this check. However, all ambiguous cases were discussed within the research team.

\subsubsection{Analysis of practice considerations}

In order to evaluate the development of sustainability relevance in practice, a content analysis of several retail magazines was conducted. To account for geographic differences, we considered magazines from the US (Progressive Grocer, Retailing Today, Retail Merchandiser), the UK (Retail Digest) and Germany (Lebensmittel Zeitung). We searched these magazines' databases for several keywords presented in Table 4. Extending the list of sustainability-related keywords seems especially necessary for the practice analysis, as sustainability considerations in practice often involve only certain aspects of sustainability, such as environmental or social issues. 
This article is (C) Emerald Group Publishing and permission has been granted for this version to appear here: https://ediss.uni-goettingen.de/handle/11858/17. Emerald does not grant permission for this article to be further copied/distributed or hosted elsewhere without the express permission from Emerald Group Publishing Limited.

\subsection{General research on sustainability}

This section presents the frequencies of sustainability considerations in different research areas and industries based on the JEL and NAICS classification scheme. Several of these categories are related to supply chains in which retailers operate.

\subsubsection{Structuring sustainability research according to economic research areas}

The analysis of sustainability according to economic research areas is based on the official JEL keywords and the search term "sustainab*". In total, 2,602 hits were counted, starting from the year 1981 (see Figure 6). Since then, a steady increase can be observed. After negligible numbers of hits until 1988, the number of sustainability-related articles rises constantly until 2002 with small interruptions in 1995 and 2000. In the 1990s, a rise from 6 (1990) to 123 hits (2000) can be observed. In particular, there was a strong increase from the mid-1990s onwards. In the 2000s, the number of hits then doubles until 2006 with 265 hits. The highest number of hits (330) is reached in 2009. Overall, an increase in sustainability considerations in academic journals lasting recent years is evident.

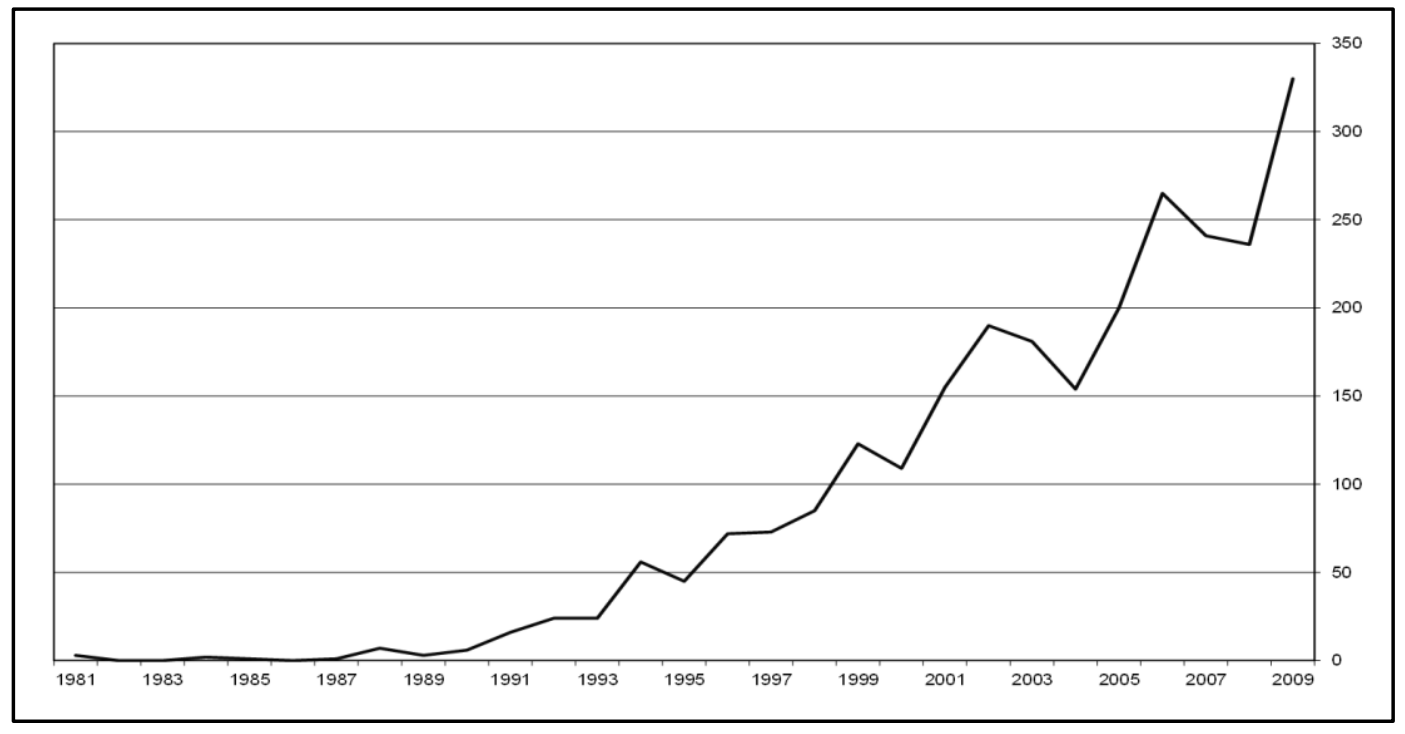

Figure 6: Development of JEL-based sustainability hits over time 
This article is (C) Emerald Group Publishing and permission has been granted for this version to appear here: https://ediss.uni-goettingen.de/handle/11858/17. Emerald does not grant permission for this article to be further copied/distributed or hosted elsewhere without the express permission from Emerald Group Publishing Limited.

11 JEL categories received more than 50 hits between 1981 and 2009 (see Figure 7). The classification O (Economic Development, Technological Change, and Growth) received the highest number of sustainability-related articles. Furthermore, the classifications R (Urban, Rural, and Regional Economics), Q (Agricultural and Natural Resource Economics; Environmental and Ecological Economics), and $\mathrm{M}$ (Business Administration and Business Economics; Marketing; Accounting) each yielded more than 200 hits. They were followed by the classifications $\mathrm{E}$ (Macroeconomics and Monetary Economics), H (Public Economics) and A (General Economics and Teaching) with more than 100 hits each and can therefore be highlighted as the important research fields in terms of sustainability considerations. Finally, with more than 50 hits each, the JEL categories I (Health, Education, and Welfare), F (International Economics), D (Microeconomics) and L (Industrial Organisation) can also be considered as relevant economic research areas with respect to sustainability considerations.

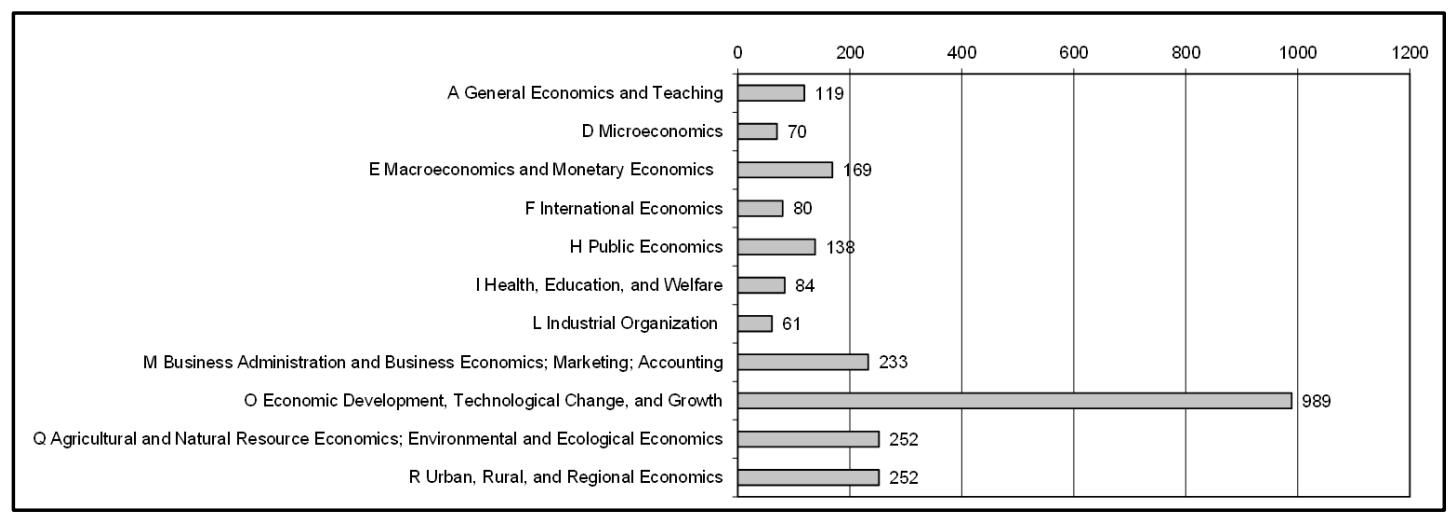

Figure 7: JEL-based sustainability hit distribution

These results clarify that the research mainly considered sustainability aspects in the areas of economic development, technological change and growth. However, the research areas of business administration, agricultural and natural resource economics and urban, rural and regional economics also yielded a high number of hits. All these categories are relevant for retailers and their role in supply chains. The agricultural industry has an influence in agricultural supply chains affecting retailers' businesses. The area of business administration is needed to implement sustainability 
This article is (C) Emerald Group Publishing and permission has been granted for this version to appear here: https://ediss.uni-goettingen.de/handle/11858/17. Emerald does not grant permission for this article to be further copied/distributed or hosted elsewhere without the express permission from Emerald Group Publishing Limited.

in the companies which should be based in the management area. Besides, single departments, e.g. the marketing or controlling department, focus on sustainability issues. This reasoning is supported by the endeavours of many businesses to publish sustainability reports (e.g. Intel Corporation, Ford Motor Company, METRO GROUP or Unilever [United Nations Global Compact, 2011]) and increasing attention towards such reporting practices on the part of international initiatives such as the Global Reporting Initiative (GRI) (Global Reporting Initiative, 2007). Furthermore, urban planning is an area that is quite relevant for the location planning of retail stores. Here, sustainability issues should be incorporated to keep passenger traffic and goods transports low, for instance.

\subsubsection{Structuring sustainability research according to industrial sectors}

In the second literature search, we used keywords derived from the 20 main industry sectors defined by NAICS to structure our findings. For this search, the first hits occurred in 1988. From then, the development is quite similar to the results for JEL. Until 1999, no more than 20 hits per year occur. There is then an increase of up to 82 hits in 2006. Although the increase in sustainability considerations is obvious, the number of hits indicates that sectorial or industry-specific sustainability research has not yet become a centrally prominent stream of research. Therefore, taking into account the spike in sustainability mentions in the recent past, it might well be one of the more promising research themes currently pursued. This result supports Carter and Easton (2011), who suggest focusing on individual industries in future research.

Six NAICS categories received more than 50 hits each between 1988 and 2009 (see Figure 8). With 200 hits, the most important category is Agriculture, Forestry, Fishing, and Hunting. The other categories yield a fairly similar number of hits with scores between 50 (Educational Services) and 69 (Management of Companies and Enterprises). 
This article is (C) Emerald Group Publishing and permission has been granted for this version to appear here: https://ediss.uni-goettingen.de/handle/11858/17. Emerald does not grant permission for this article to be further copied/distributed or hosted elsewhere without the express permission from Emerald Group Publishing Limited.

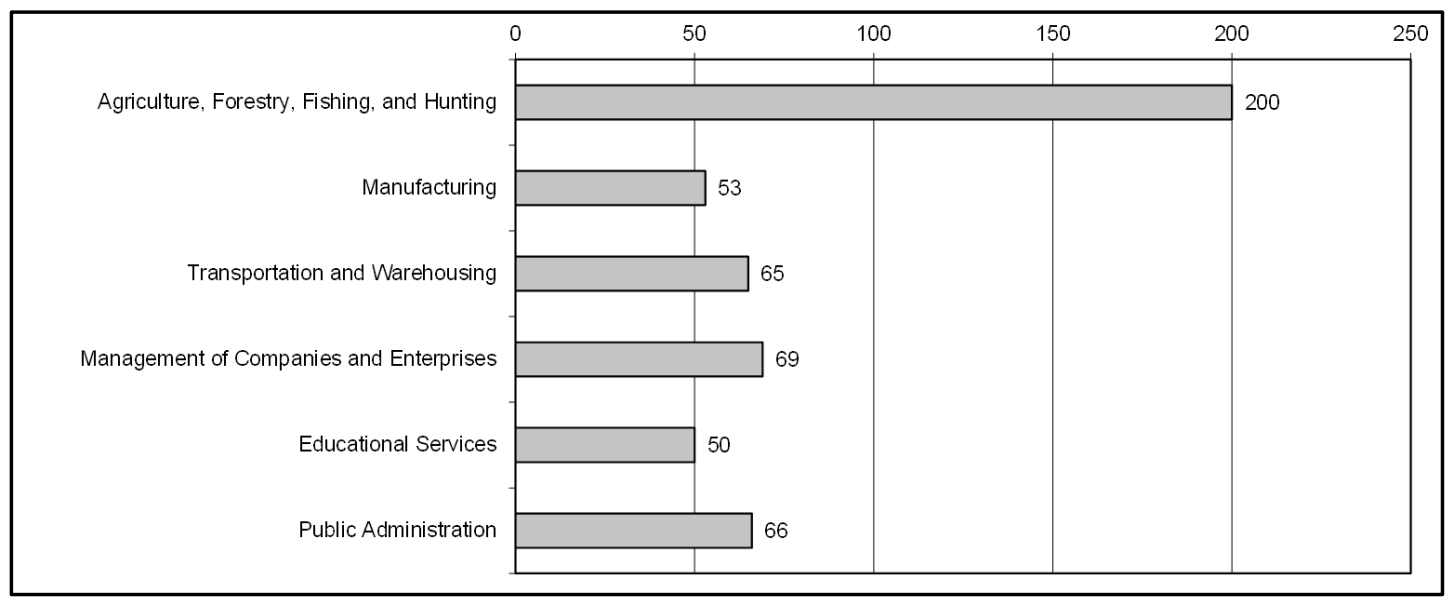

Figure 8: NAICS-based sustainability hit distribution

Relevant NAICS categories in the retail context are Retail Trade and Wholesale Trade. The category Wholesale Trade did not reveal any hits and the search for Retail Trade only yielded seven hits. A category directly related to SCM does not exist as NAICS only covers industry sectors. However, the Transport and Warehousing category is important in the SCM context. Searching for Transport and Warehousing produced 56 hits, peaking between 2003 (9) and 2005 (13). Sustainability seems to be more important in other sectors than in retail as Retail Trade is the sector with the fewest sustainability considerations. This result conflicts in some way with Brammer et al. (2011b), who named retail as the third most analysed sector in SSCM. The reason for this difference might be that we focused on scientific literature whilst their review also included non-academic research and focused on international supply chains.

Analysing the results again reveals certain connections with retail. Similar to the results of the analysis using JEL codes, the agricultural industry forms the most important sector affecting retailers in food supply chains. Besides, sustainability issues are also important for the management of companies. Hence, retail managers should incorporate sustainability. As already mentioned, the Transport and Warehousing category received a high number of hits. These areas are important for implementing sustainability along supply chains. For instance, it might be interesting to analyse how different SCM strategies, such as Cross Docking, Backhauling, Shelf- 
This article is (C) Emerald Group Publishing and permission has been granted for this version to appear here: https://ediss.uni-goettingen.de/handle/11858/17. Emerald does not grant permission for this article to be further copied/distributed or hosted elsewhere without the express permission from Emerald Group Publishing Limited.

Ready-Packaging and Vendor-Managed-Inventory, influence certain sustainability criteria.

\subsection{Sustainability considerations in retail research and practice}

After considering general aspects of sustainability research and the connection to retail in section 4.4 , the following section focuses on sustainability in retailing. We begin by analysing the retail research on sustainability in more detail before focusing on practice considerations regarding sustainability issues.

\subsubsection{Sustainability in retail research}

As stated above (see section 4.2), a combined search of "retail*" and "sustain*" yielded a total of seven studies, which fit Lozano's (2008) sustainability definition. A content review reveals several interesting findings relevant to sustainability considerations in retail research. Firstly, all sustainability-related retail articles have been published recently, which once again indicates that especially sustainable retail research is still in its infancy with a promising path ahead. Secondly, although only few papers were reviewed, they already show a prominent variety in the methods utilised (e.g. descriptive, theoretical versus normative papers, qualitative empirical research versus quantitative analyses), the retail sectors under consideration (e.g. fashion, grocery), the countries where the research was carried out (e.g. Netherlands, UK), and the unit of analysis (e.g. industries vs. supply chains). Furthermore, retail development (Doak, 2009) and sustainable commercial properties are regarded (Newell, 2009). Thirdly, articles explicitly researching sustainability issues in retail do not necessarily consider all sustainability dimensions. Rather, certain dimensions are considered in more detail (e.g. social responsibility [Quak \& de Koster, 2007] or environmental sustainability [Newell, 2009; Thompson, 2007]. Alternatively, some articles only consider certain combinations (e.g. Jones et al., 2008a). Moreover, even within a certain sustainability dimension, the research sometimes focuses on very specific aspects of that dimension. For example, Thompson (2007) mostly discusses energy savings when considering environmental sustainability relevant to retailers. 
This article is (C) Emerald Group Publishing and permission has been granted for this version to appear here: https://ediss.uni-goettingen.de/handle/11858/17. Emerald does not grant permission for this article to be further copied/distributed or hosted elsewhere without the express permission from Emerald Group Publishing Limited.

This short review shows the variety of research areas and the differing sustainability interpretations in retail research. Hence, it is currently impossible to make general statements about sustainability issues in retail.

As "sustainability" does not seem to be a very common term in retail research, we conducted an additional search using sustainability-related keywords and "retail*" to gain further insights into the relevance and development of sustainability issues in retail research.

The search for "CSR / social responsibility" yielded a total of 13 studies, 11 of which were published between 2005 and 2010. The search terms "environment / environmental" produced four hits; all of these papers were published between 2008 and 2010. Again, we received four hits searching for "organic"; one paper was published in 2003 and the others are quite recent with publication dates in 2008 and 2010. Four hits published between 2007 and 2010 also resulted for the search term "green". Searching for "carbon footprint $/ \mathrm{CO}_{2}$ " revealed three hits for the years 2009 to 2010. The term "Fair Trade" produced three hits released in 2002, 2004 and 2008. No hits were generated for "eco-friendly" and "eco-marketing". These analyses show that recent retail research has only partly focused on sustainability-related issues. An outstanding issue is CSR, with 13 hits. The other search terms yielded fewer results with between zero and four hits, which confirms that the scope of research on sustainability issues in retail is still very limited.

Considering the years of publication clarifies the growing relevance of sustainability issues in recent years. With the exception of the issues Fair Trade, organic and CSR, the papers in all other areas have been published since 2007. Regarding the characteristics of the sustainability-related issues analysed, the role of collaboration along the supply chain becomes clear. In order to behave responsibly, retailers depend on the behaviour of their suppliers and sub-suppliers, such as in cases of labour conditions at production plants, for instance. Similar situations exist for the other search terms. To sell organic products, retailers need their suppliers to produce these products and get them certified. To calculate a carbon footprint of the products 
This article is $\odot$ Emerald Group Publishing and permission has been granted for this version to appear here: https://ediss.uni-goettingen.de/handle/11858/17. Emerald does not grant permission for this article to be further copied/distributed or hosted elsewhere without the express permission from Emerald Group Publishing Limited.

sold, retailers rely on the information of their suppliers. However, retailers are in the position to push sustainability issues along supply chains by implying customer requirements for carbon footprints or organic products, for example.

Some differences occur by comparing the results for retail research with the findings of the reviews on sustainability in supply chains. Whilst environmental issues are the most important aspect in the literature review of Carter and Easton (2011) and the first important topic (or second, depending on the time period) in the review of Brammer et al. (2011b), they have less frequently been the focus of retail research. However, Carter and Easton (2011) point out the interchangeable use of the terms sustainability and environment. This was also shown in the short content analysis of the papers on sustainability in retail research. Interestingly, CSR was the main topic in retail research while it was not focussed upon that much in supply chain research (Carter \& Easton, 2011). However, more articles from outside academic research have focussed on social issues such as working conditions, human rights or low wages as well as CSR (Brammer et al., 2011b).

\subsubsection{Sustainability in retail practice}

Having illustrated sustainability considerations in scientific research areas and progress, we now turn to sustainability considerations in practice. Specifically, we aim to shed light on what sustainability progress can be observed in retail practice. Therefore, we carried out a comprehensive search and review of five retail magazines.

Our search started in the year 1993 due to database availability. The results demonstrate that sustainability issues have received increased attention in more recent years (see Figure 9). A small, but already steadily growing number of sustainability-related articles was published in magazines until 2004. Since 2005, the number of hits has increased constantly. Around three times more sustainabilityrelated articles have been published in 2009 compared to the period of 2000 to 2004 . In 2009, there appears to be a small decrease in this development. 
This article is (C) Emerald Group Publishing and permission has been granted for this version to appear here: https://ediss.uni-goettingen.de/handle/11858/17. Emerald does not grant permission for this article to be further copied/distributed or hosted elsewhere without the express permission from Emerald Group Publishing Limited.

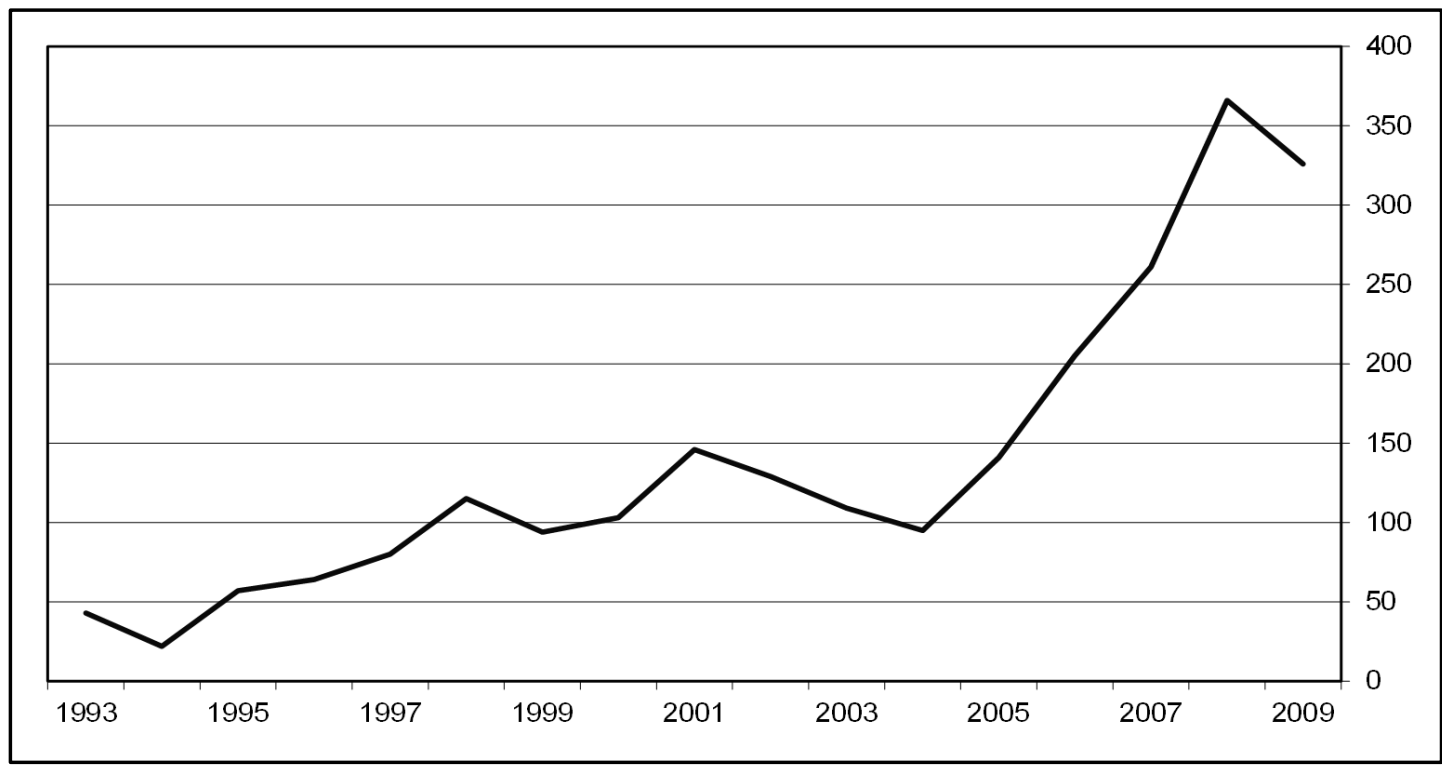

Figure 9: Development of sustainability-related keywords in retail magazines over time

(Retailing Today not included (the magazine was discontinued in 2009))

Figure 10 illustrates how certain sustainability-related topics have developed over time. The keywords "environment / environmental" received more hits than any other keyword until 1996, when "organic" became a prominent keyword. After some years of stagnant considerations, the results for "environment / environmental" increased steadily from 2006 to 2008 and fell slightly in 2009. The keyword "organic" is the most important keyword in practice. The findings for this keyword increased continuously until 2001 and increased again up to the year 2007 with 181 hits. This peak was again followed by a decrease until 2009. The hits for "green", which can be seen as strongly related to "organic", have also increased significantly since 2004. The results for the keywords "sustainable" and "sustainability" show the growing importance of the concept. The hits for these keywords are the only ones that increased from 2008 to 2009. Starting with a very small number of just seven hits in 2006, a strong increase followed which led to 88 hits in 2009. Dramatic increases are also observable for "carbon footprint / $\mathrm{CO}_{2}$ " (from 1 hit in 2005 to 41 hits in 2008 and 30 hits in 2009). The keywords “CSR / social responsibility" yielded nearly seven times more hits in 2009 compared to 2005 . Hence, these aspects of sustainability are certainly more recent trends in retail practice. The results for "eco-friendly" and "fair trade" are not included in the figure as the number of hits is still small, but has increased a lot in the last years. The 
This article is (C) Emerald Group Publishing and permission has been granted for this version to appear here: https://ediss.uni-goettingen.de/handle/11858/17. Emerald does not grant permission for this article to be further copied/distributed or hosted elsewhere without the express permission from Emerald Group Publishing Limited.

number of hits for "eco-marketing" is very small with an overall number of four hits (not included in the figure).

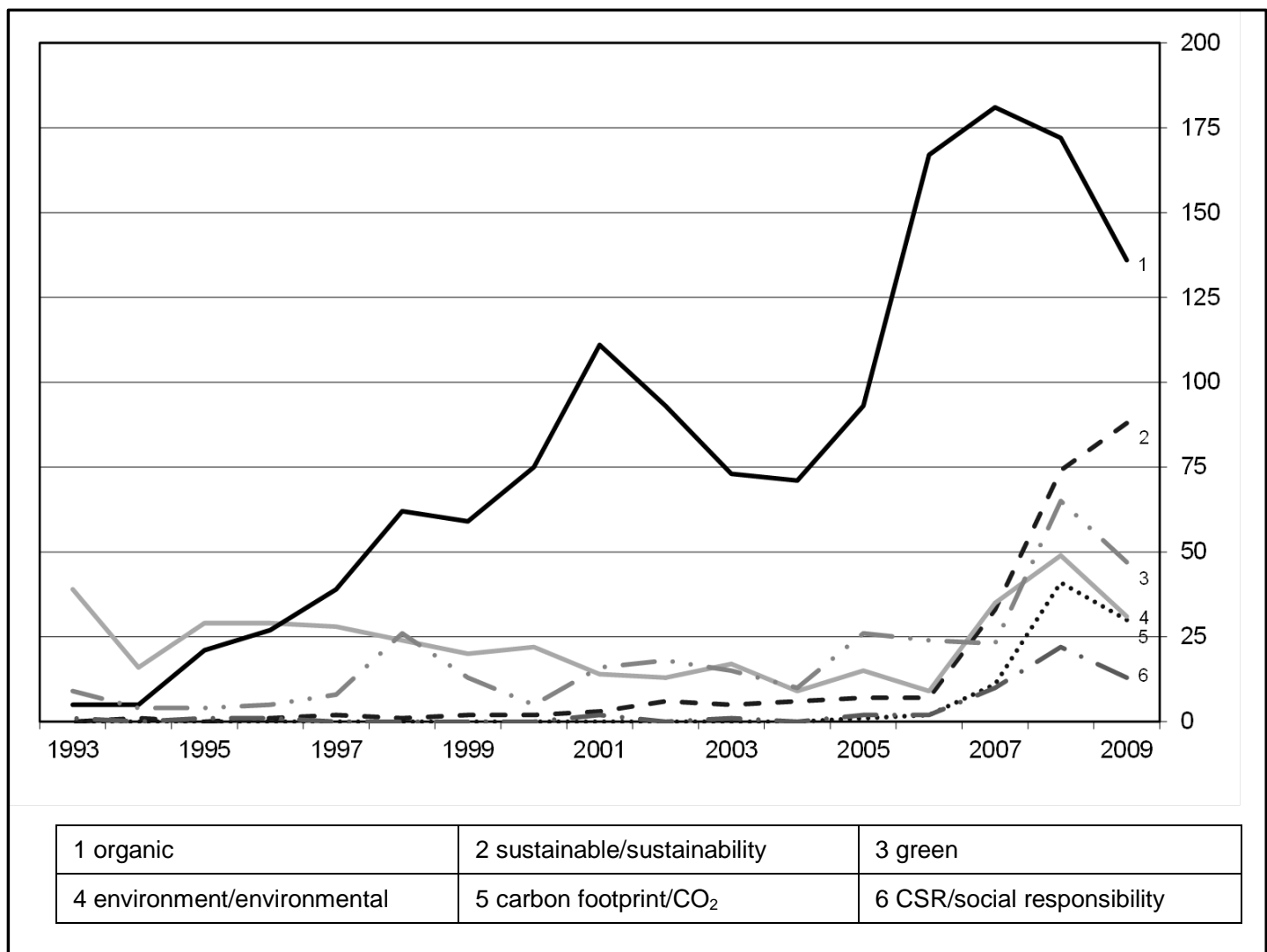

Figure 10: Development of most relevant sustainability-related keywords in retail magazines

(Retailing Today not included (the magazine was discontinued in 2009))

\subsection{Research and practice interactions}

The results from the content analyses of articles published in academic literature and retail magazines indicate that sustainability has received increased attention in recent years. While sustainability-related publications in research journals have continuously increased since 1994, publications directly related to retailing are scarce and the existing few were mostly published after 2004. Furthermore, for sustainability-related terms the number of hits in retail research was quite low, showing that many areas are still not analysed. A number of categories with a considerable number of hits refer to issues which are relevant for retailing. These include "Business Administration and Business Economics; Marketing; 
This article is (C) Emerald Group Publishing and permission has been granted for this version to appear here: https://ediss.uni-goettingen.de/handle/11858/17. Emerald does not grant permission for this article to be further copied/distributed or hosted elsewhere without the express permission from Emerald Group Publishing Limited.

Accounting”, "Agricultural and Natural Resource Economics; Environmental and Ecological Economics" and "Urban, Rural and Regional Economics" in the JEL classification or "Agriculture, Forestry, Fishing, and Hunting" and "Transportation and Warehousing" in the NAICS classification.

The analysis of retail magazines sheds some additional light on these results. Similar to the results for academic literature, the relevance of sustainability recently has increased. However, the number of hits between 2004 and 2009 is significantly higher compared to the number of hits in academic literature regarding retail. Hence, it seems that the relevance of sustainability in practice is not completely reflected by academic literature, implying an interesting and highly relevant, yet largely unexplored, field of research. In addition, retail research and practice may benefit from an application of learnings on sustainability in other research areas and a transfer of learnings. Furthermore, the results from retail magazines demonstrate that sustainability-related aspects, such as environmental issues, were already discussed before the term sustainability emerged.

An outstanding issue in retail research is CSR, which has been analysed more than other sustainability-related issues. Moreover, it has been analysed as an emerging trend in retail practice. Another trend in retail practice is carbon footprint / $\mathrm{CO}_{2}$. This topic has only been analysed very rarely in retail research, thus constituting a promising field for future research.

To sum up, sustainability-related issues have been discussed for many years and the term sustainability has received increased attention in research since 1994. In retail and SCM, there seems to be a time lag of more than ten years in using the term sustainability. At the same time, it seems that sustainability received more attention in retail practice compared to research publications, showing some new research fields. 
This article is (C) Emerald Group Publishing and permission has been granted for this version to appear here: https://ediss.uni-goettingen.de/handle/11858/17. Emerald does not grant permission for this article to be further copied/distributed or hosted elsewhere without the express permission from Emerald Group Publishing Limited.

\subsection{Implications and directions for future research}

The summative content analyses according to JEL, NAICS and retail magazines showed an obvious overall trend towards more sustainability-related research. Interestingly, retail stands out as the sector with the fewest sustainability considerations among the supply chain relevant sectors, suggesting many interesting future research directions. Hence, it is difficult to provide a general statement on the relevant issues concerning retail's sustainability considerations as only a few papers with diverse research areas exist.

One reason for the currently low numbers of sustainability-related research publications in retail may be found in the fact that retail business is usually extremely complex in terms of the article count, length, number and origins of retail supply chains, as well as a dependency on involved upstream and logistics parties to provide relevant information to retail. Hence, it is more complex to measure a carbon footprint for different retail channels than for a single product as different shopping trips and many influencing factors like vehicles used, articles bought and trip chaining have to be included. Nevertheless, with retail being the central touch point for end consumers (Ytterhus et al., 1999), who are increasingly aware of sustainability issues, retail-focused sustainability research is likely to become highly relevant in the near future. Therefore, future research should try to consider the complexity of retailing. Whilst the results from the summative content analyses indicate a major gap for sustainability research in retailing, a number of studies analyse single sustainability-related aspects, such as environmental or CSR issues.

Furthermore, sustainability research exists in areas and industries which are related to retail supply chains, such as transport. Thus, future retail research should try to integrate the research findings from those industry sectors which lie upstream in the distribution channel. Moreover, research on the consumer's perception of sustainability issues should be included to gain further insights into the relevance of sustainability for consumers. In doing so, implications for retailers and manufacturers can be deduced as to how to deal with sustainability issues in their 
This article is (C) Emerald Group Publishing and permission has been granted for this version to appear here: https://ediss.uni-goettingen.de/handle/11858/17. Emerald does not grant permission for this article to be further copied/distributed or hosted elsewhere without the express permission from Emerald Group Publishing Limited.

supply chains, for instance, and which issues are especially relevant for their customers. By incorporating both up- and downstream research, a complete view of the supply chain can be generated.

In developing the sustainability stream, researchers should particularly focus on aspects which are current topics of interest in retail practice. The analysis of retail magazines indicated that carbon footprint $/ \mathrm{CO}_{2}$ and $\mathrm{CSR}$ are emerging trends in retail practice, for example. Whilst CSR has already gained interest in retail research, $\mathrm{CO}_{2}$ emissions have not been widely analysed yet. Based on these results, it seems worthwhile to discuss any tangible applications of the sustainability concept in retailing. A research application considering the practice-relevant topic of $\mathrm{CO}_{2}$ emissions could lie in comparing the sustainability of different distribution channels (e.g. Edwards et al., 2010; Matthews, Williams, Tagami, \& Hendrickson, 2002). Regarding CSR, research could help to provide approaches to incorporate CSR in a company's operating principles, for instance.

Lastly, the research findings on the distribution of sustainability mentions presented in this paper call for a more detailed explorative content analysis within each of the research fields mentioned.

\subsection{Limitations}

The results of this study are limited in some ways. Firstly, it has to be kept in mind that we only searched the EBSCO database for sustainability articles. Furthermore, the problems of keyword-search show up in all three searches. It cannot be guaranteed that all articles that refer to sustainability use the term sustainability in their title, keywords or abstract. Therefore, an underestimation of the total number of sustainability-related articles may occur. Nevertheless, the benefit of a keywordsearch can be seen in the fact that those articles which merely mention sustainability in passing are not counted as sustainability articles. The different areas used to structure sustainability research may also partially overlap or some topics may be allocated to more than one research area or industry. 
This article is $\odot$ Emerald Group Publishing and permission has been granted for this version to appear here: https://ediss.uni-goettingen.de/handle/11858/17. Emerald does not grant permission for this article to be further copied/distributed or hosted elsewhere without the express permission from Emerald Group Publishing Limited.

Furthermore, it has to be considered that the hit likelihood over time may also have increased due to both the availability of journal articles in the database and the fact that, over time, new journals have emerged. We tested this effect by analysing the development of articles in peer-reviewed journals in the EBSCO database. Wildcard search yielded an increase of the factor 5.68 (1988: 16,359 hits, 2009: 92,913 hits). The search term "management" shows a positive development of the factor 5.13 (1988: 4,790 hits, 2009: 24,552 hits). However, the hit development for sustainability-related papers using NAICS-categories shows a rise of the factor 19 (1988: 4 hits, 2009: 76 hits) and the hit development for sustainability-related papers using JEL-categories even grows with the factor 47.14 (1988: 7 hits, 2009: 330 hits). Therefore, this effect does not seem to have a significant influence on the overall results.

While a weighted analysis considering the number of journals as a normaliser might seem reasonable, such an analysis was omitted for various reasons. The paper aims to provide a general overview of the appearance of keywords and thereby characterise the development as a whole. Moreover, due to the generality of the JEL categories and keywords, it is not possible to allocate them to particular journals. Furthermore, some journals classify into more than one JEL category, resulting in a double count of sustainability mentions.

It also has to be considered that a time lag between completed and published research may exist. Therefore, taking into account the spike in sustainability mentions in the recent past, it might well be one of the more promising research themes currently pursued.

Furthermore, some limitations refer to the specific analyses. The completeness of the results of the NAICS search cannot be guaranteed as NAICS does not provide keywords for the categories. The searches for sustainability in practitioner journals, as well as for sustainability-related aspects in retail research, were based on keywords selected by the research team. Therefore, it is possible that not all relevant developments were considered. 
This article is (C) Emerald Group Publishing and permission has been granted for this version to appear here: https://ediss.uni-goettingen.de/handle/11858/17. Emerald does not grant permission for this article to be further copied/distributed or hosted elsewhere without the express permission from Emerald Group Publishing Limited.

\subsection{Conclusion}

This paper clarifies the intermediary role of retailers in supply chains, connecting consumers and manufacturers. Hence, retailers play an important role for incorporating sustainability in supply chains. Despite this important position, retail research has only partially focussed on sustainability and related issues and is still at an early stage. In contrast, practice has already paid more attention to sustainability, thereby showing some trends for research such as $\mathrm{CO}_{2}$ emissions and CSR. Furthermore, sustainability has received more attention in such retail-related areas as transport, agriculture or business administration. Nevertheless, all literature searches revealed the increasing relevance of sustainability in the different research areas, industry sectors and in practice. Moreover, differences between the classification categories have been found. Some categories seem to have a high relevance for sustainability considerations whereas other categories obtained no hits at all.

Thus, the paper provides added value for retail and supply chain research by linking sustainability considerations in retail research, retail practice and other research areas and industries along the supply chain. 
This article is (C) Emerald Group Publishing and permission has been granted for this version to appear here: https://ediss.uni-goettingen.de/handle/11858/17. Emerald does not grant permission for this article to be further copied/distributed or hosted elsewhere without the express permission from Emerald Group Publishing Limited.

\section{References}

American Economic Association. (2009). JEL Classification Codes Guide. Retrieved 3 April 2009, from www.aeaweb.org/jel/guide/jel.php.

Brammer, S., Hoejmose, S., \& Millington, A. (2011a). Managing sustainable global supply chains. Framework and Best Practices. Networking for Business Sustainability. Retrieved 8 November 2011, from http://nbs.net/wp-content/uploads/NBS-SystematicReview-Supply-Chains.pdf.

Brammer, S., Hoejmose, S., \& Millington, A. (2011b). Managing sustainable global supply chains. A Systematic Review of the Body of Knowledge. Networking for Business Sustainability. Retrieved 8 November 2011, from http://nbs.net/wpcontent/uploads/NBS-Systematic-Review-Supply-Chains.pdf.

Carter, C. R., \& Easton, P. L. (2011). Sustainable supply chain management: evolution and future directions. International Journal of Physical Distribution \& Logistics Management, 41(1), 46-62.

Carter, C. R., \& Rogers, D. S. (2008). A framework of sustainable supply chain management: moving toward new theory. International Journal of Physical Distribution \& Logistics Management, 38(5), 360-387.

Costanza, R., \& Patten, B. C. (1995). Defining and predicting sustainability. Ecological Economics, 15(3), 193-196.

Doak, J. (2009). An inspector calls: Looking at retail development through a sustainability lens. Journal of Retail and Leisure Property, 8(4), 299-309.

Edwards, J. B., McKinnon, A. C., \& Cullinane, S. L. (2010). Comparative analysis of the carbon footprints of conventional and online retailing: A 'last mile' perspective. International Journal of Physical Distribution \& Logistics Management, 40(1/2), 103-123.

Ehrenfeld, J. R. (2005). The Roots of Sustainability. MIT Sloan Management Review, 46(2), $22-25$.

Elkington, J. (1998). Cannibals with Forks - The Triple Bottom Line of the $21^{\text {st }}$ Century. Stoney Creek, CT: New Society.

Erol, I., Cakar, N., Erel, D., \& Sari, R. (2009). Sustainability in the Turkish Retailing Industry. Sustainable Development, 17, 49-67.

Flint, D. J., \& Golicic, S. L. (2009). Searching for competitive advantage through sustainability. A qualitative study in the New Zealand wine industry. International Journal of Physical Distribution \& Logistics Management, 39(10), 841-860.

Glavič, P., \& Lukman, R. (2007). Review of sustainability terms and their definitions. Journal of Cleaner Production, 15(18), 1875-1885. 
This article is (C) Emerald Group Publishing and permission has been granted for this version to appear here: https://ediss.uni-goettingen.de/handle/11858/17. Emerald does not grant permission for this article to be further copied/distributed or hosted elsewhere without the express permission from Emerald Group Publishing Limited.

Global Reporting Initiative. (2007). Sustainability Reporting 10 Years On. Retrieved 21 June 2011, from http://www.globalreporting.org/NR/rdonlyres/430EBB4E-9AAD-4CA19478-FBE7862F5C23/0/Sustainability_Reporting_10years.pdf.

Hingley, M. K. (2005). Power imbalanced relationships: cases from UK fresh food supply. International Journal of Retail \& Distribution Management, 33(8), 551-569.

Hsieh, H.-F., \& Shannon, S. E. (2005). Three approaches to qualitative content analysis. Qualitative Health Research, 15(9), 1277-1288.

Jones, P., Comfort, D., \& Hillier, D. (2008a). UK retailing through the looking glass. International Journal of Retail \& Distribution Management, 36(7), 564-570.

Jones, P., Comfort, D., \& Hillier, D. (2008b). Moving towards sustainable food retailing? International Journal of Retail \& Distribution Management, 36(12), 995-1001.

Jones, P., Comfort, D., Hillier, D., \& Eastwood, I. (2005). Retailers and sustainable development in the UK. International Journal of Retail \& Distribution Management, 33(3), 207-214.

Kevork, E. K., \& Vrechopoulos, A. P. (2009). CRM literature: conceptual and functional insights by keyword analysis. Marketing Intelligence \& Planning, 27(1), 48-85.

Kondracki, N. L., Wellman, N. S., \& Amundson, D. R. (2002). Content analysis: review of methods and their applications in nutrition education. Journal of Nutrition Education and Behavior, 34(4), 224-230.

Kotzab, H., Munch, H. M., Faultrier, B., \& Teller, C. (2011). Environmental retail supply chains: when global Goliaths become environmental Davids. International Journal of Retail \& Distribution Management, 39(9), 658-681.

Laroche, M., Bergeron, J., \& Barbaro-Forleo, G. (2001). Targeting consumers who are willing to pay more for environmentally friendly products. Journal of Consumer Marketing, 18(6), 503-520.

Lindgreen, A., \& Hingley, M. (2003). The impact of food safety and animal welfare policies on supply chain management: The case of the Tesco meat supply chain. British Food Journal, 105(6), 328-349.

Lozano, R. (2008). Envisioning sustainability three-dimensionally. Journal of Cleaner Production, 16, 1838-1846.

Markley, M. J., \& Davis, L. (2007). Exploring future competitive advantage through sustainable supply chains. International Journal of Physical Distribution \& Logistics Management, 37(9), 763-774.

Matthews, H. S., Williams, E., Tagami, T., \& Hendrickson, C. T. (2002). Energy implications of online book retailing in the United States and Japan. Environmental Impact Assessment Review, 22(5), 493-507. 
This article is (C) Emerald Group Publishing and permission has been granted for this version to appear here: https://ediss.uni-goettingen.de/handle/11858/17. Emerald does not grant permission for this article to be further copied/distributed or hosted elsewhere without the express permission from Emerald Group Publishing Limited.

Mebratu, D. (1998). Sustainablity and sustainable developement: Historical and conceptual review. Environmental Impact Assessment Review, 18(6), 493-520.

Newell, G. (2009). The significance of sustainability best practice in retail property. Journal of Retail and Leisure Property, 8(4), 259-271.

Newholm, T., \& Shaw, D. (2007). Studying the ethical consumer: A review of research. Journal of Consumer Behaviour, 6(5), 253-270.

Parris, T. M., \& Kates, R. W. (2003). Characterizing and Measuring Sustainable Development. Annual Review of Environment and Resources, 28, 559-586.

Quak, H. J., \& de Koster, M. B. M. (2007). Exploring retailers' sensitivity to local sustainability policies. Journal of Operations Management, 25(6), 1103-1122.

Reuter, C., Foerstl, K. A. I., \& Blome, C. (2010). Sustainable Global Supplier Management: The Role of Dynamic Capabilities in Achieving Competitive Advantage. Journal of Supply Chain Management, 45(2), 45-63.

Seuring, S., \& Müller, M. (2008). From a literature review to a conceptual framework for sustainable supply chain management. Journal of Cleaner Production, 16(15), $1699-1710$.

Steinrücken, T., \& Jaenichen, S. (2007). The Fair Trade Idea: Towards an Economics of Social Labels. Journal of Consumer Policy, 30(3), 201-217.

The Consumer Goods Forum. (2011). Top Of Mind 2011 (Vol. 10, pp. 1-8). Paris.

Thompson, B. (2007). Green retail: Retailer strategies for surviving the sustainability storm. Journal of Retail and Leisure Property, 6(4), 281-286.

Trudel, R., \& Cotte, J. (2009). Does It Pay To Be Good? MIT Sloan Management Review, 50(2), 61-68.

U.S. Census Bureau. (2009). North American Industry Classification System - Introduction. Retrieved 3 April 2009, from http://www.census.gov/eos/www/naics/.

United Nations. (2005). 2005 World Summit Outcome. Retrieved 7 June 2011, from www.who.int/hiv/universalaccess2010/worldsummit.pdf.

United Nations Environment Programme Finance Initiative. (1997). UNEP Statement by Financial Institutions on the Environment \& Sustainable Development (pp. 1-2). Geneva.

United Nations Global Compact. (2011). Participants \& Stakeholders. Retrieved 21 June 2011, from www.unglobalcompact.org/participants/search.

Wiese, A., \& Toporowski, W. (2013). CSR failures in food supply chains - an agency perspective. British Food Journal, 115(1), 92-107. 
This article is $\odot$ Emerald Group Publishing and permission has been granted for this version to appear here: https://ediss.uni-goettingen.de/handle/11858/17. Emerald does not grant permission for this article to be further copied/distributed or hosted elsewhere without the express permission from Emerald Group Publishing Limited.

World Commission on Environment and Development. (1987). Our Common Future. New York, NY: Oxford University Press.

Ytterhus, B. E., Arnestad, P., \& Lothe, S. (1999). Environmental initatives in the retailing sector: an analysis of supply chain pressures and partnerships. Eco-Management and Auditing, 6(4), 181-188 


\section{Transport-Related $\mathrm{CO}_{2}$ Effects of Online and Brick-and-Mortar Shopping: A Comparison and Sensitivity Analysis of Clothing Retailing (Paper 2)}

By analysing and comparing the $\mathrm{CO}_{2}$ effects of two distribution channels, Paper 2 takes a more detailed look at one of the most important trends regarding sustainability in retail practice. This paper contributes to research by analysing real shopping data instead of average values. Furthermore, sensitivity analyses help to gain a deeper understanding of the relevant influences on the channels' advantageousness.

A shorter version of the following paper was published in Transportation Research Part D: Transport and Environment (Wiese, Toporowski, \& Zielke, 2012). The official journal version can be found at http://dx.doi.org/10.1016/j.trd.2012.05.007.

Earlier versions of the paper were presented at the EMAC 2010 (Copenhagen, Denmark), the EIRASS conferences 2010 (Istanbul, Turkey) and 2011 (San Diego, USA), and the Sustainable Consumption Conference 2011 (Hamburg, Germany). 


\subsection{Problem Delimitation}

Managers of parcel services and online retailers might worry that customers question the environmental friendliness of their delivery processes. People "perceive delivery vehicles in residential areas as noisy, dirty and a safety risk to vulnerable road users" (Cairns, 2005, p. 74). Furthermore, people may believe that the delivery process in online retailing causes many $\mathrm{CO}_{2}$ emissions and that brick-and-mortar retailing is more environmentally friendly from a transport perspective. This concern is supported by empirical results from the authors asking customers from two retail stores to rate the environmental friendliness of both channels: $53.7 \%$ thought brickand-mortar shopping to be more environmentally friendly, $32.4 \%$ believed the opposite and $13.9 \%$ were not sure about the advantageousness.

Contrary to these customer perceptions, some empirical research showed that online retailing is more environmentally friendly than brick-and-mortar retailing (for instance, Edwards, McKinnon, \& Cullinane, 2009; Sivaraman, Pacca, Mueller, \& Lin, 2007; Weber, Koomey, \& Matthews, 2010). However, it is unclear if the research findings can be generalised or if the customer perception reflects the reality at least under certain conditions. To analyse this more deeply, a review of recent research is needed.

The previous research focuses on specific product categories. Book distribution is the main research focus (Edwards, Cullinane, \& McKinnon, 2008; Williams \& Tagami, 2008; Matthews, Williams, Tagami, \& Hendrickson, 2002; Matthews, Hendrickson, \& Soh, 2001) which might be explained with the good suitability of books for online retailing. Other studies examine the distribution of electronic products (Weber et al., 2008), DVD rental (Sivaraman et al., 2007) or music delivery (Weber et al., 2010). However, the previous research has not considered other categories, such as clothing, which differs from the aforementioned products. The only exception is a study by Edwards and McKinnon (2009), in which they analyse clothing together with other small non-food items. After electronics and books, clothing is the third most important category in online retail (Datamonitor, 2011) and therefore deserves closer attention. There are some differences between clothing and the products analysed until now. Return rates might be higher compared to standardised entertainment products because customers can order diverse sizes or 
colours to have different choices (Cullinane, 2009). Also, parcels including clothes are in general bigger than parcels including books or CDs, resulting in higher $\mathrm{CO}_{2}$ emissions. Furthermore, customers might be willing to travel longer distances in brick-and-mortar retailing to reach their favourite clothing store, causing higher $\mathrm{CO}_{2}$ emissions for this channel. This might not be the case for books etc. that are available at many places in same quality. Therefore, it is to be expected that both channels cause higher $\mathrm{CO}_{2}$ emissions for clothing compared to other products. However, it is unclear how travelling distances and return rates influence the relative advantageousness of one channel over the other. The online channel might become less advantageous for smaller travelling distances, higher return rates and changes in the customers' use of public transport.

Also, nearly all prior studies are based on secondary data for information on transport modes, distances and articles bought. Therefore, they are often limited in reflecting authentic shopping situations and real consumer behaviour in a multichannel environment. Hence, this study aims to analyse the $\mathrm{CO}_{2}$ emissions of online versus brick-and-mortar shopping in the clothing sector, considering these influencing factors. In particular, this study answers the following questions:

- Which channel is more environmentally friendly from a general perspective?

- How do factors like returns, public transport use, distance to store, and information behaviour influence the advantageousness?

- Which implications can be deducted for retailers and policy makers?

To answer these questions, data is used from a customer survey conducted at a retailer's stores, order data from this retailer's online shop and information on the delivery process provided by the parcel service. Thereby, real shopping behaviour is reflected and the results can provide another perspective to supplement the existing research.

The remainder of this paper is structured as follows. In section 5.2, the research method is explained in more detail. Section 5.3 presents the results and sensitivity analyses. The paper closes with a discussion and implications in section 5.4. 


\subsection{Research Method}

We analyse the $\mathrm{CO}_{2}$ effects based on real travel and order data related to a German multi-channel clothing retailer. The retailer runs stores in several big cities in Germany and an online shop as well. The majority of parcels from the online shop are delivered by a European parcel service that provides data on the delivery processes of online orders. Consequently, two distribution channels of one retailer can be compared directly. The analysis starts at the retailer's central warehouse, which is the initial point for the store supply and the delivery of online orders. The first part of the supply chain is the same for both channels and the central warehouse is "the point at which there is no difference between store and e-shopping" (Mokhtarian, 2004, p. 278), making it the perfect starting point. Also Edwards, McKinnon, and Cullinane (2010, p. 116) suggest that emissions should be compared "as far back as the point in which they diverge". In doing so, we aim to combine customer travel paths and the freight transport.

Sivaraman et al. (2007) state that the advantageousness of the channels depends on the environmental problem considered in the analysis. We centre on $\mathrm{CO}_{2}$ emissions to keep the focus on the impact of transportation. In doing so, we exclude the energy use of running the stores and the customers' shopping in the internet. We assume that the shopping locations, i.e. traditional stores and the internet shop, run anyway, aiming to evaluate the effects caused by the customers' shopping behaviour only. In this way, we focus on the medium-term but not the long-term perspective. This would also include more complex decisions like changing the energy supply to a more environmentally-friendly supplier or closing down stores. 


\subsubsection{Calculating $\mathrm{CO}_{2}$ emissions for the brick-and-mortar supply chain}

Starting from the central warehouse, the brick-and-mortar supply chain consists of two processes as depicted in Figure 11: transport from the central warehouse to the stores and the customers' trips to the stores.

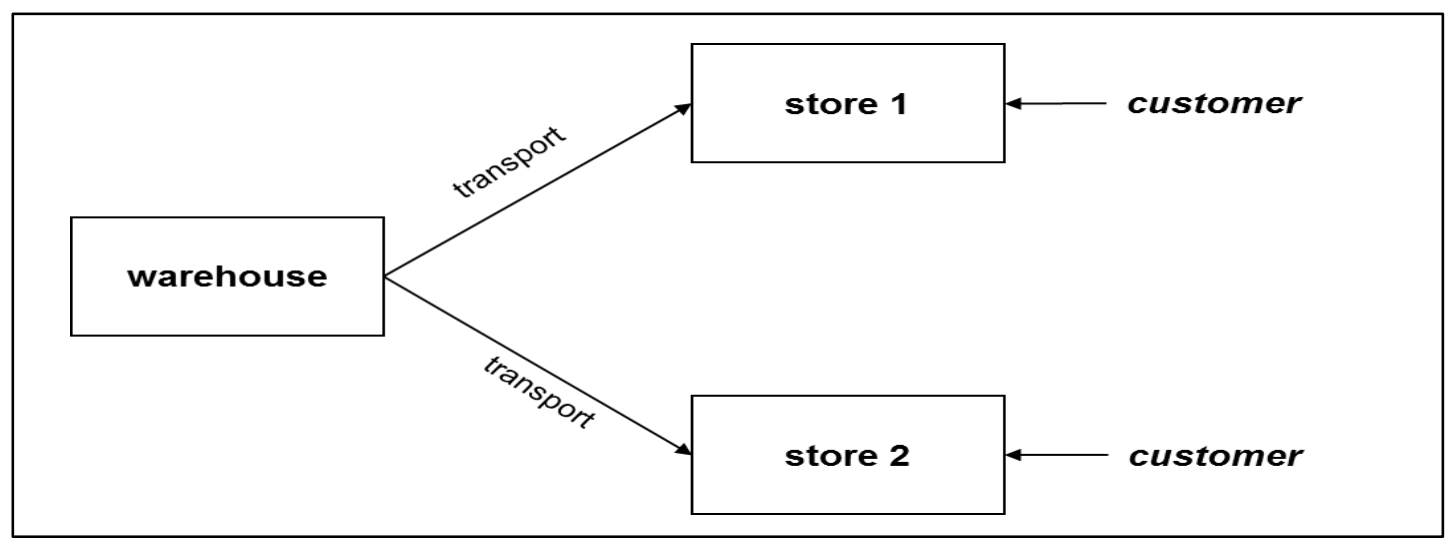

\section{Figure 11: Supply Chain for Brick-and-Mortar Retail}

The retailer provided information about store supply, such as distances, vehicles used and frequencies for two stores. Store 1 is located in the centre of a major city. Store 2 is situated in another city a little outside the centre, close to the retailer's central warehouse. We chose differently located stores to compare various situations. The supply of store 1 entails a tour of 437.0 kilometres. In contrast, the supply of store 2 only requires a distance of 10.7 kilometres. Store 1 is served six times per week, store 2 five times. The average load per tour is 3,000 parcels for store 1 and 2,200 parcels for store 2. To calculate the $\mathrm{CO}_{2}$ emissions caused by transporting the goods to the stores, in a first step the fuel consumption of the vehicle used is calculated regarding its load factor (Kranke, 2009). In a second step, the value of the fuel consumption is multiplied with the $\mathrm{CO}_{2}$ factor of the fuel. For the combustion of diesel, this factor is 2.629 kilograms of $\mathrm{CO}_{2}$ per litre (Kranke, 2009).

Customer travels are analysed based on a customer survey conducted in the two stores of the retailer. Both stores can be reached by public transport, car and bike or on foot. The questionnaire surveyed the trip to the store, such as the transport mode used, trip chaining, the customer's postal code and the products bought. The survey was conducted behind the cash desk of the two stores; consequently, only people 
who bought something were interviewed. A sample size of 702 questionnaires could be used, of which 327 were collected in store 1 and 375 in store 2.

To calculate $\mathrm{CO}_{2}$ emissions for the shopping trip caused by the customers' travelling, we used recent information on the $\mathrm{CO}_{2}$ emissions per passenger-kilometre of the different transport modes: 144 grams $\mathrm{CO}_{2}$ for cars, 73.5 grams $\mathrm{CO}_{2}$ for public transport and 139.5 grams $\mathrm{CO}_{2}$ for a motorbike (Statistisches Bundesamt, 2008; Schächtele \& Hertle, 2007). Besides, it had to be decided how to deal with customers walking or cycling to the stores. These trips do not generate any $\mathrm{CO}_{2}$ emissions but are real shopping trips. Therefore, these datasets were included in the analysis. To determine the $\mathrm{CO}_{2}$ emissions of each customer trip, the distance between the customer's home (postal code) and the store was multiplied by the $\mathrm{CO}_{2}$ emissions of the transport mode used. The $\mathrm{CO}_{2}$ emissions of each purchase were then calculated by adding the emissions caused by the store supply and customer travel. Regarding shopping trips, there are many possibilities for customers to do their shopping. Hence, it was necessary to make a major assumption to calculate the $\mathrm{CO}_{2}$ emissions caused by customers' travels to simplify the analyses: only the datasets in which the customers stated that the shopping at the retailer was the main reason for the trip were taken into account. When shopping at the retailer was not the main reason for travelling, no $\mathrm{CO}_{2}$ emissions were assumed for the respective datasets.

\subsubsection{Calculating $\mathrm{CO}_{2}$ emissions for the online supply chain}

We calculated the $\mathrm{CO}_{2}$ emissions for the processes along the online channel based on information about the orders from the online shop, i.e. the parcels' destinations and ordered articles (provided by the retailer). A dataset of 40,000 orders, delivered in a period of four weeks, was used. The parcel service provided detailed information about the parcel delivery process, such as distances, vehicles used and the load of the vehicles. The online supply chain consists of three processes (see Figure 12), also starting from the central warehouse. The parcels are transported to the outbounddepot, then allocated to the inbound-depots (line-haul) and, finally, delivered to the customers. Contrary to other studies (Weber et al., 2010; Matthews, Hendrickson, \& Soh, 2001), no airfreight is used along this supply chain due to the smaller distances in Germany. 


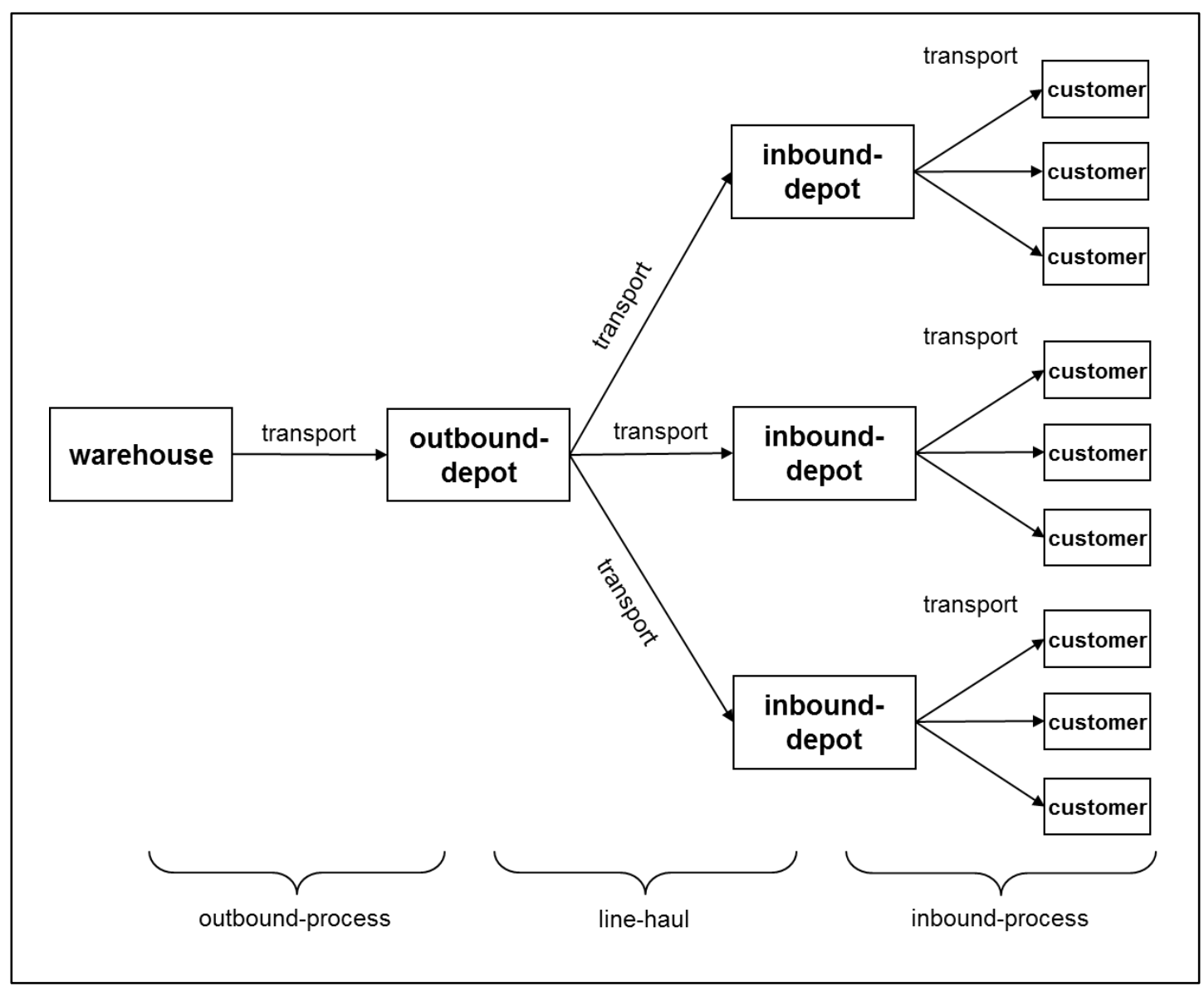

Figure 12: Supply Chain for Online Retail

These three processes have different lengths. The outbound process is quite short, having a distance of 13.0 kilometres (doubled for the calculation because the distance is only driven for the parcel delivery). The line-haul has an average length of 388.8 kilometres. The shortest distance has the inbound-process in which an average distance of 1.3 kilometres is driven per parcel. This value is calculated by the overall distance of a delivery trip (200 kilometres) divided by the average number of parcels transported (150). To calculate $\mathrm{CO}_{2}$ emissions for all the processes along the online supply chain, we used the same proceeding as for the store supply in the brick-and-mortar retail (see 5.2.1). 


\subsection{Results}

In the following, the results of the general comparison of both channels are presented. Furthermore, the impact of travel distances, returns, public transport use, and information behaviour is analysed.

\subsubsection{General comparison}

To calculate the emissions of brick-and-mortar shopping, the store supply process and the travel behaviour of customers have to be analysed. The supply of store 1 requires transport over a distance of 437.0 kilometres. For store 2, the distance is only 10.7 kilometres due to its proximity to the central warehouse. With values of 18.6 kilometres (store 1) and 16.1 kilometres (store 2), the distance covered by the customers each way per trip is quite long. Regarding the transport modes used, there are differences between the stores. The use of cars was similar (50\% in store 1; $55 \%$ in store 2 ), but more customers used public transport in store 1 (38\% to $25 \%$ ) and bikes in store $2(16 \%$ to $6 \%)$. Furthermore, more customers walked to store 1 (5\% to $1 \%$ ). These differences can be explained by the stores' different locations in the two cities.

Table 5 presents the total $\mathrm{CO}_{2}$ emissions for brick-and-mortar shopping by adding the emissions caused by store supply and customer travel paths. The relevance of customer trips for the $\mathrm{CO}_{2}$ emissions becomes obvious in comparing the $\mathrm{CO}_{2}$ emissions of both processes. In order to guarantee a fair comparison between both channels, the $\mathrm{CO}_{2}$ emissions per transaction and per article bought have been calculated. The average shopping transaction includes 1.72 articles. With this information, more detailed calculations can be made compared to other studies which did not consider shopping trip data.

\begin{tabular}{|c|c|c|c|c|c|}
\hline & \multicolumn{2}{|c|}{ Processes } & & \multicolumn{2}{c|}{ Total $\mathrm{CO}_{\mathbf{2}}$ emissions ... } \\
\cline { 2 - 3 } & Store supply & $\begin{array}{c}\text { Customer } \\
\text { travel }\end{array}$ & & $\begin{array}{c}\ldots \text { per } \\
\text { transaction }\end{array}$ & $\ldots$ per article \\
\cline { 2 - 3 } Store 1 & 0.121 & 4.514 & & 4.635 & 2.695 \\
\hline Store 2 & 0.004 & 3.801 & & 3.805 & 2.212 \\
\hline
\end{tabular}

Table 5: $\mathrm{CO}_{2}$ emissions for the brick-and-mortar supply chain (in kilograms) 
Regarding the $\mathrm{CO}_{2}$ emissions caused by the online channel, an important result is that the inbound process with the shortest distance of all three processes (just 1.3 kilometres per parcel) causes the most $\mathrm{CO}_{2}$ emissions. This is consistent with recent results (Edwards et al., 2010; Weber et al., 2008), identifying the last mile as the most important cause of $\mathrm{CO}_{2}$ emissions. A comparison of the value of 0.449 kilograms of $\mathrm{CO}_{2}$ emissions with the value that Edwards et al. (2010) state for the parcel delivery (0.181 kilograms) reveals that the last mile in our study causes more $\mathrm{CO}_{2}$ than was supposed in their analysis. Table 6 provides a summary of the relevant processes in the online supply chain by showing the resulting $\mathrm{CO}_{2}$ emissions per transaction (including 3.22 articles) and per article.

\begin{tabular}{|c|c|c|c|c|c|}
\hline \multicolumn{3}{|c|}{ Processes } & & \multicolumn{2}{c|}{ Total $\mathrm{CO}_{2}$ emissions ... } \\
\hline Outbound & Line-haul & Inbound & & \multirow{3}{*}{ per } & $\ldots$ per article \\
\hline 0.030 & 0.268 & 0.449 & & & \\
\cline { 5 - 6 } & & & 0.747 & 0.232 \\
\hline
\end{tabular}

Table 6: $\mathrm{CO}_{2}$ emissions in the online supply chain (in kilograms)

A comparison of the $\mathrm{CO}_{2}$ emissions reveals that online shopping causes ten times fewer $\mathrm{CO}_{2}$ emissions per article than brick-and-mortar shopping (2.454 kilograms as the average of both stores versus 0.232 kilograms). Regarded per transaction, the online channel still causes six times fewer $\mathrm{CO}_{2}$ emissions (4.220 kilograms as the average of both stores versus 0.747 kilograms). These results appear robust due to the large differences between the channels.

Nevertheless, further analyses seem necessary for more precise statements about the influence of different factors. The advantageousness of the channels depends also on factors that have not been considered so far, i.e. the distance to stores, returns, utilisation of public transport modes, and information behaviour. The sensitivity analyses are only presented for store 1 as the situation for store 2 is somewhat special due to its proximity to the central warehouse. 


\subsubsection{Distance to store}

Matthews et al. (2002) showed that population density has a high impact on the advantageousness of online shopping. Following their results, it can be assumed that there are situations in which the use of traditional retail causes fewer $\mathrm{CO}_{2}$ emissions in urban, densely populated areas. In general, a high population density can be equated with short distances to stores. Therefore, we analyse whether a break-even point exists until which the traditional retail is advantageous.

For this analysis, we assumed that the brick-and-mortar customers we collected the data from switched to the online channel. Hypothetical $\mathrm{CO}_{2}$ emissions, assuming that each purchase in brick-and-mortar retail would have been done online, were calculated based on information from the parcel service. When the $\mathrm{CO}_{2}$ emissions of the traditional channel were higher than those of the (hypothetical) online retail, the break-even point is reached. For store 1, a break-even point of 14 kilometres was found by this procedure. Table 7 illustrates the break-even point for store 1 and presents further results of the comparison of both channels for different distance zones.

\begin{tabular}{|c|c|c|c|c|c|}
\hline \multicolumn{2}{|l|}{ Store 1 } & \multicolumn{2}{c|}{$\begin{array}{c}\mathbf{C O}_{2} \text { emissions in brick-and- } \\
\text { mortar retail ... }\end{array}$} & \multicolumn{2}{|c|}{$\begin{array}{c}\mathbf{C O}_{2} \text { emissions in online retail } \\
\text { (hypothetical) .. }\end{array}$} \\
\hline $\begin{array}{c}\text { Distance in } \\
\text { kilometres }\end{array}$ & $\mathbf{n}$ & $\begin{array}{c}\ldots \text { per } \\
\text { transaction }\end{array}$ & $\ldots$ per article & $\begin{array}{c}\ldots \text { per } \\
\text { transaction }\end{array}$ & $\ldots$ per article \\
\hline $\mathrm{d}<14$ & 119 & 0.739 & 0.430 & 0.779 & 0.242 \\
\hline $\mathrm{d}<25$ & 156 & 1.377 & 0.801 & 0.779 & 0.242 \\
\hline $\mathrm{d}<50$ & 228 & 2.485 & 1.445 & 0.774 & 0.240 \\
\hline $\mathrm{d}<100$ & 274 & 3.893 & 2.263 & 0.772 & 0.240 \\
\hline $\mathrm{d} \geq 100$ & 327 & 4.514 & 2.624 & 0.763 & 0.237 \\
\hline
\end{tabular}

Table 7: $\mathrm{CO}_{2}$ emissions caused by different distances (in kilograms)

An advantage of the brick-and-mortar retail emerges with a small distance between the customers' homes and the store. The online channel becomes advantageous with a greater distance between customers' homes and the store due to the strongly increasing $\mathrm{CO}_{2}$ emissions of private cars and public transport. 


\subsubsection{Returns}

Returns are a special characteristic worth of recognition in the clothing sector. Due to the attributes of clothing, higher returns can be assumed than for other products. For instance, Edwards et al. (2010) use a return rate of $25 \%$ for small, non-food items in the online channel whilst $40 \%$ are assumed for clothing. The retailer supporting this study could not provide any information about returns in the brick-and-mortar format. Therefore, a return rate of 6 to $10 \%$, as reported in the literature (Edwards et al., 2010), is used. In contrast, for the online channel the retailer reported returns of $35 \%$. However, this value may underestimate the emissions caused by returns in online retail as every item returned implies one parcel sent back. To account for this, we assumed in a second analysis that every customer returns part of the order and thereby every parcel is sent back. Considering that many customers order different sizes or colours (Cullinane, 2009), this appears more realistic. This calculation implies that the $\mathrm{CO}_{2}$ emissions of the online channel are doubled. For a more detailed perspective on the influence of returns, we separated the results for the different distance zones. Table 8 presents the results for store 1 showing that the brick-andmortar retail under the consideration of returns becomes more advantageous for short distances than without returns. With the first calculation method, assuming $35 \%$ returns from online retail, the break-even point is reached at 19 kilometres. The second calculation method, assuming $100 \%$ returns from online retail, changes the results in the way that the break-even point is reached even later at 25 kilometres.

\begin{tabular}{|c|c|c|c|c|c|}
\hline \multicolumn{2}{|l|}{ Store 1} & \multicolumn{2}{|c|}{$\begin{array}{c}\mathrm{CO}_{2} \text { emissions of a transaction } \\
\text { in brick-and-mortar retail } \\
\text { including ... }\end{array}$} & \multicolumn{2}{|c|}{$\begin{array}{c}\mathrm{CO}_{2} \text { emissions of a transaction } \\
\text { in online retail including ... }\end{array}$} \\
\hline $\begin{array}{l}\text { Distance in } \\
\text { kilometres }\end{array}$ & $\mathbf{n}$ & $\begin{array}{c}\ldots . \text { a return } \\
\text { quota of } 6 \%\end{array}$ & $\begin{array}{c}\ldots . \text { a return } \\
\text { quota of } 10 \%\end{array}$ & $\begin{array}{c}\ldots \text { a return } \\
\text { quota of } 35 \%\end{array}$ & $\begin{array}{c}\ldots \text { a return } \\
\text { quota of } \\
100 \%\end{array}$ \\
\hline $\mathrm{d}<14$ & 119 & 0.783 & 0.813 & 1.052 & 1.558 \\
\hline$d<25$ & 156 & 1.460 & 1.515 & 1.051 & 1.557 \\
\hline $\mathrm{d}<50$ & 228 & 2.634 & 2.734 & 1.045 & 1.548 \\
\hline $\mathrm{d}<100$ & 274 & 4.127 & 4.282 & 1.042 & 1.544 \\
\hline $\mathrm{d} \geq 100$ & 327 & 4.785 & 4.965 & 1.030 & 1.526 \\
\hline
\end{tabular}

Table 8: Influence of returns on $\mathrm{CO}_{2}$ emissions in both channels (in kilograms) 


\subsubsection{Public transport use}

The utilisation of public transport can influence the channels' advantageousness as it is more environmentally friendly than cars. However, still the $\mathrm{CO}_{2}$ emissions for public transport are relatively high compared to cars ( 73.5 grams to 144 grams) due to the low utilisation beyond the rush hour. The environmental friendliness of traditional retail could be improved if the use of these transport modes would produce fewer $\mathrm{CO}_{2}$ emissions, such as through better technologies or a higher utilisation, implying lower $\mathrm{CO}_{2}$ values per passenger. To analyse the impact of this factor, we varied the $\mathrm{CO}_{2}$ emissions of public transport to simulate a higher utilisation, i.e. lower $\mathrm{CO}_{2}$ emissions per passenger. The results show that a reduction in $\mathrm{CO}_{2}$ emissions of the transport modes would only slightly decrease the $\mathrm{CO}_{2}$ emissions per transaction. The break-even point between the channels can be increased to 15 kilometres when 50 grams of $\mathrm{CO}_{2}$ are assumed instead of 73.5 grams. The break-even point stays the same for assuming 30 grams of $\mathrm{CO}_{2}$ instead of 73.5 grams.

In addition, we analysed what would happen if everyone used public transport, which is directly connected with a decrease in $\mathrm{CO}_{2}$ emissions per passenger. In this case, the break-even point occurs at 21 kilometres when 73.5 grams of $\mathrm{CO}_{2}$, which is the real value, are assumed for all trips. For a value of 50 grams of $\mathrm{CO}_{2}$, the break-even point can be extended to 30 kilometres and for a value of 30 grams of $\mathrm{CO}_{2}$ even to 74 kilometres.

\subsubsection{Influence of information behaviour}

The advantageousness of the channels is also influenced when customers search for information in one channel and buy in another. Schröder and Zaharia (2008) found that the main channel switching behaviour is online information search and offline buying within the channels of one retailer offering clothing and non-food goods. This behaviour does not cause many additional emissions because no extra trips are undertaken. The channel switching behaviour might be explained by shipping costs and the wish to buy the product immediately due to a limited amount of items (Schröder \& Zaharia, 2008). However, these explanations might be reasonable for shopping within one multi-channel retailer, but when customers seek the cheapest costs they might switch retailers and also switch from offline to online. Hence, there 
are situations in which customers seek information offline and buy online (Farag, Schwanen, Dijst, \& Faber, 2007). This behaviour strongly increases the environmental effects of online shopping. Assuming that $50 \%$ (Verhoef, Neslin, \& Vroomen, 2007) of online shoppers searched for information in brick-and-mortar stores, the break-even point shifts from 14 to 27 kilometres. This result indicates the strong impact that information behaviour and channel switching can have on the environmental effects of shopping.

\subsection{General Discussion and Implications}

Our analysis broadens the existing research by regarding real shopping trips. Therefore, a closer look at the effects of consumer behaviour in a multi-channel environment is taken. In addition, we conducted different sensitivity analyses to add new information on the influence of distance zones, returns, the utilisation of public transport modes, and information behaviour. In doing so, it was shown that brickand-mortar retail is advantageous for short distances. We also considered the combined impact of the influencing factors, such as returns from customers living nearby the store. The results of our methodological approach are concordant with recent research, but the sensitivity analysis sheds additional light on the situational factors influencing the advantageousness of one channel over the other. It has to be kept in mind that the break-even points were calculated for one distance zone, i.e. the entity of customers from this zone. Hence, it might be possible that the situation might differ for single customers.

Our results yield several management implications. Online retailers should communicate the better general performance of online retailing, especially when they sell their goods to environmentally-conscious consumers, such as retailers selling outdoor or organic products. Logistics service providers should also inform customers about the advantages of their distribution system in contrast to the traditional brick-and-mortar channel. Communicating the environmental friendliness of online shopping is extremely important for these companies as many customers believe brick-and-mortar shopping is the greener alternative. Hence, there are apparently gaps in the retailers' and parcel services' communication strategies regarding sustainability issues. Nevertheless, traditional retailers can also 
communicate their environmental friendliness at least for small shopping trips. Especially fashion retailers with a large store network can be an environmentallyfriendly alternative to online shopping as many customers lives in the short-distance zone of at least one store in the network.

Furthermore, retailers should emphasise the customers' own responsibility and their influence on avoiding environmental pollution by changes in shopping behaviour. This could have an impact on channel choices as well as on the use of transport modes when brick-and-mortar stores are visited. Moreover, the attractiveness of retail locations for bikes or public transport should be improved, such as through special parking spaces for bikes. In the process of opening new stores, the accessibility of the location by public transport should be kept in mind.

For multi-channel retailers, certain conflicts occur. On the one hand, they want to strengthen their online sales; on the other hand, they do not want to harm their brickand-mortar channel. They should provide detailed information on the advantages of the different channels for various shopping situations. Moreover, the retailers should provide information on different return possibilities, such as returning an online order in the city store while customers are there anyway. $\mathrm{CO}_{2}$ emissions could thus be lowered.

All retailers should aim to keep returns as low as possible to minimise the customers' trips. For instance, online retailers could use methods like only paying shipping costs when returns occur or giving a discount on the next order when no goods are returned. Providing as much information as possible, such as many photos, a virtual changing room and detailed explanations, could also help to reduce returns. Another possibility for online retail to reduce the impact of returns could be to use plastic bags instead of cardboard boxes to keep the capacity of returned parcels to a minimum.

Implications can also be drawn for public policy. It was shown that a higher utilisation of public transport could improve the environmental friendliness of brickand-mortar retail considerably. Therefore, one aim should be to increase the use of these transport modes further. Besides, customers should receive more information 
about the environmental impact of their shopping behaviour to have the chance to change it.

Our study is one of the first to analyse real shopping trips. Future research could focus on some additional aspects. This study focused on $\mathrm{CO}_{2}$ emissions only although there are also other greenhouse gases causing pollution (Khalil, 1999). Nevertheless, $\mathrm{CO}_{2}$ emissions can be seen as an important measure of environmental pollution. Furthermore, it would be interesting to see whether similar results apply for other sectors than clothing. Also, a further breakdown in different product categories might yield new insights. Future research might also include the information behaviour before a purchase is made (Edwards, McKinnon, \& Cullinane, 2011). Furthermore, trip chaining can be considered more thoroughly. Another important aspect could be the fragmentation of shopping (Cullinane, 2009; Cairns, 2005; Mokhtarian, 2004). It might be possible that customers who normally chain trips to different traditional stores substitute this by different online orders, which might produce higher $\mathrm{CO}_{2}$ emissions overall. A further point is that e-commerce is not superior for customers who would normally walk or cycle to the store. If these people use online retail, they will cause additional $\mathrm{CO}_{2}$ emissions (Cairns, 2005; Siikavirta, Punakivi, Kärkkäinen, \& Linnanen, 2003). Besides, it would be of great interest to analyse how consumers choose channels when they have information about the environmental impact of their behaviour. However, the costs of channel choices have to be considered as these might be a main barrier for (more) environmentally-friendly behaviour as it can be assumed that consumer would not only behave altruistically. 


\section{References}

Cairns, S. (2005). Delivering Supermarket Shopping: More or Less Traffic? Transport Reviews, 25(1), 51-84.

Cullinane, S. L. (2009). From Bricks to Clicks: The Impact of Online Retailing on Transport and the Environment. Transport Reviews, 29(6), 759-776.

Datamonitor. (2011). Online Retail in Germany. Without location.

Edwards, J. B., McKinnon, A. C., \& Cullinane, S. L. (2009). Carbon Auditing the 'Last Mile': Modelling the Environmental Impacts of Conventional and Online Non-food Shopping. Logistics Reseach Centre, Heriot-Watt University, Edinburgh.

Edwards, J., Cullinane, S., \& McKinnon, A. (2008). Carbon auditing conventional and online book supply chains. Proceedings of the Logistics Research Network Conference, Liverpool.

Edwards, J., McKinnon, A., \& Cullinane, S. (2011). Comparative carbon auditing of conventional and online retail supply chains: a review of methodological issues. Supply Chain Management: An International Journal, 16(1), 57-63.

Edwards, Julia B., \& McKinnon, A. C. (2009). Shopping trip or home delivery: which has the smaller carbon footprint?. FOCUS, July, 20-24.

Edwards, Julia B., McKinnon, A. C., \& Cullinane, S. L. (2010). Comparative analysis of the carbon footprints of conventional and online retailing: A 'last mile' perspective. International Journal of Physical Distribution \& Logistics Management, 40(1/2), $103-123$.

Farag, S., Schwanen, T., Dijst, M., \& Faber, J. (2007). Shopping online and/or ins-store? A structural equation model of the relationships between e-shopping and in-store shopping. Transportation Research Part A: Policy and Practice, 41(2), 125-141.

Khalil, M. A. K. (1999). Non- $\mathrm{CO}_{2}$ greenhouse gases in the atmosphere. Annual Review of Energy and the Environment, 24, 645-661.

Kranke, A. (2009). $\mathrm{CO}_{2}$-Berechnung: Wie Sie die $\mathrm{CO}_{2}$-Emissionen bei LKW-Transporten konkret berechnen können. Logistik Inside, 05, 47-49.

Matthews, H. S., Hendrickson, C. T., \& Soh, D. L. (2001). Environmental and Economic Effects of E-Commerce. A Case Study of Book Publishing and Retail Logistics. Transportation Research Record, 1763, 6-12.

Matthews, H. S., Williams, E., Tagami, T., \& Hendrickson, C. T. (2002). Energy implications of online book retailing in the United States and Japan. Environmental Impact Assessment Review, 22(5), 493-507.

Menon, A., \& Menon, A. (1997). Enviropreneurial Marketing Strategy: The Emergence of Corporate Environmentalism as Market Strategy. Journal of Marketing, 61(1), 51-67.

Mokhtarian, P. L. (2004). A conceptual analysis of the transportation impacts of B2C e-commerce. Transportation, 31(3), 257-284. 
Schröder, H., \& Zaharia, S. (2008). Linking multi-channel customer behavior with shopping motives: an empirical investigation of a German retailer. International Journal of Retail \& Distribution Management, 15(6), 452-468.

Schächtele, K., \& Hertle, H. (2007). Die $\mathrm{CO}_{2}$ Bilanz des Bürgers. Recherche für ein internetbasiertes Tool zur Erstellung persönlicher $\mathrm{CO}_{2}$ Bilanzen. Publikationen des Umweltbundesamtes. Heidelberg.

Siikavirta, H., Punakivi, M., Kärkkäinen, M., \& Linnanen, L. (2003). Effects of E-Commerce on Greenhouse Gas Emissions. A Case Study of Grocery Home Delivery. Journal of Industrial Ecology, 6(2), 83-97.

Sivaraman, D., Pacca, S., Mueller, K., \& Lin, J. (2007). Comparative Energy, Environmental, and Economic Analysis of Traditional and E-commerce DVD Rental Networks. Journal of Industrial Ecology, 11(3), 77-91.

Statistisches Bundesamt. (2008). Bericht zu den umweltökonomischen Gesamtrechnungen 2008. Wiesbaden.

Verhoef, P. C., Neslin, S. A., \& Vroomen, B. (2007). Multichannel customer management: Understanding the research-shopper phenomenon. International Journal of Research in Marketing, 24(2), 129-148.

Weber, C., Hendrickson, C., Jaramillo, P., Matthews, S., Nagengast, A., \& Nealer, R. (2008). Life Cycle Comparison of Traditional Retail and E-commerce Logistics for Electronic Products: A Case Study of buy.com. Green Design Institute, Carnegie Mellon University, Pittsburgh, PA.

Weber, C. L., Koomey, J. G., \& Matthews, H. S. (2010). The Energy and Climate Change Implications of Different Music Delivery Methods. Journal of Industrial Ecology, 14(5), 754-769.

Williams, E., \& Tagami, T. (2008). Energy Use in Sales and Distribution via E-Commerce and Conventional Retail. A Case Study of the Japanese Book Sector. Journal of Industrial Ecology, 6(2), 99-114. 


\section{Environmental effects of shopping trips - a qualitative analysis of consumer travel behaviour (Paper 3)}

Paper 3 provides a more detailed view on consumer travel behaviour, which was only addressed fleetingly in Paper 2. It was shown that consumer behaviour, like the transport mode choice, can have a considerable impact on the environmental pollution caused by shopping processes in the brick-and-mortar channel. Therefore, this aspect should be analysed further. The paper reveals that research gaps exist in the knowledge on consumer travel behaviour and its environmental effects. For that reason, the paper applies a qualitative approach to better understand the behavioural aspects of shopping trips and their influences on environmental pollution.

So far, the paper has been presented at the Social Business Conference 2013 (Eskişehir, Turkey) and at the EAERCD 2013 (Valencia, Spain). 


\subsection{Problem Delimitation}

Some recent research studies found that shopping in online retailing causes fewer $\mathrm{CO}_{2}$ emissions than in brick-and-mortar retailing (Wiese, Toporowski, et al., 2012; Edwards et al., 2010; Weber et al., 2008). This result might endanger the traditional business formats as it may trigger negative publicity. Interestingly, the $\mathrm{CO}_{2}$ emissions of shopping in the brick-and-mortar channel are mainly caused by customer journeys to the stores and not by the previous transport processes along the supply chain (Wiese, Toporowski et al., 2012; Edwards et al., 2009). Hence, when aiming to reduce the environmental pollution, retailers and policy makers should try to influence consumer travel behaviour. In recent years, energy consumption during shopping trips has augmented, due to structural changes in land use and transport facilities as well as increased car ownership (Kitamura, Sakomoto, \& Waygood, 2008).

A deeper understanding of travel behaviour is needed to deduce appropriate strategies for mitigating the environmental effects of shopping trips as "the first step toward bringing about changes in travel behaviour that reduce GHG emissions is an understanding of the component behaviours and the factors that influence them what people do and why they do it" (Handy \& Krizek, 2012, p. 43). Also, Schultz and Stieß (2006, p. 69) mention that "strategies to sustainable consumption must start from a consumer perspective and have to take different everyday life practices and situations into account". To understand consumer travel behaviour and its environmental effects, first of all the particularly relevant influences affecting how consumers behave have to be identified and analysed. Afterwards, the second step involves evaluating how the resulting behaviour affects the environmental impact of shopping trips. This leads to the main research questions:

Which factors influence consumer travel behaviour and the related environmental effects? Do various consumer groups differ in the way their behaviour is affected by the influences?

So far, research has mainly focussed on particular influences on travel behaviour. For instance, how the perception of transport modes (Ibrahim, 2005) or trip chaining (Lee et al., 2002) affect travel behaviour has been evaluated. To our knowledge, a 
comprehensive overview regarding consumer motivation for shopping trip behaviour does not exist. By conducting a broader analysis, interdependencies between the influences can be highlighted. Also, a deeper understanding is gained because consumer travel decisions are considered completely and not only partly. Due to its complexity, travel behaviour is difficult to understand and should therefore be evaluated with a holistic approach.

Until now, researchers have primarily used quantitative methods to analyse travel behaviour, e.g. travel diaries. Therefore, mainly the outcomes of travel behaviour, but not the processes steering the behaviour are examined (Ye et al., 2007). Al-Jammal and Parkany (2002, p. 8) highlight that "when studying the choices people make, results will revolve around the choices that have been selected by the individuals without reference to reasons why certain individuals tend to make certain choices". Following this argumentation, a research gap with respect to the underlying reasons of travel behaviour is apparent. The research on motivation for travel behaviour is still in its infancy, making a qualitative, more explorative approach reasonable, which helps to gain a deeper understanding of the influences on consumer behaviour (Sinkovics et al., 2005; Clifton \& Handy, 2001). Qualitative research is useful for analysing questions regarding processes, i.e. "how and why things happen, rather than whether there is a particular difference in relationship or how much it is explained by other variables" (Maxwell, 2008, p. 232).

Based on the empirical results derived from interviews it has to be analysed how retailers and policy makers can enhance the environmental friendliness of travel behaviour. Using the comprehensive knowledge gained, broad implications for three target audiences can be derived:

How can brick-and-mortar retailers and policy makers influence shopping trip behaviour? Which implications can be deduced for researchers?

To answer these questions, a twofold approach was chosen. The first step was to conduct a broad literature review to learn what research has discovered about consumer travel behaviour and its environmental effects so far. In the second step, 
qualitative interviews based on the findings of the literature review reveal how consumers design their shopping trips and which aspects are particularly relevant.

To this end, the paper is structured as follows. In section 6.2, the theoretical background and the literature review on travel behaviour are presented. Then the structure of the qualitative method and the analysis of the sample are explained in section 6.3. The results of the qualitative interviews are presented and discussed in section 6.4. The paper finishes with a discussion on implications for retailers, policy makers and researchers in section 6.5.

\subsection{Theoretical Background and Literature Review}

This section presents a short theoretical background and the literature review on research about consumer behaviour in designing shopping trips. A trip is defined as "a tour that may involve several activities and a trip segment to be the travel between a particular pair of activities" (Primerano, Taylor, Pitaksringkarn, \& Tisato, 2007, p. 56). Hence, shopping can be part of and even the main reason for a trip. An important aspect in forming trips is trip chaining, "a succession of trip segments" (Hensher \& Reyes, 2000, p. 343). Mostly, trip chains consist of one primary activity linked with secondary activities and start and end at the customer's home (Primerano et al., 2008; Ye et al., 2007). Closely related to trip chaining, i.e. a multi-stop trip, is a multi-purpose trip, which is a trip during which a person visits different stores at one stop (Ingene \& Ghosh, 1990). Hence, a trip chain can include various multipurpose stops.

With respect to the environmental effects of shopping trips, the transport mode is highly relevant. By using environmentally-friendly modes like walking, cycling or public transportation (Haustein \& Hunecke, 2007), the environmental effects of shopping trips are mitigated. Here, a more detailed view is necessary to analyse how consumers choose transport modes when planning their shopping trips. Furthermore, trip chaining is particularly relevant as it reduces the number of trips.

An overview of the relevant aspects of travel behaviour influencing the environmental effects of shopping trips is presented in the following. There is 
already some research that analyses the relevant influences, but it will be shown that there are still research gaps. Also, most research does not refer to shopping trips but trip chaining in general, quite often focussing on work trips which can be explained with the relevance of compulsory activities as a basis for trip chaining (Golob, 1986).

\subsubsection{Relevant influences on travel behaviour}

In the following, four areas of influences are presented and discussed. Firstly, the influences of sociodemographic characteristics are analysed. Secondly, the impact of personal consumer characteristics is evaluated. Thirdly, situational aspects related to the shopping trips are analysed for their effects on travel behaviour. Finally, external influences, which cannot be influenced by the consumer, are discussed.

Most research has found that sociodemographic variables help to explain travel behaviour, although some authors mention that "personal characteristics are not an important determinant of attitudes or any differences in behaviour" (Anable, 2005, p. 71). As per McGuckin, Zmud, and Nakamoto (2005), life cycle, gender and the number of children in the household are meaningful whilst income and age are not. In contrast, Golob (1986) highlights the impact of life cycle, age and income. Al-Jammal and Parkany (2002) discuss that children cause more regular activities, leading to a more constrained timetable that favours trip chaining. In their study, $97 \%$ of the people participating in work or school activities chained trips. Moreover, they show exemplary differences in trip chaining behaviour for consumers of different ages, illustrating the relevance of the life cycle for trip chaining behaviour. Also, better earners are prone to more complex tours (Ye et al., 2007; Golob, 1986). This counteracts the results of McGuckin et al. (2005) that income does not have a relevant influence. Moreover, the residential location is also relevant as it influences the availability of transport modes and thereby affects the transport mode choice discussed above. Haustein and Hunecke (2007) show that two factors influence a person's mobility behaviour: personal living circumstances and the traffic infrastructure provided. This shows the interrelation between the influences. Transport mode choice is related to personal characteristics as well as situational factors and external factors, which will be discussed later. 
In addition to the aforementioned sociodemographic variables, personal consumer characteristics are also relevant. In contrast to the sociodemographic variables, this influence refers in particular to the consumers' psychological characteristics. Here, the perceived mobility necessity is important, which is defined as "people's perceptions of mobility-related consequences of their personal living circumstances" (Haustein \& Hunecke, 2007, p. 1878). It is relevant because certain living situations make it more difficult to reduce car use when public transport is not able to fulfil the transport needs (Haustein and Hunecke, 2007). In general, younger people, people with a high workload and parents have a high perceived mobility necessity (Haustein \& Hunecke, 2007). This is supported by Hensher and Reyes (2000), identifying children as a barrier to public transport use. Hence, there is also an interrelation between sociodemographic and personal characteristics, Besides, Haustein and Hunecke (2007) discuss that the traffic infrastructure might be perceived differently depending on the perceived mobility necessity. Furthermore, the perception of transport modes might be relevant, i.e. whether people drive because of the attractiveness of car use or because of the unattractiveness of non-car travel (Gardner \& Abraham, 2010). Also, symbolic and affective aspects are of similar relevance to traditional motives such as cost and time (Steg, 2005). Moreover, the environmental consciousness of a person is related to his or her travel behaviour as environmental beliefs might support a reduction of car use (Anable, 2005; Nilsson \& Küller, 2000). Incorporating the complexity of transport mode decisions, Anable (2005, p. 66) concludes: "Important factors that influence people's car use include feelings of responsibility, perceived effectiveness, personal norms, social value orientation and trust in the co-operative behaviour of others". This short overview shows the various influences that personal characteristics can have on the travel behaviour. Shedding more light on the interdependencies between these aspects and their effects on travel behaviour seems worthwhile to facilitate future research and deduce better implications. For instance, the influence of children can differ. Some people might feel that they need to go by car all the time now; others might change their life style and become more ecologically conscious, using the bike.

Travel behaviour is also influenced by situational variables, which are defined as aspects that depend on the goods to be purchased and the day the shopping trip is conducted. Hence, these aspects can differ with every shopping trip a person makes. 
Hensher and Reyes (2000) show that the more complex a trip, the higher the probability of using the car as the utility of travelling by public transport modes decreases. Ye et al. (2007, p. 111) find that "the activity agenda or tour formation drives mode choice for both non-work and work tours". Primerano et al. (2008) detect that most trip chains are related to the employer's business and work. Closely related to work trips are fixed activities that lead to restrictive travel schedules (Al-Jammal \& Parkany, 2002). Another important issue might be the differentiation between weekdays. Shopping during the week connected with work or other fixed activities might be designed differently compared to a kind of leisure shopping at the weekend. Al-Jammal and Parkany (2002) demonstrate the huge differences that can occur in consumer trip chaining behaviour over various days, clarifying the need for more qualitative research for a deeper understanding of consumer behaviour. Besides, the routine in doing some trips might influence trip chaining as there is some evidence that people do not question these tours as much as others (Lee et al., 2002). The authors discovered that 25 to $40 \%$ of the trips they were analysing had been planned completely and could therefore be regarded as a kind of routine behaviour. Furthermore, 44 to $51 \%$ of the trips analysed combined planned and spur-of-the-moment trips. All in all, the authors show that 50 to $60 \%$ of the trips in their study were developed within the day and therefore are not compatible with the idea of random utility maximisation, refuting the assumption that all information is available before the trip. Lee et al. (2002) assume that the probability of spontaneously participating in activities increases with the availability of a car. This aspect is countered by Golob (1986), who only found a minor impact of car ownership, possibly due to the sample analysed. A more detailed perspective on this issue is adopted by Primerano et al. (2008), arguing that the design of trip chains might differ between various transport modes. When using public transport, customers might mainly travel to locations with mixed land use. In contrast, when visiting a number of locations that are not necessarily in close proximity, the private car might be used. This short overview shows that there is still a lack of knowledge of how consumers choose transport modes and design their trip chains. In particular, the causal relationship between transport mode choice and trip chain complexity needs to be examined in more detail. 
Closely related to the aforementioned aspects is multi-purpose shopping, which often leads to trip chaining. The importance of multi-purpose shopping has increased a lot in recent years (Popkowski Leszczyc, Sinha, \& Sahgal, 2004). Research found that in general consumers prefer multi-stop shopping trips to specialty or convenience stores over single-stop shopping trips to a combination store (Popkowski Leszczyc \& Timmermans, 2001). This is important because consumers might differ in their behaviour with respect to the purpose of their shopping trip. For instance, single-purpose shoppers will try to minimise prices and distance costs. Multi-purpose shoppers optimise their trip as well, but also include regional characteristics like other retailers or restaurants in their destination choice (Popkowski Leszczyc et al., 2004). Hence, multi-purpose shoppers might drive greater distances and stop more than once to do their shopping. Dellaert et al. (1998) measured consumer choices of multi-purpose, multi-stop shopping trips, incorporating the buying frequency of products. They showed that multi-stop options lose utility when all products are available at many locations. Besides, the buying frequency is also relevant as consumers attach less weight to more frequently bought product combination options than to less frequent purchases. In addition, consumers seem to care more about reducing travel time when buying cheaper products, i.e. goods in a drugstore compared to clothing purchases. This shows that the item to be purchased is of high relevance. In particular combinations of the lower-order products are relevant to consumers. Besides, there are other relevant aspects in consumer behaviour. Brooks et al. (2008) analyse preferences for different geographical destinations within trip chaining. They find that customers do not only try to minimise the travel distance but also the subjective travel costs. Yet, the enjoyability or importance of destinations in the trip chain might lead to discounting the distance costs. Regarding shopping trips, consumers might be willing to travel long distances to reach their favourite clothing store, for instance. Hence, shopping motives, i.e. utilitarian, hedonic and social, might also be relevant (Rintamäki, Kanto, Kuusela, \& Spence, 2006).

The aspects discussed above show that difficulties might occur when only the results of travel behaviour, i.e. shopping diaries etc., are considered as the underlying decisions the consumer made cannot be analysed with these methods because the reasons for the behaviour cannot be evaluated. Also, consumer behaviour does not always seem to be rational enough for its quantitative modelling. 
Furthermore, external variables that cannot be influenced by the consumer can affect the behaviour. As some of them can be influenced by retailers and policy makers, they should be analysed as well. The connection to public transport modes is one important aspect. Consumers living in an area with limited public transport options might use the car. Furthermore, opening times of stores are relevant (Al-Jammal \& Parkany, 2002). They might, for instance, hamper trip chaining after work or lead to car use to reach the location faster. Other aspects cannot be influenced at all, such as the weather, which can have a major influence on the transport mode choice. For example, rain might hinder environmentally-friendly behaviour as consumers might not be willing to use the bike or walk to the stores.

\subsubsection{Impact on the environmental effects}

Regarding the environmental effects of shopping trips, the transport mode used and trip chaining behaviour have the highest influence. The discussion above clarified that there is an interrelationship between the use of a particular transport mode and the design of a shopping trip. In general, trip chaining has a positive influence on the environmental effects of shopping, but this positive effect gets smaller when the car is used. Moreover, additional stops cause pollution through extra car starts or waiting times at drive-ins (McGuckin et al., 2005). Ye et al. (2007) note that, besides a higher car usage, peak period travel might also increase as many people chain trips on their way to or back from work. This might influence the overall environmental effects of work or shopping trips as congestion and pollution might increase. Also, multi-purpose shopping might influence the environmental effects as consumers may drive greater distances and stop more than once to do their shopping. However, compared to diverse single-purpose trips, it can be assumed that this might be more environmentally friendly in most cases.

The literature review showed that consumers can behave less optimally in designing their shopping trips than one would expect from a cost-minimizing perspective (Dellaert, Arentze, Bierlaire, Borgers, \& Timmermans, 1998). Also, the complexity of travel decisions was clarified. Hence, the various influences should be incorporated together and not considered individually. Furthermore, the review showed that there are still some research gaps that should be addressed from another perspective (Maxwell, 2008). 
Figure 13 provides a concluding overview of the four categories identified relevant for travel behaviour and its environmental effects. The three aspects pictured in the upper line show the influences related to the consumer and his or her behaviour. In contrast, the right-hand side depicts the external influences that can either be steered by retailers and policy makers (like public transport connections) or cannot be influenced at all (like the weather). In general, all aspects affect the travel behaviour, which mainly shows in trip chaining and the transport mode choice. These consumer decisions predominantly influence the pollution caused by shopping trips.

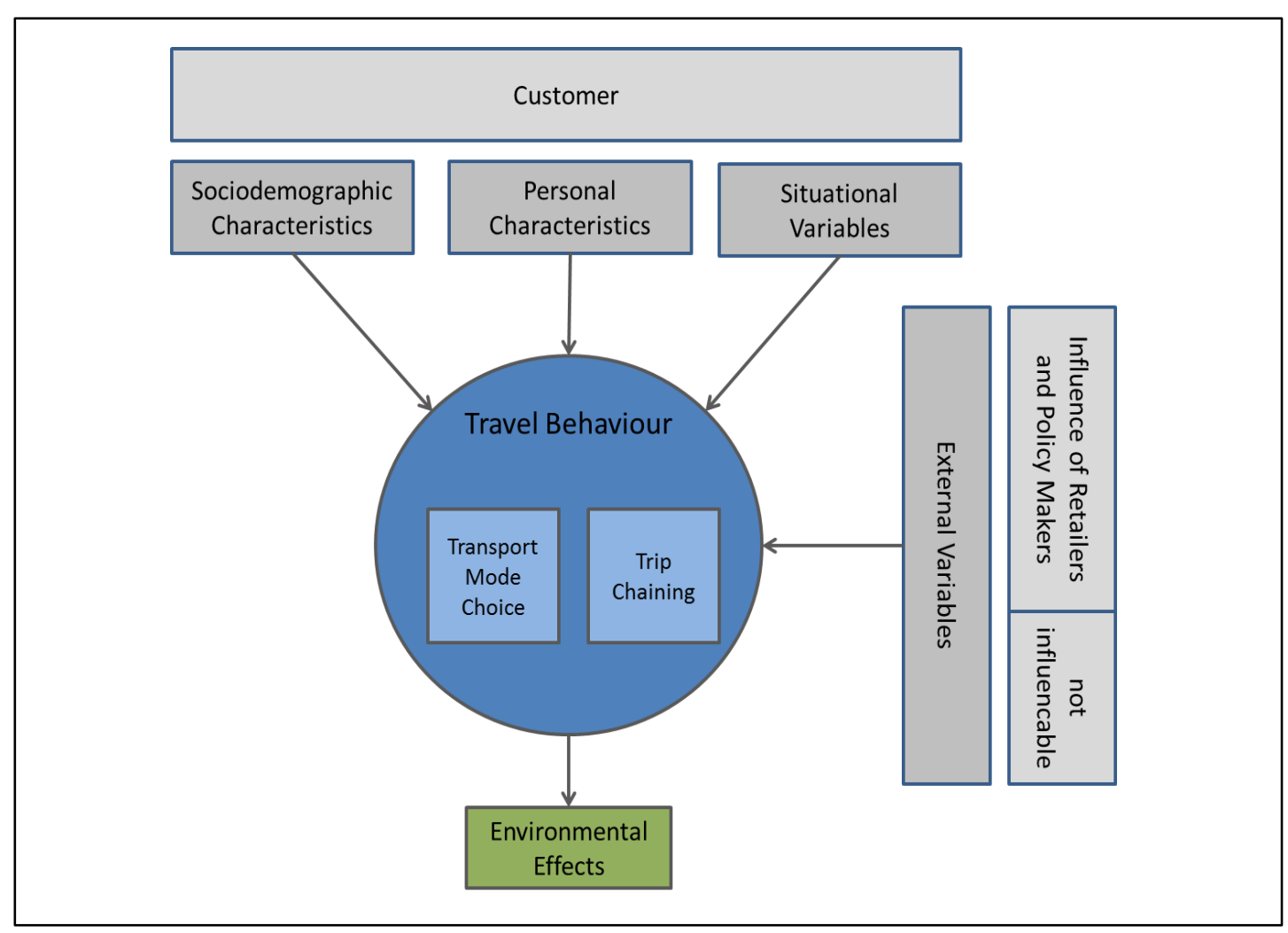

Figure 13: Relevant influences on travel behaviour and its environmental effects

To gain a deeper understanding of the relevant aspects identified, a qualitative approach was chosen which will be explained in the following section. 


\subsection{Qualitative Analysis of Consumer Shopping Trip Behaviour}

This section clarifies why a qualitative approach was selected for this paper. Furthermore, detailed research questions based on the literature review and the research design are presented, and the procedure for the analysis is explained.

\subsubsection{Research approach}

The literature review showed that travel choices are complex and involve various attributes. Analysing them is "computationally burdensome" and leads to a "tradeoff between behavioural realism and complexity" (Ben-Akiva, Bowman, Ramming, \& Walker, 1998, pp. 11, 13). Due to this constraint, a lot of studies only analyse few aspects together, such as the influence of multi-purpose (Arentze, Borgers, \& Timmermans, 1993) and multi-destination shopping (Brooks, Kaufmann, \& Lichtenstein, 2008) or the effect of trip chaining on the use of public transport (Hensher \& Reyes, 2000). By contrast, a qualitative approach facilitates the incorporation of various influences on travel behaviour and makes the motives steering consumer behaviour visible. Al-Jammal and Parkany (2002, unpaged) reveal that "such methods explain why people make certain travel choices through probing for underlying reasons leading to final outcomes". Ye, Pendyala, and Gottardi (2007, p. 112) point out that "to truly understand and identify causal relationships, data regarding underlying behavioural processes and decision mechanisms are needed". In particular, the concurrence of the different influences should be analysed. Furthermore, it is interesting to evaluate how consumers differ in their behaviour. Here, qualitative research can help to clarify the important drivers (Clifton \& Handy, 2001) and provide "insights into the meaning and the context of consumption" (Sinkovics et al., 2005, p. 14).

Following these arguments, a qualitative approach is suitable in the current research situation. To shed more light on the relationships between the influences identified and travel behaviour, more detailed research questions are deduced based on the literature review. Hence, this study follows a theory-driven approach. It is recommended not to frame the research questions too early, which might cause a neglect of relevant aspects that might just occur during the analysis (Maxwell, 2008). However, to plan the research approach, the research questions were deduced from 
the results of the literature review, forming the basis for focussing and conducting the study (Maxwell, 2008). Research questions that are too general might pose difficulties for designing the study, such as for decisions on the choice of informants and relevant data (Maxwell, 2008). Hence, while it is important to focus the study on the one hand, on the other hand the researcher has to be open-minded for new issues. Table 9 provides an overview of the research questions, structured following the influences depicted in Figure 13. Furthermore, consumers' expectations of retailers and policy makers are evaluated.

\begin{tabular}{|c|c|l|l|}
\hline Influence & No. & \multicolumn{1}{|c|}{ Research Questions } \\
\hline $\begin{array}{c}\text { Sociodemographic } \\
\text { characteristics }\end{array}$ & $\mathbf{1}$ & $\begin{array}{l}\text { How do the influences differ between several life cycle stages? } \\
\text { How do children influence the use of public transport? }\end{array}$ \\
\hline \multirow{2}{*}{$\begin{array}{c}\text { Personal } \\
\text { characteristics }\end{array}$} & $\mathbf{2}$ & $\begin{array}{l}\text { How do the interviewees evaluate their perceived mobility } \\
\text { necessity? What is the influence of the perceived mobility } \\
\text { necessity on the behaviour? }\end{array}$ \\
\cline { 2 - 4 } & $\mathbf{3}$ & $\begin{array}{l}\text { How do consumers perceive the public transport modes in their } \\
\text { area? }\end{array}$ \\
\cline { 2 - 4 } & $\mathbf{4}$ & $\begin{array}{l}\text { How does a person's environmental consciousness affect the } \\
\text { travel behaviour? }\end{array}$ \\
\hline Situational & $\mathbf{5}$ & $\begin{array}{l}\text { How do the goods to be purchased influence the shopping trip } \\
\text { behaviour? How is transport mode choice related to trip chain } \\
\text { variables }\end{array}$ & $\begin{array}{l}\text { complexity? How does multi-purpose shopping influence the } \\
\text { behaviour? How does the ownership of a car influence the use of } \\
\text { public transport? }\end{array}$ \\
\cline { 2 - 4 } & $\mathbf{6}$ & $\begin{array}{l}\text { How do enjoyable or important destinations affect the travel } \\
\text { behaviour? }\end{array}$ \\
\hline \multirow{2}{*}{$\begin{array}{c}\text { Influences of } \\
\text { potailers and }\end{array}$} & $\mathbf{8}$ & $\begin{array}{l}\text { How do external factors (i.e. design of transport systems, } \\
\text { weather) affect choices of travel behaviour? }\end{array}$ \\
\hline \multirow{2}{*}{$\begin{array}{l}\text { External variables } \\
\text { makers? How can retailers and policy makers offer incentives to } \\
\text { mitigate the environmental effects of consumer travel behaviour? }\end{array}$}
\end{tabular}

Table 9: Research questions for the qualitative analysis

The next section presents the research design chosen to collect the data relevant to answering these questions. 


\subsubsection{Data collection}

As explained, a qualitative approach was considered suitable. In particular, qualitative interviews were conducted to obtain data to answer the research questions at hand. As this paper aims to gain a deeper understanding of consumer behaviour, detailed information is required and influence from or interactions with other people should be avoided (Sayre, 2001). Hence, individual interviews were used instead of group interviews. In particular, semi-structured interviews were chosen. This method "involves prepared questioning guided by identified themes in a consistent and systematic manner interposed with probes designed to elicit more elaborate responses" (Qu \& Dumay, 2011, p. 246). Thus, the interviewer can apply the same thematic approach in all interviews, but is still able to react flexibly to the responses of the interviewee ( $\mathrm{Qu} \&$ Dumay, 2011). The interviewee can "add important insights as they occur during the course of conversation, while (...) previous prepared questions provide some focus" (Myers, 2009, p. 125). Due to these advantages, semi-structured interviews are the most used interview approach in business and management (Myers, 2009).

Various aspects need to be considered in choosing the interviewees. Research showed that different stages in life cycle are relevant for travel behaviour (McGuckin, Zmud, \& Nakamoto, 2005; Al-Jammal \& Parkany, 2002; Golob, 1986). To focus the selection of interviewees, five groups have been considered: young people without children, people with preschool children, people with school children, older people without or with out-of-house children and retired people. This procedure is similar to Clarke et al. (1981), who identified eight relevant groups in family life cycles. As a more narrow analysis would not be purposeful for this study, three groups identified by Clarke et al. (1981) have been excluded or combined: families with preschool and school children, families with young and old school children, and families only with adults.

In addition to the life cycle phase, the residential location is important as there might be differences in shopping behaviour depending on the residential area of the people in question. These aspects were considered when choosing the interviewees, applying theoretical sampling (Brannen, 1992). This procedure also fulfils the 
recommendation to interview a variety of people to obtain different views (Myers, 2009).

Table 10 provides an overview of the interview partners. To give a structure to the different residential areas, the classification of the central place theory is applied as a basis (King, 1985). This theory assumes that settlements offer different kinds of supply, defining three kinds of centres. Low-order centres provide a basic supply, such as supermarkets, a medical service and an elementary school. Some interviewees in this study even live in villages that do not offer this supply. Middleorder centres offer a basic supply and periodical supply; they also have hospitals, cinemas and secondary schools. A high-order centre is a city offering a basic supply, periodical supply and specific supply, including specialised hospitals, universities, museums, etc. To secure relationship-based ethics (Qu \& Dumay, 2011), the interviewees were not friends or family of the interviewer. Instead, the contacts were arranged by people known to the author and their friends or family fitting into the predefined sociodemographic requirements.

\begin{tabular}{|c|l|c|c|c|}
\hline \multirow{2}{*}{ Phase in Life Cycle } & \multicolumn{3}{|c|}{ Residential Location } \\
\cline { 2 - 5 } 1 & $\begin{array}{l}\text { Younger Person } \\
\text { without children }\end{array}$ & A & B & C \\
\hline 2 & $\begin{array}{l}\text { Person with preschool } \\
\text { children }\end{array}$ & D & E & F \\
\hline 3 & $\begin{array}{l}\text { Person with school } \\
\text { children }\end{array}$ & G & H & I \\
\hline 4 & $\begin{array}{l}\text { Older person with out- } \\
\text { of-house children / no } \\
\text { children }\end{array}$ & J & K & L \\
\hline 5 & Retired person & M & N & O \\
\hline
\end{tabular}

Table 10: Selection of interviewees 
This procedure is called purposeful sampling, i.e. "persons (...) are deliberately selected for the important information they can provide that cannot be gotten as well from other choices" (Maxwell, 2008, p. 235), which contrasts the convenience or probability sampling applied in quantitative research. Purposeful sampling helps to compare reasons for differences between individuals and "capture adequately the heterogeneity in the population" (Maxwell, 2008, p. 235).

The interviews were conducted in the winter of 2012/13. To avoid any bias caused by differences in interviewer behaviour, all the interviews were conducted by one interviewer. The guideline designed to answer the research questions is displayed in the appendix (Table 13). It is important to keep in mind that in qualitative research, the "interview questions should not be judged by whether they can be logically derived from your research questions, but whether they provide the data that will contribute to answering these questions" (Maxwell, 2008, p. 236).

The interviews comprised five steps. First of all, the interviewer introduced the topic, described as shopping behaviour to prevent social desirability (Qu \& Dumay, 2011). Detailed information about the aim of the research project was provided afterwards. Secondly, the interviewee was encouraged to talk about his or her last shopping trip. Consequently, "rather than simply presenting numbers and generalisations to back up (...) recommendations", this approach "tells it like it really was" (Maxwell, 2008, p. 222). Thirdly, the interviewer asked more detailed questions about the transport mode use, trip chaining, etc. based on the information given. Fourthly, the focus shifted to the perceived mobility necessity, the perception of environmental issues and expectations of policy makers and retailers. Finally, the interview was concluded with general questions about the interviewee's sociodemographic characteristics.

The interviews lasted between twelve and thirty-three minutes, very much depending on the interviewees' way of providing information. Whilst some of them talked freely, others had to be prompted with questions, leading to shorter interviews. The interviews were recorded and subsequently transcribed verbatim. 


\subsubsection{Analysis}

The analysis was conducted with the widely used computer-assisted qualitative data analysis software (CAQDAS) NVivo, which helps to control the huge amount of data generated in qualitative research (Maclaran \& Catterall, 2002). In general, the analysis consists of five processes: organising, linking, coding, searching, and modelling (Sinkovics et al., 2005). As this study is theory-driven, the main categories can be formulated a priori following the influence factors derived from the literature review (Maxwell, 2008; Sinkovics et al., 2005). Furthermore, eyes are kept open for new categories that might not be included into the analysis yet. The sub-categories are deduced during the analysis. Contrary to quantitative methods, coding is not aimed at producing counts, but at fracturing and rearranging data (Maxwell, 2008), nowadays mainly supported by CAQDAS. It is often mentioned that the researcher has to be careful not to get lost in coding by "falling into the coding trap" (Marshall, 2002 , p. 62) and keep the focus on the complete context. To guarantee this, the transcribed interviews were read completely several times and every interview was given a short summary highlighting the main findings.

\subsection{Results}

This section provides the results of analysing the interviews. At the beginning, an overview of the shopping behaviour is given. The impact of different life cycles is analysed afterwards. As the research questions yield various interdependencies, the results are presented together in the following without reference to the single research questions.

\subsubsection{Consumer behaviour and life cycle influence}

Most interviewees use the car for their shopping trips, including those living in cities. Only one person uses public transport modes for grocery-shopping or other purchases from time to time, which displays the unattractiveness of public transport for shopping trips. Mostly, it was mentioned that huge shopping baskets hamper public transport use. Multi-purpose shopping was not explicitly mentioned as a barrier to using public transport. Most interviewees trip chain a lot, but some also do their grocery shopping as a single trip. Most interviewees have a detailed list but are also open-minded for impulse buying (except interviewee L, who only buys things 
from his list). There are only small differences in behaviour between grocery and other shopping. The car is mainly used and nearly all the interviewees try to connect trips. Hence, the influence of products appears to be quite small. In general, most interviewees did not have enjoyable shopping destinations for which they would be willing to travel long distances. Interviewees $\mathrm{B}, \mathrm{K}$ and $\mathrm{I}$ undertake longer trips to favoured shopping centres or other cities. These trips are planned and conducted rarely to buy many things at once. Interviewee I even used the train to go shopping in another city.

The interviews highlighted the relevance of mobility for most interviewees. In particular, parents with older children have a high perceived mobility necessity. They have to bring their children to appointments with friends, sport, doctor's appointments, etc., structuring their life based on the requirements of their children. Combining childcare with job issues complicates the situation and hence influences transport mode choices. For instance, interviewee $\mathrm{G}$ has to hurry up after work to be home in time to prepare lunch. She would consider cycling to work when her children are older and she no longer has to hurry as much. Interviewee I mentioned that due to juggling all of her obligations, she only cycles rarely as it takes more time than driving, even though she used to cycle a lot. For parents with younger children, the perceived mobility necessity is smaller, but for them using public transport is complicated on account of having to take the pram with them etc. In general, public transport cannot fulfil the requirements of these life cycle groups.

All in all, the interviewees evaluated public transport negatively. They predominantly mentioned poor connections, e.g. few services per day or too lengthy travel times, as the main reason. Some also mentioned high fares as another factor. However, they mainly stated that they would be willing to use public transport if there were better connections. The main advantage of using the car instead of public transport mentioned was "flexibility". Only one person (interviewee N) said that she does not like public transport modes and prefers walking or driving as public transport is mostly crowded and she sees a high risk of illness, especially in the wintertime. The availability of public transport greatly influences the transport mode choice. Most interviewees mentioned the insufficient connections as a reason for not using public transport, particularly in rural areas, but also in cities. Interviewee C 
always cycles, even in the snow and rain, as using the bus is very unattractive to her. Using the car also seems to be a matter of course for most interviewees. Although interviewee $\mathrm{C}$ generally cycles in everyday life, she automatically uses the car when she stays at her mother's home as "it is there". Interviewee E does not know anything about the bus timetable as she does not think about it because she has a car. Interviewee $\mathrm{F}$ has a company car, which he uses all time, and says that he might not use the car that often if he had to pay for petrol etc. himself. These examples show that the availability of a car seems to "blind" people to other transport modes. One of the most interesting results is that the interviewees do not change transport modes as often and as much as might be expected from the research. Most people only use one transport mode regularly, which in most cases is the car (interviewees A, B, D, E, F, G, J, K, L, M and O) and in one case the bike (interviewee C). Interviewee I mostly uses the car, but also cycles or takes the bus, whilst interviewee $\mathrm{H}$ changes between car and bike. Interviewee $\mathrm{N}$ does not own a car, but goes shopping with her daughter, who drives her to the shops, or sometimes walks to the city centre.

With one exception, all the interviewees stated that they try to behave in an environmentally-conscious manner and consider environmental issues in daily life. The interviewees differ greatly in terms of their dedication, e.g. from eating a vegetarian diet, buying mainly organic products or saving energy and water (which also carries financial benefits). Regarding the environmental effects of travel, many interviewees trip chain a lot and also mentioned that they try to avoid additional journeys. Moreover, it was often noted that people would be willing to use public transport more if there were better connections. This supports Belz (2006), who said that convenience for the consumer is an important aspect in sustainability marketing. However, the flexibility and comfort of a car seem to be difficult to substitute with public transport. Here, a person's environmental consciousness might be the catalyst behind the decision to use public transport instead of the car.

The discussion above shows that there are differences between the life cycles. Although the three people interviewed in each life cycle group differ in their behaviour and characteristics, they have some commonalities that are presented in Table 11 to provide an overview of the aspects considered relevant for shopping trip behaviour. The table clarifies the main characteristics and the perceived mobility 
necessity. In addition, the relevance of cars and the perception of public transport are analysed. Using this table, implications can be deduced for retailers and policy makers based on the differences in life cycles.

\begin{tabular}{|c|c|c|c|c|}
\hline \multirow[b]{2}{*}{$\begin{array}{l}\text { Life } \\
\text { Cycle }\end{array}$} & \multicolumn{4}{|c|}{ Characteristics } \\
\hline & Everyday Life & $\begin{array}{l}\text { Perceived } \\
\text { Mobility } \\
\text { Necessity }\end{array}$ & Relevance of Car & $\begin{array}{c}\text { Perception of } \\
\text { Public } \\
\text { Transport }\end{array}$ \\
\hline $\begin{array}{l}\text { Young } \\
\text { person }\end{array}$ & $\begin{array}{l}\text { life is mainly } \\
\text { structured around } \\
\text { work / education }\end{array}$ & $\begin{array}{l}\text { important for } \\
\text { work / education } \\
\text { and leisure time }\end{array}$ & $\begin{array}{l}\text { not needed in } \\
\text { urban area, highly } \\
\text { relevant in rural } \\
\text { areas }\end{array}$ & $\begin{array}{l}\text { inflexible, } \\
\text { insufficient in } \\
\text { rural areas }\end{array}$ \\
\hline $\begin{array}{l}\text { With } \\
\text { young } \\
\text { child }\end{array}$ & $\begin{array}{l}\text { children become } \\
\text { important part of } \\
\text { life, habits are } \\
\text { changed }\end{array}$ & $\begin{array}{l}\text { in the beginning, } \\
\text { one parent stays } \\
\text { at home }\end{array}$ & $\begin{array}{l}\text { helps transporting } \\
\text { the pram etc. and } \\
\text { provides comfort }\end{array}$ & $\begin{array}{l}\text { not comfortable, } \\
\text { insufficient in } \\
\text { rural areas }\end{array}$ \\
\hline $\begin{array}{l}\text { With } \\
\text { school } \\
\text { child }\end{array}$ & $\begin{array}{l}\text { life is very much } \\
\text { planned around } \\
\text { the children and } \\
\text { their } \\
\text { appointments }\end{array}$ & $\begin{array}{l}\text { children require } \\
\text { many journeys } \\
\text { and high } \\
\text { flexibility }\end{array}$ & $\begin{array}{l}\text { provides the } \\
\text { flexibility needed }\end{array}$ & $\begin{array}{l}\text { not flexible } \\
\text { enough, } \\
\text { connections are } \\
\text { insufficient, } \\
\text { children have to } \\
\text { wait too long etc. }\end{array}$ \\
\hline $\begin{array}{l}\text { Mature } \\
\text { stage }\end{array}$ & $\begin{array}{l}\text { only have to plan } \\
\text { for themselves, } \\
\text { spontaneous }\end{array}$ & $\begin{array}{l}\text { mainly work and } \\
\text { shopping trips }\end{array}$ & $\begin{array}{l}\text { provides } \\
\text { flexibility }\end{array}$ & $\begin{array}{l}\text { not flexible } \\
\text { enough, } \\
\text { connections are } \\
\text { insufficient }\end{array}$ \\
\hline Retired & $\begin{array}{l}\text { walking and using } \\
\text { public transport } \\
\text { becomes difficult, } \\
\text { a lot of time spent } \\
\text { at home }\end{array}$ & $\begin{array}{l}\text { varies with age } \\
\text { and health }\end{array}$ & $\begin{array}{l}\text { provides freedom } \\
\text { and comfort }\end{array}$ & $\begin{array}{l}\text { connections are } \\
\text { insufficient, } \\
\text { expensive, not } \\
\text { comfortable }\end{array}$ \\
\hline
\end{tabular}

Table 11: Important characteristics for the five life cycles

\subsubsection{Shopping types}

Although commonalities can be identified within the life cycles, personal characteristics are also relevant, e.g. how a person plans a shopping trip or the need for spontaneity. To gain a deeper understanding of various types of consumer behaviour, we structured the interviewees with respect to different characteristics. Hence, the information gained in the interviews is used to develop a typology that provides a broader perspective on consumer behaviour by including personal characteristics. 
The interviews showed that in particular the expectations towards flexibility and comfort diverge between the interviewees. Hence, mainly the planning and the role the transport modes have to fulfil for the consumer are relevant for the shopping trip and its environmental effects. An overview of these two aspects and a general description of each type are provided in Table 12. 


\begin{tabular}{|c|c|c|c|}
\hline \multirow{2}{*}{$\begin{array}{l}\text { Consumer Type and } \\
\text { Related Interviewees }\end{array}$} & \multicolumn{3}{|c|}{ Characteristics } \\
\hline & General description & Planning & Role of transport mode \\
\hline $\begin{array}{l}\text { The Naïve ... } \\
\text { Life cycle: } 2\end{array}$ & $\begin{array}{l}\ldots \text { does not question his or her } \\
\text { behaviour very much, e g. the car is } \\
\text { used, because it is there } \\
\ldots \text { does not consider other transport } \\
\text { modes or considers them unattractive }\end{array}$ & $\begin{array}{l}\ldots \text { plans sometimes, shopping lists are } \\
\text { only written for special things }\end{array}$ & $\begin{array}{l}\text {... does not question transport mode } \\
\text { choices, mode mainly needs to be } \\
\text { comfortable }\end{array}$ \\
\hline $\begin{array}{l}\text { The Rational } \ldots \\
\text { Life cycle: } \\
1,2,3,4\end{array}$ & $\begin{array}{l}\ldots \text { is behaving rationally, but not as } \\
\text { extremely as the "Optimiser", e.g. trips } \\
\text { are connected with dropping off their } \\
\text { children etc. }\end{array}$ & ... plans mainly to ease the shopping & $\begin{array}{l}\ldots \text { chooses a transport mode that fits } \\
\text { the requirements, e.g. saving time and } \\
\text { being flexible }\end{array}$ \\
\hline $\begin{array}{l}\text { The Spontaneous ... } \\
\text { Life cycle: } 4,5\end{array}$ & $\begin{array}{l}\ldots \text { has a kind of basic organisation, but } \\
\text { is quite flexible, e.g. going shopping } \\
\text { when things are needed }\end{array}$ & $\begin{array}{l}\ldots \text { plans sometimes, shopping lists are } \\
\text { only written for special things }\end{array}$ & $\begin{array}{l}\text {... chooses a transport mode that is } \\
\text { flexible and supports his or her } \\
\text { spontaneity }\end{array}$ \\
\hline $\begin{array}{l}\text { The Optimiser ... } \\
\text { Life cycle: } 4,5\end{array}$ & $\begin{array}{l}\text {... plans a lot and tries to optimise the } \\
\text { shopping trip or the prices of the things } \\
\text { bought, e. } g \text { various stores are visited } \\
\text { to reach the lowest prices for the } \\
\text { shopping basket }\end{array}$ & $\begin{array}{l}\text {... plans a lot to optimise the shopping } \\
\text { trip, e.g. a shopping list is written with } \\
\text { respect to recent advertising }\end{array}$ & $\begin{array}{l}\text {... chooses a transport mode that fits } \\
\text { the requirements, e.g. being flexible to } \\
\text { reach many stores or being comfortable }\end{array}$ \\
\hline
\end{tabular}

Table 12: Typology of general shopping behaviour 
Table 12 shows that all people with children were grouped as "Rational" or "Naïve". This displays that these people have a high need for planning and comfort in transport mode choices in their daily lives. In contrast, people without children can either behave more flexibly, e.g. go shopping when food is empty, or more optimizing, e.g. detailed planning or intensive trips to get the cheapest offer. In general, flexibility and comfort seem to be the most important aspects of travel behaviour. Hence, these aspects should particularly be addressed when aiming to improve the environmental friendliness of shopping trips.

Furthermore, the typology clarifies that consumers should be addressed differently to enhance the use of more environmentally-friendly transport modes. The "Naïve" should be provided with information about transport alternatives, clarifying that they are also attractive and can fulfil their needs, too. The "Rational" generally considers other transport modes, but mainly feels that they do not meet the requirements, such as a high degree of flexibility. Here, an improvement of transport modes seems necessary, e.g. regarding flexibility and comfort. The "Spontaneous" needs transport modes that support his or her behaviour, including a low level of planning and a high degree of spontaneity. Hence, limited timetables and a limited public transport service hinder use. The "Optimiser" mainly uses the car because it offers support for his or her behaviour. For instance, only one, perfectly planned shopping trip is conducted per week, which leads to one huge shopping basket or purchases at various retailers are connected to gain the best price. Public transport modes mainly lack the flexibility that is needed for connecting stops at different retailers or the comfort needed for taking huge shopping baskets home. Here, the usefulness should be improved and communicated. For instance, delivery services might help enhance the attractiveness of public transport use.

In addition to the information on consumer behaviour, the expectations consumers have of retailers and policy makers with regard to environmental aspects were also evaluated in the interviews. The main results with a focus on travel behaviour are presented in the following. 


\subsubsection{Expectations from retailers and policy makers}

When the interviewees were asked about their expectations for the environmental performance of retailers, they mainly mentioned aspects of assortment, packaging or commitment to social or environmental issues. Aspects of consumer travel were only mentioned when the interviewer asked about it directly. This might show that consumers have got into a habit in their travel behaviour and do not really think about other options. This emphasises the importance of interventions by retailers and policy makers. An interesting option might be delivery services, which can curb environmental pollution (Cairns, 2005). When asked about the willingness to use services such as home delivery, most interviewees disliked using them. Mainly, it was stated that they prefer shopping on their own so they can check out the assortment offered. Also, the social component of shopping such as meeting neighbours was mentioned. This result supports the findings of Teller, Kotzab, and Grant (2006), who only found few chances for delivery services.

At this point, a more detailed examination of consumer characteristics is required to evaluate which consumers might be receptive to delivery services. Interviewee $\mathrm{L}$ only buys things he noted earlier on his shopping list and mentioned that he might be very willing to use a delivery service as this would save him the time to go to the stores. Interviewee $\mathrm{H}$ came up with the suggestion of doing the shopping herself, but having it delivered to her home later by the retailer. This would enable her to walk or go by bike and she would not have to go home directly after the shopping but could do some other errands as well on the same tour. Interviewee F expressed an interest in a service that provides cooking recipes and delivers the ingredients required to the customer's home. This interviewee could also imagine sending his shopping list online and then picking up the shopping bags at the store. However, he has not tried these services yet as his wife is not convinced. Once, interviewee I used the delivery service of a department store that was offered for free when she spontaneously bought a huge play house for her children and was in the city by bike. Interviewee A already receives the so-called "green box" ("Grüne Kiste" in German), which contains local fruit and vegetables and is delivered once a week by a local farmer. She also has a subscription at Amazon.de to supply her regularly with the household goods she needs, such as toilet paper etc. This shows that these business concepts already receive some attention and can be successful. 
In particular, delivery concepts seem attractive to people who plan their shopping in detail (and do not act spontaneously) or who are highly stressed out in their daily lives. Moreover, delivery services offering an additional utility such as the "green box" or the complete package with cooking recipes might be valued highly. This could also give retailers a great opportunity to differentiate themselves from competitors by reaching a USSP (Belz, 2006).

The interviewees differed greatly in their opinions on the influence and responsibility of policy makers. Whilst some mentioned that enough information is provided and that the policy makers are doing enough on environmental sustainability in Germany, others said that they expect greater efforts. When asked about travel issues, the interviewees mainly mentioned better connections on public transport as a way to reduce their car usage. However, others added that capacity utilisations are also important, particularly in rural regions. For instance, interviewee D mentioned that a shuttle bus supposed to bring tourists to a nearby castle drives past her house several times per day and every time she sees the bus, it is either empty or nearly empty. Hence, she questions whether offering this shuttle makes sense or just causes additional pollution. Consequently, this needs to be examined in more detail by policy makers to make sure that the transport modes are really used.

This discussion clarifies that retailers and policy makers should try to understand consumer behaviour as well as possible to offer appropriate solutions that fit the consumers' needs and help to prevent environmental damage. Some interviewees also expressed resignation as they either think that they can have only little impact or think that other consumers do not care enough about these issues. It was also noted that industries are huge polluters and that policy makers should mainly address these companies instead of consumers. Here, retailers and policy makers should try to clarify the impact that each consumer can have on the environmental effects. This is supported by Ölander and Thøgersen (1995), who mention that policies that increase a feeling of empowerment may also have a positive effect on consumer motivation to make an effort. 


\subsection{Discussion}

The paper was aimed at improving the knowledge of influences on consumer shopping trip behaviour with a particular focus on the environmental effects of shopping trips. It clarified the complexity of travel decisions and the appropriateness of a qualitative approach. In contrast to earlier research, a broader approach was chosen to provide a comprehensive perspective on the influences and effects of consumer shopping behaviour. Therefore, the relevant drivers of consumer behaviour were identified. It was shown that two aspects mainly hinder environmentallyfriendly behaviour: the negative evaluation of public transport and the perceived mobility necessity of the different life cycles, by which parents are affected in particular. Issues of comfort and flexibility are mainly important in travel mode choices. Also, it was discovered that consumers differ in their behaviour with respect to the planning of shopping trips and the evaluation of transport modes.

The results support qualitative and quantitative research in various ways. Researchers should address the needs and characteristics of consumers in their studies in more detail. As the life cycle situation has a considerable impact on behaviour, the research should try to incorporate different groups of consumers to achieve more specific results. Furthermore, personal characteristics are relevant as the willingness to change behaviour can differ. Consumers vary in their environmental consciousness, causing different predispositions for environmental issues. Also, the way consumers plan and conduct their shopping trips diverges, leading to different starting points for addressing changes, as the typology and derived implications showed. Hence, researchers should evaluate the respondents' characteristics to identify applicable approaches.

It was not possible to clarify the relationship between transport mode choice and trip complexity further as, unexpectedly, the interviewees did not vary the transport modes very much. However, this outcome might indicate that the topic is not as relevant as suspected in earlier research. To learn more about this, future research should analyse this aspect further, perhaps by only conducting interviews in cities to increase the probability of switching transport mode. Moreover, it would be interesting to address users of different transport modes directly to evaluate their perception and behaviour. Besides, future research should address this issue by 
incorporating cultural differences. For instance, bicycles are commonly used as transport modes in India or the Netherlands whilst cycling is a leisure activity in the USA (van Herk, Poortinga and Verhallen 2005).

Furthermore, the results add knowledge on how certain theories should be developed further. It was shown that consumers tend to underestimate the impact they can have on environmental effects. This aspect should be analysed in more detail to evaluate how consumer efforts towards sustainability can be enhanced. It was also shown that comfort and flexibility are very important for consumer behaviour. Hence, these aspects should be evaluated as characteristics in quantitative methods for calculating utility functions, e.g. conjoint analyses or discrete choice models. For instance, flexibility might be evaluated by the frequency with which public transport is offered (i.e. every 5 minutes, every 30 minutes, etc.). The aspect of comfort can be evaluated by additional information on extra space for prams for family friendliness, for instance. By incorporating these aspects, more can be learnt about the relevance they have for the various life cycle groups as it can be assumed that utility values differ between the groups.

Besides, implications can be deduced for retailers who want to improve their image regarding sustainability issues and policy makers who want to encourage environmentally-friendly behaviour. In general, there seems to be a basic problem in communication. Consumers underestimate their impact on environmental issues and the effects of shopping trips. Some interviewees mentioned that they do not have a high impact and that they expect policy makers and industries to start with mitigating environmental impacts. Hence, in a first step the communication policies of retailers and policy makers need to be enhanced. Consumers should receive more detailed information about the effects of their behaviour, clarifying the high impact they have. Therefore, consumers can be motivated to improve their behaviour and a significant reduction in environmental pollution might be achieved. In a second step, retailers and policy makers should support consumers in enhancing their behaviour. Some starting points for this are discussed in the following.

For retailers, offering delivery services would be an option to reduce consumer journeys and substitute them with more efficient processes. However, the interviews showed that most consumers prefer shopping on their own. Hence, delivery services 
seem to have little chance of success. Nevertheless, some interviewees expressed an interest in such business ideas. Innovative delivery concepts might be attractive by adding an extra value, such as the idea of providing a recipe and the related ingredients as a service. This is supported by Teller et al. (2006), who suggest that delivery services should concentrate on niche markets or add differential criteria to traditional business models. Hence, retailers should focus on innovative concepts that offer an extra value to the consumers. Consequently, a unique sustainable selling position might be reached (Belz, 2006). Some interviewees were also open-minded for services, such as doing the shopping themselves but having the goods delivered to their homes. This approach would enable walking or cycling to the stores as the consumers would not have to carry their shopping home. Furthermore, trip chaining might be facilitated as the consumer could run some other errands together with their shopping trip. This aspect can also be supported by shopping agglomerations, which facilitate trip chaining.

As it was found that the interviewees differ in their behaviour and needs, the request to optimise public transport based on socioeconomic characteristics (Hensher \& Reyes, 2000) is supported by the results. Retailers could make the shopping more relaxed, such as by offering childcare etc., to enhance the use of public transport by families. Furthermore, they could support using public transport, such as by offering a discount on the ticket. When choosing new locations, they should focus on the public transport connection. They could also offer information to their customers on the environmental effects of their shopping trips. Policy makers should improve the child-friendliness of public transport modes to increase their use, e.g. more space for prams or special fares for families.

The analysis for different consumer types regarding the general shopping behaviour yielded four types that vary in their transport mode requirements. Hence, in addition to sociodemographic aspects the differences in consumer types should also be considered. For instance, an amalgamation of private and public transport might become important in the future as issues of flexibility and comfort were mentioned a lot. Hence, more flexible transport modes are needed to fulfil the needs of consumers, such as shared taxis, for instance. As some consumer types seem to be very set on using their cars, the policy should be to increase the perception of public 
transport and point out that other possibilities exist. Here again, aspects of communication policy are highly relevant.

The interviewees trip chain a lot, which should be considered in urban planning to facilitate environmentally-friendly behaviour. Retail agglomerations should be created to provide possibilities for multi-purpose shopping. Also, people might favour job-site locations "because of their ability to make midday personal business tours" (Ben-Akiva et al. 1998, p. 12). Urban planning that incorporates work and shopping places, i.e. multi-mix land use, can support this and enhance environmentally-friendly behaviour.

The limitations of this study are similar to those related to qualitative studies in general (Maxwell, 2008; Sinkovics et al., 2005). In particular, the sample size and composition might have influenced the results. Most of the interviewees own a car and mainly use it, which limits the information that could be gained on switching transport modes. However, bearing in mind the high level of car ownership in Germany, the results might be representative. An important aspect in qualitative research is the discussion on its generalizability. As the study was conducted in Germany, the use and perception of transport modes may differ in other countries, as mentioned above for bicycles in India or the USA (van Herk et al., 2005). Therefore, different results might emerge for other countries. 


\section{Appendix}

\begin{tabular}{|c|c|}
\hline Introduction & $\begin{array}{l}\text { - Self-introduction of the interviewer } \\
\text { - Information that the interview is about shopping behaviour and } \\
\text { that more detailed information on the research topic can be } \\
\text { provided after finishing the interview } \\
\text { - Request for an account of the last shopping trip, starting with the } \\
\text { planning, ending with the arrival at home }\end{array}$ \\
\hline $\begin{array}{l}\text { Questions related } \\
\text { to the reported } \\
\text { shopping trip }\end{array}$ & $\begin{array}{l}\text { - Questions about the transport mode used: Why did you use this } \\
\text { mode? What does it mean to you? What would be necessary for } \\
\text { you to switch the mode, e.g. from car to bus? } \\
\text { - Questions about the planning of the shopping trip: You } \\
\text { mentioned that you did the trip spontaneously / planned. Can you } \\
\text { explain this in more detail? What do you think about spontaneity } \\
\text { regarding shopping? When is planning important to you? } \\
\text { - Questions about trip chaining: You mentioned that you connected } \\
\text { the shopping at ... with ... Can you tell me more about this? What } \\
\text { do you think about the connection of shopping or work trips? } \\
\text { Which influence does this have on the transport mode you use? } \\
\text { - Questions about products: You mentioned that you bought ... on } \\
\text { your last shopping trip. Would there be any difference if you } \\
\text { would have bought clothing etc.? How do you connect shopping } \\
\text { trips for these products? } \\
\text { - Questions about enjoyable destinations: Please reflect on whether } \\
\text { there is a particular store that you like a lot and for which you } \\
\text { would be willing to travel longer distances. How would you } \\
\text { behave in such a situation? }\end{array}$ \\
\hline $\begin{array}{l}\text { General questions } \\
\text { on behaviour }\end{array}$ & $\begin{array}{l}\text { - What do you think about environmental consciousness in } \\
\text { general? What do you think about environmental consciousness } \\
\text { related to shopping and mobility? How do you transport your } \\
\text { goods? Which products do you buy? Under which conditions } \\
\text { would you be willing to shoulder disadvantages for more } \\
\text { environmentally-friendly behaviour? } \\
\text { - What do you think about the responsibility of retailers and policy } \\
\text { makers regarding the environment? What do you expect from } \\
\text { retailers and policy makers? }\end{array}$ \\
\hline $\begin{array}{l}\text { Sociodemographic } \\
\text { aspects }\end{array}$ & $\begin{array}{l}\text { - Living area } \\
\text { - Family situation } \\
\text { - Job situation, income }\end{array}$ \\
\hline Open end & $\begin{array}{l}\text { - Are there aspects you would like to amend? Are there any aspects } \\
\text { that are important to you that have not been covered yet? } \\
\text { - Do you have any further questions? }\end{array}$ \\
\hline
\end{tabular}

Table 13: Interview guideline 


\section{References}

Al-Jammal, R., \& Parkany, E. (2002). The integration of qualitative and quantitative methodologies: Framework and quick examples. Transportation Research Board $82^{\text {nd }}$ Annual Meeting.

Anable, J. (2005). 'Complacent Car Addicts' or 'Aspiring Environmentalists'? Identifying travel behaviour segments using attitude theory. Transport Policy, 12(1), 65-78.

Arentze, T., Borgers, A., \& Timmermans, H. (1993). A model of multi-purpose shopping trip behavior. Paper in Regional Science: The Journal of the RSAI, 72(3), 239-256.

Belz, F.-M. (2006). Marketing in the Age of Sustainable Development. In M. Munch Andersen \& A. Tukker (Eds.), Perspectives on Radical Changes to Sustainable Consumption and Production (SCP) (pp. 299-314).

Ben-Akiva, M., Bowman, J., Ramming, S., \& Walker, J. (1998). Behavioral Realism in Urban Transportation Planning Models. Transportation Models in the Policy-Making Process: A Symposium in Memory of Greig Harvey.

Brannen, J. (1992). Combining qualitative and quantitative approaches: an overview. In J. Brannen (Ed.), Mixing Methods: Qualitative and Quantitative Research (pp. 3-37). Aldershot: Avebury Ashgate Publishing Limited.

Brooks, C., Kaufmann, P., \& Lichtenstein, D. (2008). Trip chaining behavior in multidestination shopping trips: A field experiment and laboratory replication. Journal of Retailing, 84(1), 29-38.

Cairns, S. (2005). Delivering Supermarket Shopping: More or Less Traffic? Transport Reviews, 25(1), 51-84.

Clifton, K. J., \& Handy, S. L. (2001). Qualitative methods in travel behaviour research. International Conference on Transport Survey Quality and Innovation (pp. 1-20).

Dellaert, B. G. C., Arentze, T. A., Bierlaire, M., Borgers, A. W. J., \& Timmermans, H. J. P. (1998). Investigating Consumers' Tendency to Combine Multiple Shopping Purposes and Destinations. Journal of Marketing Research, 35(2), 177-188.

Edwards, J. B., McKinnon, A. C., \& Cullinane, S. L. (2010). Comparative analysis of the carbon footprints of conventional and online retailing: A 'last mile' perspective. International Journal of Physical Distribution \& Logistics Management, 40(1/2), 103-123.

Edwards, J. B., McKinnon, A. C., \& Cullinane, S. L. (2009). Carbon Auditing the 'Last Mile': Modelling the Environmental Impacts of Conventional and Online Non-food Shopping (pp. 1-43). Logistics Reseach Centre, Heriot-Watt University, Edinburgh.

Gardner, B., \& Abraham, C. (2010). Going Green? Modeling the Impact of Environmental Concerns and Perceptions of Transportation Alternatives on Decisions to Drive. Journal of Applied Social Psychology, 40(4), 831-849.

Golob, T. F. (1986). A nonlinear canonical correlation analysis of weekly trip chaining behaviour. Transportation Research Part A, 2(5), 385-399. 
Handy, S. L., \& Krizek, K. J. (2012). The role of travel behaviour research in reducing the carbon footprint: A US perspective. In R. M. Pendyala \& C. R. Bhat (Eds.), Travel behaviour research in an evolving world (pp. 37-58). International Association for Travel Behavior Research (IATBR).

Haustein, S., \& Hunecke, M. (2007). Reduced Use of Environmentally Friendly Modes of Transportation Caused by Perceived Mobility Necessities: An Extension of the Theory of Planned Behavior. Journal of Applied Social Psychology, 37(8), 1856-1883.

Hensher, D. A., \& Reyes, A. J. (2000). Trip chaining as a barrier to the propensity to use public transport. Transportation, 27, 341-361.

Ibrahim, M. F. (2005). Attitudes to transport modes for shopping purposes in Singapore. Transport Reviews, 25(2), 221-243.

Ingene, C. A., \& Ghosh, A. (1990). Consumer and Producer Behavior in a Multipurpose Shopping Environment. Geographical Analysis, 22(1), 70-93.

King, L. J. (1985). Central place theory ( $2^{\text {nd }}$ ed.). Bevery Hills, CA: Sage Publications, Inc.

Kitamura, R., Sakomoto, K., \& Waygood, O. (2008). Declining sustainability: The case of shopping trip energy consumption. Journal of Sustainable Transportation, 2(3), $158-176$.

Lee, M. S., Chung, J.-H., \& McNally, M. G. (2002). An Empirical Investigation of the Underlying Behavioral Processes of Trip Chaining. Irvine, CA.

Maclaran, P., \& Catterall, M. (2002). Analysing qualitative data: computer software and the market research practitioner. Qualitative Market Research: An International Journal, $5(1), 28-39$.

Marshall, H. (2002). What do we do when we code? Qualitative Research Journal, 2(1), $56-70$.

Maxwell, J. A. (2008). Designing a Qualitative Study. In L. Bickman \& D. J. Rog (Eds.), The handbook of applied social research methods ( $2^{\text {nd }}$ ed., pp. 214-253). Thousand Oaks, CA: Sage Publications.

McGuckin, N., Zmud, J., \& Nakamoto, Y. (2005). Trip Chaining Trends in The U.S. Understanding Travel Behavior for Policy Making. Transportation Research Record, (1917), 199-204.

Myers, M. D. (2009). Qualitative research in business and management. London et al.: Sage Publications, Ltd.

Popkowski Leszczyc, P. T. L., Sinha, A., \& Sahgal, A. (2004). The effect of multi-purpose shopping on pricing and location strategy for grocery stores. Journal of Retailing, 80(2), 85-99.

Popkowski Leszczyc, P. T. L., \& Timmermans, H. (2001). Experimental choice analysis of shopping strategies. Journal of Retailing, 77(4), 493-509.

Primerano, F., Taylor, M. A. P., Pitaksringkarn, L., \& Tisato, P. (2008). Defining and understanding trip chaining behaviour. Transportation, 35, 55-72. 
Qu, S. Q., \& Dumay, J. (2011). The qualitative research interview. Qualitative Research in Accounting \& Management, 8(3), 238-264.

Rintamäki, T., Kanto, A., Kuusela, H., \& Spence, M. T. (2006). Decomposing the value of department store shopping into utilitarian, hedonic and social dimensions: Evidence from Finland. International Journal of Retail \& Distribution Management, 34(1), 6-24.

Rocco, T. S. (2003). Shaping the future: Writing up the method on qualitative studies. Human Resource Development Quarterly, 14(3), 343-349.

Sayre, S. (2001). Marketplace research. Thousand Oaks; London; New Delhi: Sage Publications, Inc.

Schultz, I., \& Stieß, I. (2006). Linking Sustainable Consumption to Everyday Life: A socialecological approach to consumption research. In M. Munch Andersen \& A. Tukker (Eds.), Perspectives on Radical Changes to Sustainable Consumption and Production (SCP) (pp. 69-78).

Sinkovics, R. R., Penz, E., \& Ghauri, P. N. (2005). Analysing textual data in international marketing research. Qualitative Market Research: An International Journal, 8(1), 9-38.

Thøgersen, J. (2005). How May Consumer Policy Empower Consumers for Sustainable Lifestyles? Journal of Consumer Policy, 28(2), 143-177.

van Herk, H., Poortinga, Y. H., \& Verhallen, T. M. M. (2005). Equivalence of survey data : Relevance for international marketing: The importance for international marketing. European Journal of Marketing, 39(3/4), 351-364.

Weber, C., Hendrickson, C., Jaramillo, P., Matthews, S., Nagengast, A., \& Nealer, R. (2008). Life Cycle Comparison of Traditional Retail and E-commerce Logistics for Electronic Products : A Case Study of buy.com. Pittsburgh, PA.

Wiese, A., Toporowski, W., \& Zielke, S. (2012). Transport-related $\mathrm{CO}_{2}$ effects of online and brick-and-mortar shopping: A comparison and sensitivity analysis of clothing retailing. Transportation Research Part D: Transport and Environment, 17(6), 473-477.

Ye, X., Pendyala, R. M., \& Gottardi, G. (2007). An exploration of the relationship between mode choice and complexity of trip chaining patterns. Transportation Research Part B: Methodological, 41(1), 96-113. 


\section{References (complete thesis)}

Ackerman, J. (2003). Balancing the triple bottom line: the human face of sustainable business at Pick'n Pay. Industry and Environment, 26(1), 23-26.

Al-Jammal, R., \& Parkany, E. (2002). The integration of qualitative and quantitative methodologies: Framework and quick examples. In Transportation Research Board $82^{\text {nd }}$ Annual Meeting.

American Economic Association. (2009). JEL Classification Codes Guide. Retrieved 3 April 2009, from www.aeaweb.org/jel/guide/jel.php.

Anable, J. (2005). 'Complacent Car Addicts' or 'Aspiring Environmentalists'? Identifying travel behaviour segments using attitude theory. Transport Policy, 12(1), 65-78.

Andorfer, V. A., \& Liebe, U. (2011). Research on Fair Trade Consumption - A Review. Journal of Business Ethics, 106(4), 415-435.

Arentze, T., Borgers, A., \& Timmermans, H. (1993). A model of multi-purpose shopping trip behavior. Paper in Regional Science: The Journal of the RSAI, 72(3), 239-256.

Autio, M., Heiskanen, E., \& Heinonen, V. (2009). Narratives of 'green' consumers - the antihero, the environmental hero and the anarchist. Journal of Consumer Behaviour, $8(1), 40-53$.

Bamberg, S., Hunecke, M., \& Blöbaum, A. (2007). Social context, personal norms and the use of public transportation: Two field studies. Journal of Environmental Psychology, 27(3), 190-203.

Bansal, P., \& Kilbourne, W. E. (2001). The ecologically sustainable retailer. Journal of Retailing and Consumer Services, 8(3), 139-146.

Barry, M. (2003). Drawing together sustainable production and consumption at Marks and Spencer. Industry and Environment, 26(1), 13-15.

Belz, F.-M. (2006). Marketing in the Age of Sustainable Development. In M. Munch Andersen \& A. Tukker (Eds.), Perspectives on Radical Changes to Sustainable Consumption and Production (SCP) (pp. 299-314).

Ben-Akiva, M., Bowman, J., Ramming, S., \& Walker, J. (1998). Behavioral Realism in Urban Transportation Planning Models. In Transportation Models in the Policy-Making Process: A Symposium in Memory of Greig Harvey.

Berman, S. L., Wicks, A. C., Kotha, S., \& Jones, T. M. (1999). Does Stakeholder Orientation Matter? The Relationship between Stakeholder Management Models and Firm Financial Performance. Academy of Management, 42(5), 488-506.

Bhate, S. (2001). One world, one environment, one vision: Are we close to achieving this? An exploratory study of consumer environmental behaviour across three countries. Journal of Consumer Behaviour, 2(2), 169-184. 
Brammer, S., Hoejmose, S., \& Millington, A. (2011a). Managing sustainable global supply chains. Framework and Best Practices. Networking for Business Sustainability. Retrieved 8 November 2011, from http://nbs.net/wp-content/uploads/NBS-SystematicReview-Supply-Chains.pdf.

Brammer, S., Hoejmose, S., \& Millington, A. (2011b). Managing sustainable global supply chains. A Systematic Review of the Body of Knowledge. Networking for Business Sustainability. Retrieved 8 November 2011, from http://nbs.net/wpcontent/uploads/NBS-Systematic-Review-Supply-Chains.pdf.

Brannen, J. (1992). Combining qualitative and quantitative approaches: an overview. In J. Brannen (Ed.), Mixing Methods: Qualitative and Quantitative Research (pp. 3-37). Aldershot: Avebury Ashgate Publishing Limited.

Brooks, C., Kaufmann, P., \& Lichtenstein, D. (2008). Trip chaining behavior in multidestination shopping trips: A field experiment and laboratory replication. Journal of Retailing, 84(1), 29-38.

Burchell, J., \& Cook, J. (2007). Stakeholder dialogue and organisational learning: changing relationships between companies and NGOs. Business Ethics: A European Review, 17(1), 35-46.

Cairns, S. (2005). Delivering Supermarket Shopping: More or Less Traffic? Transport Reviews, 25(1), 51-84.

Carling, K., Håkansson, J., \& Jia, T. (2013). Out-of-town shopping and its induced $\mathrm{CO}_{2}$-emissions. Journal of Retailing and Consumer Services, in press, 1-7.

Carney, M., Gedajlovic, E., \& Sur, S. (2011). Corporate governance and stakeholder conflict. Journal of Management \& Governance, 15(3), 483-507.

Carter, C. R., \& Easton, P. L. (2011). Sustainable supply chain management: evolution and future directions. International Journal of Physical Distribution \& Logistics Management, 41(1), 46-62.

Carter, C. R., \& Rogers, D. S. (2008). A framework of sustainable supply chain management: moving toward new theory. International Journal of Physical Distribution \& Logistics Management, 38(5), 360-387.

Chabowski, B. R., Mena, J. A., \& Gonzalez-Padron, T. L. (2011). The structure of sustainability research in marketing, 1958-2008: a basis for future research opportunities. Journal of the Academy of Marketing Science, 39(1), 55-70.

Clarkson, M. B. E. (1995). A Stakeholder Framework for Analyzing and Evaluating Corporate Social Performance. The Academy of Management Review, 20(1), 92-117.

Clifton, K. J., \& Handy, S. L. (2001). Qualitative methods in travel behaviour research. In International Conference on Transport Survey Quality and Innovation (pp. 1-20).

Connelly, B. L., Ketchen, D. J., \& Slater, S. F. (2010). Toward a 'theoretical toolbox' for sustainability research in marketing. Journal of the Academy of Marketing Science, 39(1), 86-100. 
Costanza, R., \& Patten, B. C. (1995). Defining and predicting sustainability. Ecological Economics, 15(3), 193-196.

Cullinane, S. L. (2009). From Bricks to Clicks: The Impact of Online Retailing on Transport and the Environment. Transport Reviews, 29(6), 759-776.

Datamonitor. (2011). Online Retail in Germany. Without location.

de Man, R., \& Burns, T. R. (2006). Sustainability: Supply chains, partner linkages, and new forms of self-regulation. Human Systems Management, 25(1), 1-12.

Dellaert, B. G. C., Arentze, T. A., Bierlaire, M., Borgers, A. W. J., \& Timmermans, H. J. P. (1998). Investigating Consumers' Tendency to Combine Multiple Shopping Purposes and Destinations. Journal of Marketing Research, 35(2), 177-188.

Doak, J. (2009). An inspector calls: Looking at retail development through a sustainability lens. Journal of Retail and Leisure Property, 8(4), 299-309.

Doh, J. P., \& Guay, T. R. (2006). Corporate Social Responsibility, Public Policy, and NGO Activism in Europe and the United States: An Institutional-Stakeholder Perspective. Journal of Management Studies, 43(1), 47-73.

Driscoll, C., \& Starik, M. (2004). The Primordial Stakeholder: Advancing the Conceptual Consideration of Stakeholder Status for the Natural Environment. Journal of Business Ethics, 49(1), 55-73.

Durieu, X. (2003). How Europe's retail sector helps promote sustainable production and consumption. Industry and Environment, 26(1), 7-10.

Edwards, J. B., McKinnon, A. C., \& Cullinane, S. L. (2009). Carbon Auditing the 'Last Mile': Modelling the Environmental Impacts of Conventional and Online Non-food Shopping. Logistics Reseach Centre, Heriot-Watt University, Edinburgh.

Edwards, J., Cullinane, S., \& McKinnon, A. (2008). Carbon auditing conventional and online book supply chains. In Proceedings of the Logistics Research Network Conference. Liverpool.

Edwards, J., McKinnon, A., \& Cullinane, S. (2011). Comparative carbon auditing of conventional and online retail supply chains: a review of methodological issues. Supply Chain Management: An International Journal, 16(1), 57-63.

Edwards, J. B., \& McKinnon, A. C. (2009). Shopping trip or home delivery: which has the smaller carbon footprint? FOCUS, July, 20-24.

Edwards, J. B., McKinnon, A. C., \& Cullinane, S. L. (2010). Comparative analysis of the carbon footprints of conventional and online retailing: A 'last mile' perspective. International Journal of Physical Distribution \& Logistics Management, 40(1/2), $103-123$.

Ehrenfeld, J. R. (2005). The Roots of Sustainability. MIT Sloan Management Review, 46(2), $22-25$.

Eisenhardt, K. M. (1989). Agency Theory: An Assessment and Review. Academy of Management Review, 14(1), 57-74. 
Elkington, J. (1998). Cannibals with Forks - The Triple Bottom Line of the $21^{\text {st }}$ Century. Stoney Creek, CT: New Society.

Ellen, P. S. (1994). Do We Know What We Need to Know? Objective and Subjective Knowledge Effects on Pro-Ecological Behaviors. Journal of Business Research, 30(1), $43-52$.

Erol, I., Cakar, N., Erel, D., \& Sari, R. (2009). Sustainability in the Turkish Retailing Industry. Sustainable Development, 17, 49-67.

Farag, S., Schwanen, T., Dijst, M., \& Faber, J. (2007). Shopping online and/or in-store? A structural equation model of the relationships between e-shopping and in-store shopping. Transportation Research Part A: Policy and Practice, 41(2), 125-141.

Fichter, K. (2003). E-Commerce. Sorting Out the Environmental Consequences. Journal of Industrial Ecology, 6(2), 25-41.

First, I., \& Khetriwal, D. S. (2010). Exploring the Relationship Between Environmental Orientation and Brand Value: Is There Fire or Only Smoke? Business Strategy and the Environment, 19(2), 90-103.

Flint, D. J., \& Golicic, S. L. (2009). Searching for competitive advantage through sustainability. A qualitative study in the New Zealand wine industry. International Journal of Physical Distribution \& Logistics Management, 39(10), 841-860.

Freeman, R. E. (1984). Strategic management: A stakeholder approach. Boston: Pitman Publishing.

Gardner, B., \& Abraham, C. (2007). What drives car use? A grounded theory analysis of commuters' reasons for driving. Transportation Research Part F: Traffic Psychology and Behaviour, 10(3), 187-200.

Gardner, B., \& Abraham, C. (2010). Going Green? Modeling the Impact of Environmental Concerns and Perceptions of Transportation Alternatives on Decisions to Drive. Journal of Applied Social Psychology, 40(4), 831-849.

Garvare, R., \& Johansson, P. (2010). Management for sustainability - A stakeholder theory. Total Quality Management \& Business Excellence, 21(7), 737-744.

Gibson, K. (2012). Stakeholders and Sustainability: An Evolving Theory. Journal of Business Ethics, 109(1), 15-25.

Glavič, P., \& Lukman, R. (2007). Review of sustainability terms and their definitions. Journal of Cleaner Production, 15(18), 1875-1885.

Global Reporting Initiative. (2007). Sustainability Reporting 10 Years On. Retrieved 21 June 2011, from http://www.globalreporting.org/NR/rdonlyres/430EBB4E-9AAD4CA1-9478-FBE7862F5C23/0/Sustainability_Reporting_10years.pdf.

Golob, T. F. (1986). A nonlinear canonical correlation analysis of weekly trip chaining behaviour. Transportation Research Part A, 2(5), 385-399. 
Götz, K. (2003). A research concept for mobility styles. In Moving through nets: The physical and social dimensions of travel: $10^{\text {th }}$ International Conference on Travel Behaviour.

Gould, J., \& Golob, T. F. (1997). Shopping without travel or travel without shopping? An investigation of electronic home shopping. Transport Reviews, 17(4), 355-376.

Guy, C. (2009). 'Sustainable transport choices' in consumer shopping: a review of the UK evidence. International Journal of Consumer Studies, 33(6), 652-658.

Handy, S. L., \& Krizek, K. J. (2012). The role of travel behaviour research in reducing the carbon footprint: A US perspective. In R. M. Pendyala \& C. R. Bhat (Eds.), Travel behaviour research in an evolving world (pp. 37-58). International Association for Travel Behavior Research (IATBR).

Hanson, S., \& Huff, J. (1986). Classification issues in the analysis of complex travel behavior. Transportation, 13, 271-293.

Haustein, S., \& Hunecke, M. (2007). Reduced Use of Environmentally Friendly Modes of Transportation Caused by Perceived Mobility Necessities: An Extension of the Theory of Planned Behavior. Journal of Applied Social Psychology, 37(8), 1856-1883.

Heiskanen, E., \& Pantzar, M. (1997). Toward sustainable consumption: two new perspectives. Journal of Consumer Policy, 20(4), 409-442.

Hensher, D. A., \& Reyes, A. J. (2000). Trip chaining as a barrier to the propensity to use public transport. Transportation, 27, 341-361.

Hillman, A. J., \& Keim, G. D. (2001). Shareholder Value, Stakeholder Management, and Social Issues: What's the Bottom Line? Strategic Management Journal, 22(2), $125-139$.

Hingley, M. K. (2005). Power imbalanced relationships: cases from UK fresh food supply. International Journal of Retail \& Distribution Management, 33(8), 551-569.

Hsieh, H.-F., \& Shannon, S. E. (2005). Three approaches to qualitative content analysis. Qualitative Health Research, 15(9), 1277-1288.

Huselid, M. A. (1995). The impact of human resource management practices on turnover, productivity, and coporate financial performance. Academy of Management Journal, 38(3), 635-672.

Ibrahim, M. F. (2005). Attitudes to transport modes for shopping purposes in Singapore. Transport Reviews, 25(2), 221-243.

Ingene, C. A., \& Ghosh, A. (1990). Consumer and Producer Behavior in a Multipurpose Shopping Environment. Geographical Analysis, 22(1), 70-93.

International Institute for Sustainable Development. (1992). Business Strategy for Sustainable Development. Leadership and accountability for the '90s. Winnipeg.

Jones, P., Comfort, D., \& Hillier, D. (2005). Corporate social responsibility and the UK's top ten retailers. International Journal of Retail \& Distribution Management, 33(12), 882-892. 
Jones, P., Comfort, D., \& Hillier, D. (2008a). Moving towards sustainable food retailing? International Journal of Retail \& Distribution Management, 36(12), 995-1001.

Jones, P., Comfort, D., \& Hillier, D. (2008b). UK retailing through the looking glass. International Journal of Retail \& Distribution Management, 36(7), 564-570.

Jones, P., Comfort, D., Hillier, D., \& Eastwood, I. (2005). Retailers and sustainable development in the UK. International Journal of Retail \& Distribution Management, 33(3), 207-214.

Jones, P., Hillier, D., Comfort, D., \& Eastwood, I. (2003). Sustainable Retailing and Consumerism. Management Research News, 28(1), 34-44.

Kevork, E. K., \& Vrechopoulos, A. P. (2009). CRM literature: conceptual and functional insights by keyword analysis. Marketing Intelligence \& Planning, 27(1), 48-85.

Khalil, M. . A. K. (1999). Non- $\mathrm{CO}_{2}$ greenhouse gases in the atmosphere. Annual Review of Energy and the Environment, 24, 645-661.

Kim, J., Xu, M., Kahhat, R., Allenby, B., \& Williams, E. (2009). Designing and Assessing a Sustainable Networked Delivery (SND) System: Hybrid Business-to-Consumer Book Delivery Case Study. Environmental Science \& Technology, 43(1), 181-187.

King, L. J. (1985). Central place theory ( $2^{\text {nd }}$ ed.). Bevery Hills, CA: Sage Publications, Inc.

Kitamura, R., Sakomoto, K., \& Waygood, O. (2008). Declining sustainability: The case of shopping trip energy consumption. Journal of Sustainable Transportation, 2(3), $158-176$.

Kolk, A., Hong, P., \& Dolen, W. Van. (2010). Corporate Social Responsibility in China: an Analysis of Domestic and Foreign Retailers' Sustainability Dimensions. Business Strategy and the Environment, 19(5), 289-303.

Kondracki, N. L., \& S., W. N. (2002). Content analysis: review of methods and their applications in nutrition education. Journal of Nutrition Education and Behavior, 34(4), 224-230.

Kotzab, H., Munch, H. M., Faultrier, B., \& Teller, C. (2011). Environmental retail supply chains: when global Goliaths become environmental Davids. International Journal of Retail \& Distribution Management, 39(9), 658-681.

Kranke, A. (2009). $\mathrm{CO}_{2}$-Berechnung: Wie Sie die $\mathrm{CO}_{2}$-Emissionen bei LKW-Transporten konkret berechnen können. Exklusive Basisdaten. Logistik Inside, 05, 47-49.

Lai, K., Cheng, T. C. E., \& Tang, A. K. Y. (2010). Green Retailing: Factors for success. California Management Review, 52(2), 6-32.

Laroche, M., Bergeron, J., \& Barbaro-Forleo, G. (2001). Targeting consumers who are willing to pay more for environmentally friendly products. Journal of Consumer Marketing, 18(6), 503-520.

Lee, M. S., Chung, J.-H., \& McNally, M. G. (2002). An Empirical Investigation of the Underlying Behavioral Processes of Trip Chaining. Irvine, CA. 
Lee, M.-Y., Fairhurst, A., \& Wesley, S. (2009). Corporate Social Responsibility: A Review of the Top 100 US Retailers. Corporate Reputation Review, 12(2), 140-158.

Lindgreen, A., \& Hingley, M. (2003). The impact of food safety and animal welfare policies on supply chain management: The case of the Tesco meat supply chain. British Food Journal, 105(6), 328-349.

Lozano, R. (2008). Envisioning sustainability three-dimensionally. Journal of Cleaner Production, 16, 1838-1846.

Maclaran, P., \& Catterall, M. (2002). Analysing qualitative data: computer software and the market research practitioner. Qualitative Market Research: An International Journal, $5(1), 28-39$.

Markley, M. J., \& Davis, L. (2007). Exploring future competitive advantage through sustainable supply chains. International Journal of Physical Distribution \& Logistics Management, 37(9), 763-774.

Marshall, H. (2002). What do we do when we code? Qualitative Research Journal, 2(1), $56-70$.

Matthews, H. S., Hendrickson, C. T., \& Soh, D. L. (2001). Environmental and Economic Effects of E-Commerce. A Case Study of Book Publishing and Retail Logistics. Transportation Research Record, (1763), 6-12.

Matthews, H. S., Williams, E., Tagami, T., \& Hendrickson, C. T. (2002). Energy implications of online book retailing in the United States and Japan. Environmental Impact Assessment Review, 22(5), 493-507.

Maxwell, J. A. (2008). Designing a Qualitative Study. In L. Bickman \& D. J. Rog (Eds.), The handbook of applied social research methods ( $2^{\text {nd }}$ ed., pp. 214-253). Thousand Oaks, CA: Sage Publications.

McGuckin, N., \& Murakami, E. (2005). Examining Trip-Chaining Behavior - A Comparison of Travel by Men and Women. In Transportation Research Board Conference Proceedings, 35 (pp. 49-56).

McGuckin, N., Zmud, J., \& Nakamoto, Y. (2005). Trip Chaining Trends in The U.S. Understanding Travel Behavior for Policy Making. Transportation Research Record, (1917), 199-204.

Mebratu, D. (1998). Sustainablity and sustainable developement: Historical and conceptual review. Environmental Impact Assessment Review, 18(6), 493-520.

Menon, A. A. (1997). Enviropreneurial Marketing Strategy: The Emergence of Corporate Environmentalism as Market Strategy. Journal of Marketing, 61(1), 51-67.

Mokhtarian, P. L. (2004). A conceptual analysis of the transportation impacts of B2C e-commerce. Transportation, 31(3), 257-284.

Mulligan, G. F. (1987). Consumer Travel Behavior: Extensions of a Multipurpose Shopping Model. Geographical Analysis, 19(4), 364-375. 
Myers, M. D. (2009). Qualitative research in business and management. London et al.: Sage Publications, Ltd.

Newell, G. (2009). The significance of sustainability best practice in retail property. Journal of Retail and Leisure Property, 8(4), 259-271.

Newholm, T., \& Shaw, D. (2007). Studying the ethical consumer: A review of research. Journal of Consumer Behaviour, 6(5), 253-270.

Nilsson, M., \& Küller, R. (2000). Travel behaviour and environmental concern. Transportation Research Part D: Transport and Environment, 5(3), 211-234.

Ölander, F., \& Thøgersen, J. (1995). Understanding of Consumer Behaviour as a Prerequisite for Environmental Protection. Journal of Consumer Policy, 18(4), $345-385$.

Parris, T. M., \& Kates, R. W. (2003). Characterizing and Measuring Sustainable Development. Annual Review of Environment and Resources, 28, 559-586.

Piacentini, M., MacFadyen, L., \& Eadie, D. (2000). Corporate social responsibility in food retailing. International Journal of Retail \& Distribution Management, 28(11), 459-469.

Popkowski Leszczyc, P. T. L., Sinha, A., \& Sahgal, A. (2004). The effect of multi-purpose shopping on pricing and location strategy for grocery stores. Journal of Retailing, 80(2), 85-99.

Popkowski Leszczyc, P. T. L., \& Timmermans, H. (2001). Experimental choice analysis of shopping strategies. Journal of Retailing, 77(4), 493-509.

Primerano, F., Taylor, M. A. P., Pitaksringkarn, L., \& Tisato, P. (2008). Defining and understanding trip chaining behaviour. Transportation, 35, 55-72.

Qu, S. Q., \& Dumay, J. (2011). The qualitative research interview. Qualitative Research in Accounting \& Management, 8(3), 238-264.

Quak, H. J. \& de Koster, M. B. M. (2007). Exploring retailers' sensitivity to local sustainability policies. Journal of Operations Management, 25(6), 1103-1122.

Reuter, C., Foerstl, K. A. I., \& Blome, C. (2010). Sustainable Global Supplier Management: The Role of Dynamic Capabilities in Achieving Competitive Advantage. Journal of Supply Chain Management, 45(2), 45-63.

Rintamäki, T., Kanto, A., Kuusela, H., \& Spence, M. T. (2006). Decomposing the value of department store shopping into utilitarian, hedonic and social dimensions: Evidence from Finland. International Journal of Retail \& Distribution Management, 34(1), 6-24.

Rocco, T. S. (2003). Shaping the future: Writing up the method on qualitative studies. Human Resource Development Quarterly, 14(3), 343-349.

Sanne, C. (2002). Willing consumers - or locked-in? Policies for a sustainable consumption. Ecological Economics, 42(1-2), 273-287.

Sayre, S. (2001). Marketplace research. Thousand Oaks; London; New Delhi: Sage Publications, Inc. 
Schächtele, K., \& Hertle, H. (2007). Die $\mathrm{CO}_{2}$ Bilanz des Bürgers. Recherche für ein internetbasiertes Tool zur Erstellung persönlicher $\mathrm{CO}_{2}$ Bilanzen. Heidelberg.

Schröder, H., \& Zaharia, S. (2008). Linking multi-channel customer behavior with shopping motives: an empirical investigation of a German retailer. International Journal of Retail \& Distribution Management, 15(6), 452-468.

Schultz, I., \& Stieß, I. (2006). Linking Sustainable Consumption to Everyday Life: A socialecological approach to consumption research. In M. Munch Andersen \& A. Tukker (Eds.), Perspectives on Radical Changes to Sustainable Consumption and Production (SCP) (pp. 69-78).

Seuring, S., \& Müller, M. (2008). From a literature review to a conceptual framework for sustainable supply chain management. Journal of Cleaner Production, 16(15), $1699-1710$.

Shaw Hughner, R., McDonagh, P., Prothero, A., Shultz, C. J., \& Stanton, J. (2007). Who are organic food consumers? A compilation and review of why people purchase organic food. Journal of Consumer Behaviour, 6(2-3), 94-110.

Shrivastava, P. (1995). The Role of Corporations in Achieving Ecological Sustainability. Academy of Management, 20(4), 936-960.

Siikavirta, H., Punakivi, M., Kärkkäinen, M., \& Linnanen, L. (2003). Effects of E-Commerce on Greenhouse Gas Emissions. A Case Study of Grocery Home Delivery. Journal of Industrial Ecology, 6(2), 83-97.

Sinkovics, R. R., Penz, E., \& Ghauri, P. N. (2005). Analysing textual data in international marketing research. Qualitative Market Research: An International Journal, 8(1), 9-38.

Sivaraman, D., Pacca, S., Mueller, K., \& Lin, J. (2007). Comparative Energy, Environmental, and Economic Analysis of Traditional and E-commerce DVD Rental Networks. Journal of Industrial Ecology, 11(3), 77-91.

Statistisches Bundesamt. (2008). Bericht zu den umweltökonomischen Gesamtrechnungen 2008. Wiesbaden.

Steg, L. (2005). Car use: lust and must. Instrumental, symbolic and affective motives for car use. Transportation Research Part A: Policy and Practice, 39(2-3), 147-162.

Steinrücken, T., \& Jaenichen, S. (2007). The Fair Trade Idea: Towards an Economics of Social Labels. Journal of Consumer Policy, 30(3), 201-217.

Teller, C., Kotzab, H., \& Grant, D. B. (2006). The Consumer Direct Services Revolution in Grocery Retailing: An Exploratory Investigation. Managing Service Quality, 16(1), $78-96$.

The Consumer Goods Forum. (2011). Top Of Mind 2011 (Vol. 10, pp. 1-8). Paris.

Thøgersen, J. (2005). How May Consumer Policy Empower Consumers for Sustainable Lifestyles? Journal of Consumer Policy, 28(2), 143-177.

Thompson, B. (2007). Green retail: Retailer strategies for surviving the sustainability storm. Journal of Retail and Leisure Property, 6(4), 281-286. 
Trudel, R., \& Cotte, J. (2009). Does It Pay To Be Good? MIT Sloan Management Review, $50(2), 61-68$.

United Nations Environment Programme. (2003). Shopping for a better world: facts and figures. Industry and Environment, 26(1), 4-6.

United Nations Environment Programme Finance Initiative. (1997). UNEP Statement by Financial Institutions on the Environment \& Sustainable Development. Geneva.

van Herk, H., Poortinga, Y. H., \& Verhallen, T. M. M. (2005). Equivalence of survey data: Relevance for international marketing. European Journal of Marketing, 39(3/4), 351-364.

Verhoef, P. C., Neslin, S. A., \& Vroomen, B. (2007). Multichannel customer management: Understanding the research-shopper phenomenon. International Journal of Research in Marketing, 24(2), 129-148.

Waddock, S. A., \& Boyle, M.-E. (1995). The Dynamics of Change in Corporate Community Relations. California Management Review, 37(4), 125-140.

Waddock, S. A., \& Graves, S. B. (1997). The corporate social performance-financial performance link. Strategic Management Journal, 18(4), 303-319.

Weber, C., Hendrickson, C., Jaramillo, P., Matthews, S., Nagengast, A., \& Nealer, R. (2008). Life Cycle Comparison of Traditional Retail and E-commerce Logistics for Electronic Products: A Case Study of buy.com. Pittsburgh, PA.

Weber, C. L., Koomey, J. G., \& Matthews, H. S. (2010). The Energy and Climate Change Implications of Different Music Delivery Methods. Journal of Industrial Ecology, 14(5), 754-769.

Wiese, A., Kellner, J., Lietke, B., Toporowski, W., \& Zielke, S. (2012). Sustainability in retailing - a summative content analysis. International Journal of Retail \& Distribution Management, 40(4), 318-335.

Wiese, A., \& Toporowski, W. (2013). CSR failures in food supply chains - an agency perspective. British Food Journal, 115(1), 92-107.

Wiese, A., Toporowski, W., \& Zielke, S. (2012). Transport-related $\mathrm{CO}_{2}$ effects of online and brick-and-mortar shopping: A comparison and sensitivity analysis of clothing retailing. Transportation Research Part D: Transport and Environment, 17(6), 473-477.

Williams, E., \& Tagami, T. (2008). Energy Use in Sales and Distribution via E-Commerce and Conventional Retail. A Case Study of the Japanese Book Sector. Journal of Industrial Ecology, 6(2), 99-114.

World Commission on Environment and Development. (1987). Our Common Future. New York, NY: Oxford University Press.

Ye, X., Pendyala, R. M., \& Gottardi, G. (2007). An exploration of the relationship between mode choice and complexity of trip chaining patterns. Transportation Research Part B: Methodological, 41(1), 96-113. 
Ytterhus, B. E., Arnestad, P., \& Lothe, S. (1999). Environmental initatives in the retailing sector: an analysis of supply chain pressures and partnerships. Eco-Management and Auditing, 6(4), 181-188. 


\section{Curriculum Vitae}

Contact: annewiese104@gmail.com

\section{Education}

10/2008 - 10/2013 PhD student at the Economic Faculty of the Georg-AugustUniversität Göttingen

10/2006-09/2008 Master's Degree Programme in "Marketing and Channel Management" at the Georg-August-Universität Göttingen

10/2003 - 07/2006 Bachelor's Degree Programme in "Economics" at the GeorgAugust-Universität Göttingen

08/2001 - 01/2003 Apprenticeship at Peek\&Cloppenburg (Einzelhandelskauffrau)

08/1992 - 07/2001 Abitur (German school-leaver's education) at Bischöfliches Gymnasium Josephinum in Hildesheim

\section{Professional Experience}

01/2010 - present Representative of the International Helpdesk of the Graduate School of Humanities Göttingen (GSGG) at the Georg-AugustUniversität Göttingen

10/2008 - present Research Assistant at the Chair of Retailing at the GeorgAugust-Universität Göttingen

10/2008 - present Representative of the International Helpdesk of the Göttingen Graduate School of Social Sciences (GGG) at the GeorgAugust-Universität Göttingen

09/2006-09/2008 Student Assistant at the Chair of Retailing at the GeorgAugust-Universität Göttingen

08/2007 - 10/2007 Student Apprentice at the Business Consultancy Dr. Lademann \& Partner in Hamburg

08/2005 - 10/2005 Student Apprentice at the Logistics and Marketing Department of Blaupunkt in Hildesheim

04/2003 - 07/2003 Campsite Representative for Eurosites at Camping Ca'Savio (Venice Area, Italy)

08/2001 - 01/2003 Apprentice at Peek\&Cloppenburg in Hildesheim 


\section{Didactical Expertise}

10/2008-present Teaching at the Chair of Retailing at the Georg-AugustUniversität Göttingen (supervision of theses and seminar papers, exercise courses, lectures, correction of exams)

03/2010 - 03/2013 Teaching Assignment at the Technische Universität München for Scientific Writing in the Master Programme Clima Design

$2009-2011$

Certificate for Teaching and Learning in Higher Education of the Georg-August-Universität Göttingen (120 work units)

\section{Publications}

\section{Papers in Peer-reviewed Academic Journals}

Wiese, A./Toporowski, W. (2013): CSR Failures in Food Supply Chains - an Agency Perspective, British Food Journal, Vol. 115, No. 1, pp. 92-107.

Wiese, A./Toporowski, W./Zielke, S. (2012): Transport-Related $\mathrm{CO}_{2}$ Effects of Online and Brick-and-Mortar Shopping: A Comparison and Sensitivity Analysis of Clothing Retailing, in: Transportation Research Part D: Transport and Environment, Vol. 17, No. 6, pp. 473-477.

Wiese, A./Kellner, J./Lietke, B./Toporowski, W./Zielke, S. (2012): Sustainability in Retailing - a Summative Content Analysis, in: International Journal of Retail \& Distribution Management, Vol. 40, No. 4, pp. 318-335.

Highly Commended Paper of the Emerald Literati Network Awards for Excellence 2013

\section{Papers in Conference Proceedings}

Wiese, A. (2013): Consumer Travel Behaviour and its Environmental Impact - a Qualitative Analysis, in: Proceedings of $17^{\text {th }}$ Conference of the European Association for Education and Research in Commercial Distribution (EAERCD), Valencia, Spain.

Wiese, A./Toporowski, W. (2013): Sustainability in cities - a comparison of different approaches and their effects on urban transformation, in: Proceedings of the European Roundtable on Sustainable Consumption and Production 2013 (ERSCP), Istanbul, Turkey. 
Wiese, A. (2013): Mitigating the environmental effects of shopping trips - influences of retailers and policy makers, in: Proceedings of the Social Business Conference 2013, Eskişehir, Turkey.

Kellner, J./Wiese, A./Toporowski, W./Zielke, S. (2012): Exploring Retail Formats in the Online Arena - A Consumer-Based Approach, in: Marketing to Citizens: Going Beyond Consumer and Customers, Proceedings of the $41^{\text {st }}$ EMAC Conference, European Marketing Academy (EMAC), Lisbon, Portugal.

Kellner, J./Wiese, A./Toporowski, W./Zielke, S. (2012): Store Formats in Online Retailing: A Consumer-Based Approach, in: Timmermans, H. (ed.): Proceedings of the $19^{\text {th }}$ Recent Advances in Retailing \& Services Science Conference, European Institute of Retailing and Service Studies (EIRASS), Vienna, Austria.

Wiese, A./Toporowski, W./Louis, J. (2011): CSR-Failures along Grocery Supply Chains - an Analysis Using Principal-Agent-Theory, in: Timmermans, H. (ed.): Proceedings of the $18^{\text {th }}$ Recent Advances in Retailing \& Services Science Conference, European Institute of Retailing and Service Studies (EIRASS), San Diego, USA.

Wiese, A./Toporowski, W./Zielke, S. (2011): $\mathrm{CO}_{2}$-Effects of Online and Brick-andMortar Shopping - Results of a Sensitivity Analysis, in: Timmermans, H. (ed.): Proceedings of the $18^{\text {th }}$ Recent Advances in Retailing \& Services Science Conference, European Institute of Retailing and Service Studies (EIRASS), San Diego, USA.

Wiese, A./Toporowski, W./Zielke, S./Friedrich, T. J. (2011): Who Purchases Organic Products at Grocery Discounters?, in: Timmermans, H. (ed.): Proceedings of the $18^{\text {th }}$ Recent Advances in Retailing \& Services Science Conference, European Institute of Retailing and Service Studies (EIRASS), San Diego, USA.

Wiese, A./Toporowski, W./Zielke, S. (2010): A comparison of $\mathrm{CO}_{2}$-emissions between online and brick-and-mortar formats, in: Timmermans, H. (ed.): Proceedings of the $17^{\text {th }}$ Recent Advances in Retailing \& Services Science Conference, European Institute of Retailing and Service Studies (EIRASS), Istanbul, Turkey.

Wiese, A./Toporowski, W./Zielke, S. (2010): Is Online-Retailing More Environmentally-Friendly Than Brick-and-Mortar Retailing? A Comparison of $\mathrm{CO}_{2}$ Emissions, in: The six sens $€ s$ - The Essentials of Marketing, Proceedings of the $39^{\text {th }}$ EMAC Conference, European Marketing Academy (EMAC), Copenhagen, Denmark. 
Wiese, A./Kellner, J./Lietke, B./Toporowski, W./Zielke, S. (2009): Sustainability Research Areas, Developments and Resulting Perspectives for Supply Chain and Retail Research, in: Timmermans, H. (ed.): Proceedings of the $16^{\text {th }}$ Recent Advances in Retailing \& Services Science Conference, European Institute of Retailing and Service Studies (EIRASS), Niagara Falls, Canada.

Wiese, A./Lietke, B./Toporowski, W. (2009): The Impact of Efficient Consumer Response on Company Success - a Meta-analysis, in: Timmermans, H. (ed.): Proceedings of the $16^{\text {th }}$ Recent Advances in Retailing \& Services Science Conference, European Institute of Retailing and Service Studies (EIRASS), Niagara Falls, Canada.

\section{Presentations}

"Consumer Travel Behaviour and its Environmental Impact - a Qualitative Analysis", $17^{\text {th }}$ Conference of the European Association for Education and Research in Commercial Distribution (EAERCD), Valencia, Spain, 5 July 2013.

"Sustainability in cities - a comparison of different approaches and their effects on urban transformation", European Roundtable on Sustainable Consumption and Production 2013 (ERSCP), Istanbul, Turkey, 5 June 2013.

"Mitigating the environmental effects of shopping trips - influences of retailers and policy makers", Social Business Conference 2013, Eskişehir, Turkey, 31 May 2013.

"Does Environmental Friendliness Matter? A Discrete Choice Experiment Analysing Environmental Issues in Channel Choices", International Sustainability Conference, Basel, Switzerland, 22 August 2012.

"Organic buyers at grocery discounters - an empirical analysis", Congress „Lebensmitteldiscounter" - der "neue” Typ von Nachbarschaftsladen? ("Food Discounters" - the new 'kind' of neighbourhood store?), Kiel, Germany, 27 April 2012.

" $\mathrm{CO}_{2}$-effects of shopping patterns in a multi-channel environment", Sustainable Consumption Conference 2011, Hamburg, Germany, 8 November 2011.

"Buying behaviour for organic products in grocery discounters", Sustainable Consumption Conference 2011, Hamburg, Germany, 7 November 2011 (Poster). 
"CSR-Failures along Grocery Supply Chains - an Analysis Using Principal-AgentTheory", $18^{\text {th }}$ Recent Advances in Retailing \& Services Science Conference, European Institute of Retailing and Service Studies (EIRASS), San Diego, USA, 17 July 2011.

"Who Purchases Organic Products at Grocery Discounters?", $18^{\text {th }}$ Recent Advances in Retailing \& Services Science Conference, European Institute of Retailing and Service Studies (EIRASS), San Diego, USA, 17 July 2011.

" $\mathrm{CO}_{2}$-Effects of Online and Brick-and-Mortar Shopping - Results of a Sensitivity Analysis", $18^{\text {th }}$ Recent Advances in Retailing \& Services Science Conference, European Institute of Retailing and Service Studies (EIRASS), San Diego, USA, 16 July 2011.

"A comparison of $\mathrm{CO}_{2}$-emissions between online and brick-and-mortar formats", $17^{\text {th }}$ Recent Advances in Retailing \& Services Science Conference, European Institute of Retailing and Service Studies (EIRASS), Istanbul, Turkey, 3 July 2010.

"Is Online-Retailing More Environmentally-Friendly Than Brick-and-Mortar Retailing? A Comparison of $\mathrm{CO}_{2}$-Emissions", $39^{\text {th }}$ EMAC Conference, European Marketing Academy (EMAC), Copenhagen, Denmark, 2 June 2010.

"Sustainability - Research Areas, Developments and Resulting Perspectives for Supply Chain and Retail Research", $16^{\text {th }}$ Recent Advances in Retailing \& Services Science Conference, European Institute of Retailing and Service Studies (EIRASS), Niagara Falls, Canada, 7 July 2009.

"The Impact of Efficient Consumer Response on Company Success - a Metaanalysis", $16^{\text {th }}$ Recent Advances in Retailing \& Services Science Conference, European Institute of Retailing and Service Studies (EIRASS), Niagara Falls, Canada, 7 July 2009.

\section{Workshops}

SCORAI Europe: "Bridging Across Communities and Cultures Towards Sustainable Consumption”, Istanbul, Turkey, 4 June 2013.

Corpus: "Policy Meets Research" Workshop on Sustainable Housing, Helsinki, Finland, 7 - 8 June 2012.

Rewe Stakeholder-Forum: "Raus aus der Nische - Nachhaltigkeit 2011" ("Out of the Niche - Sustainability 2011”), Berlin, Germany, 5 September 2011. 


\section{Other Publications}

"Nachhaltigkeit steht noch am Anfang" ("Sustainability is still in its beginning"), article about the dissertation project, in: Young Professional by High Potential, May/June 2013, p. 32, available at: http://www.academicworld.net/fileadmin/ Magazinehomepages/YP_1-2013/.

\section{Review Activities}

Journals:

- British Food Journal

- International Journal of Retail \& Distribution Management

- Journal of Food Products Marketing

- The Journal of Retailing and Consumer Services

Conferences:

2012 AMA Summer Marketing Educators' Conference, Chicago, USA

\section{Awards}

Highly Commended Paper of the Emerald Literati Network Awards for Excellence 2013 for Wiese, A./Kellner, J./Lietke, B./Toporowski, W./Zielke, S. (2012): Sustainability in Retailing - a Summative Content Analysis, in: International Journal of Retail \& Distribution Management, Vol. 40, No. 4, pp. 318-335. 